\title{
Effect of FORTA-FI Fibers on the Rutting Potential, Dynamic Modulus, Flow Number, and Fatigue of Asphalt Concrete
}

\author{
Elbert Rohrbough
}

Follow this and additional works at: https://researchrepository.wvu.edu/etd

\section{Recommended Citation}

Rohrbough, Elbert, "Effect of FORTA-FI Fibers on the Rutting Potential, Dynamic Modulus, Flow Number, and Fatigue of Asphalt Concrete" (2018). Graduate Theses, Dissertations, and Problem Reports. 6524. https://researchrepository.wvu.edu/etd/6524

This Thesis is protected by copyright and/or related rights. It has been brought to you by the The Research Repository @ WVU with permission from the rights-holder(s). You are free to use this Thesis in any way that is permitted by the copyright and related rights legislation that applies to your use. For other uses you must obtain permission from the rights-holder(s) directly, unless additional rights are indicated by a Creative Commons license in the record and/ or on the work itself. This Thesis has been accepted for inclusion in WVU Graduate Theses, Dissertations, and Problem Reports collection by an authorized administrator of The Research Repository @ WVU. For more information, please contact researchrepository@mail.wvu.edu. 


\title{
Effect of FORTA-FI Fibers on the Rutting Potential, Dynamic Modulus, Flow Number, and Fatigue of Asphalt Concrete
}

\author{
Elbert Rohrbough \\ Thesis submitted to the \\ Benjamin Statler College of Engineering and Mineral Resources \\ at West Virginia University \\ in partial fulfillment of the requirements for the degree of \\ Master of Science in Civil Engineering
}

John P. Zaniewski, Ph. D., P.E., Chair

John D. Quaranta, Ph. D., P.E.

Liyaning Tang, Ph.D.

Department of Civil and Environmental Engineering

Morgantown, West Virginia

2018

Keywords: Asphalt Concrete, FORTA-FI Fibers, APA, AMPT, Dynamic Modulus, Flow Number, Fatigue

Copyright 2018 Elbert Rohrbough 


\section{ABSTRACT \\ Effect of FORTA-FI Fibers on the Rutting Potential, Dynamic Modulus, Flow Number, and Fatigue of Asphalt Concrete}

\section{Elbert Rohrbough}

The effect of fiber- reinforcement on asphalt concrete mixes is better explored through laboratory performance testing. Two mixes were evaluated throughout this research. One mix was a standard West Virginia Department of Highways Wearing I, and the other was the Wearing I mix reinforced with FORTA- FI® fibers. The testing was done using the Asphalt Pavement Analyzer (APA) and the Asphalt Mixture Performance Tester (AMPT).

First, the rutting potential of the two mixes was determined using the APA. Next, the performance of the two mixes was compared using the AMPT. The tests performed on the AMPT determined the dynamic modulus, flow number, and fatigue characteristics of the two mixes. Dynamic modulus master curves were developed using Bonaquist's MasterSolver Version 2.2 to compare the stiffness of the two mixes. The flow number was evaluated using the Data Smoothing Method and the Francken Model Method to compare the rutting potential of the two mixes. Last, Instrotek's Alpha-Fatigue ${ }^{\mathrm{TM}}$ software was used to determine the coefficients needed to model the fatigue behavior of the mixes. 


\section{ACKNOWLEDGEMENT}

I would like to first and foremost thank my wife for her unwavering support as I completed my graduate studies. I would next like to thank my advisor, Dr. John Zaniewski. Without his support and guidance, I could have never achieved this endeavor. I would like to give additional thanks to my committee members, Dr. John Quaranta and Dr. Liyaning Tang, for

their support. I owe a debt of gratitude to my fellow graduate students, Justin Pentz and Elizabeth Bashiti. They provided me with countless hours of support. I would, lastly, like to thank the FORTA Corporation for the opportunity to conduct this research. 


\section{Table of Contents}

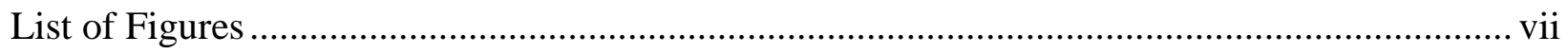

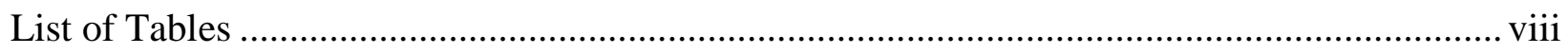

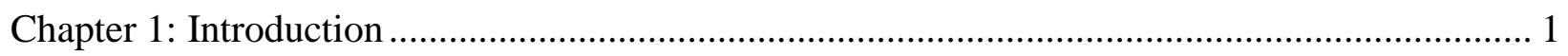

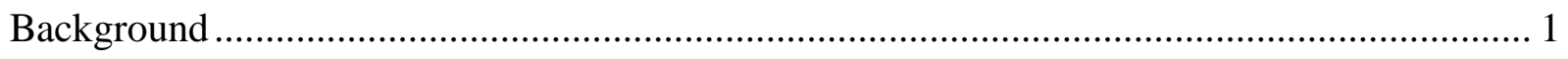

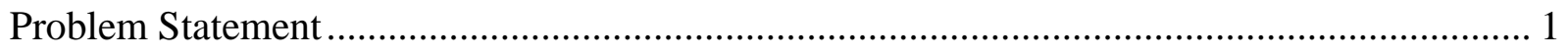

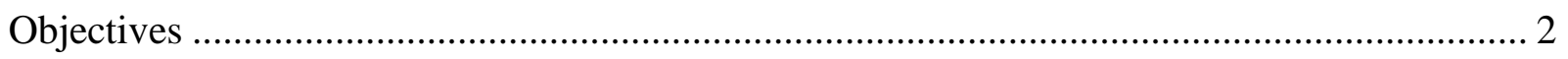

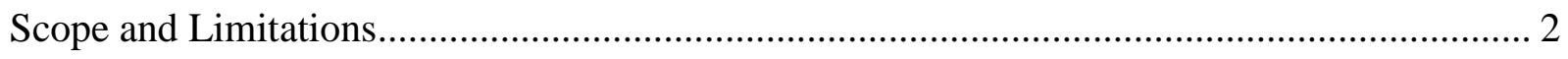

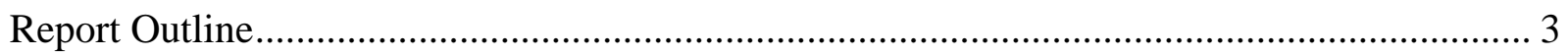

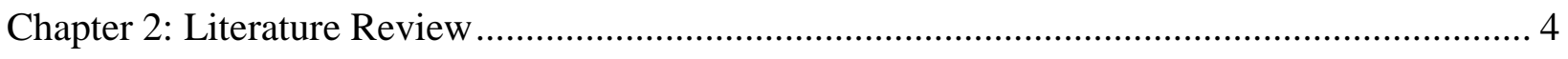

Performance Testing of Fiber Reinforced Asphalt ...................................................... 4

Dynamic Modulus and Phase Angle Mastersolver .......................................................... 9

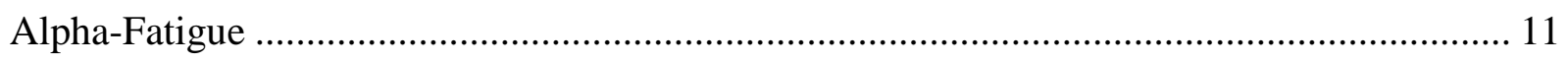

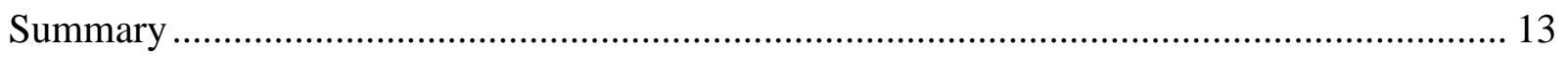

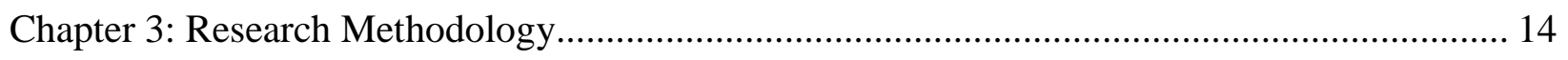

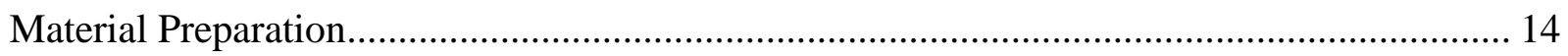

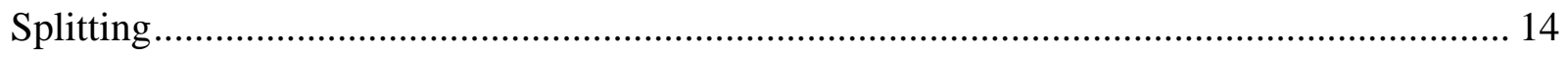

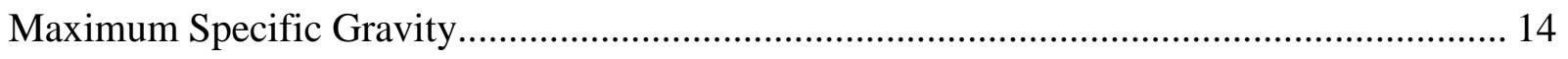

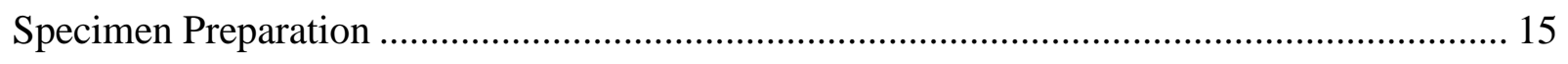

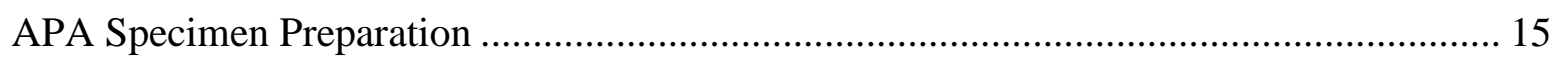

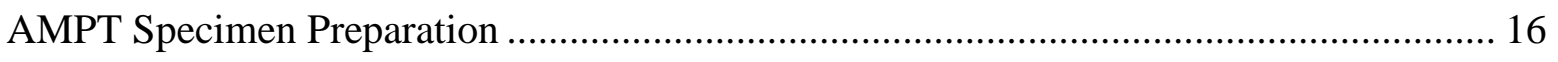

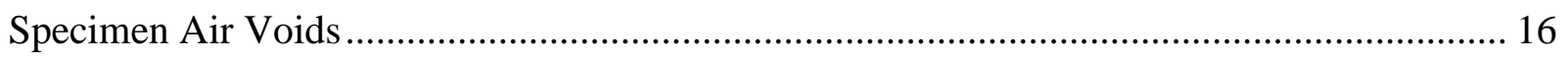

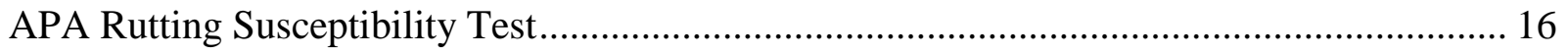

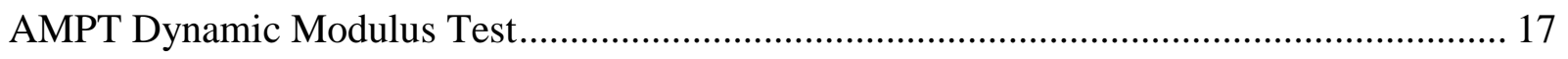

AMPT Flow Number Test ........................................................................................ 19 
AMPT Direct Tension Cyclic Fatigue Test …............................................................. 19

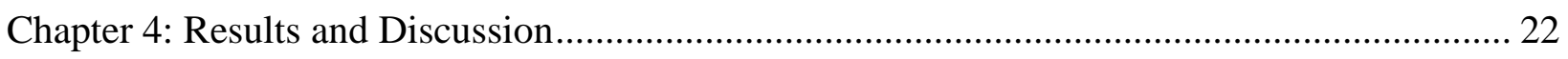

Maximum Specific Gravity....................................................................................... 22

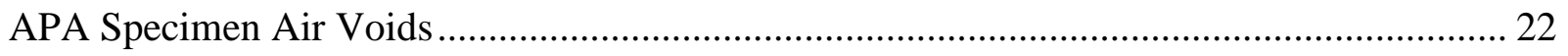

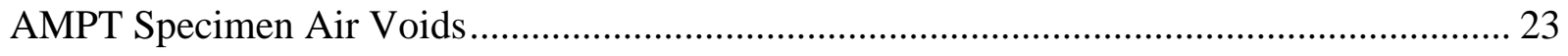

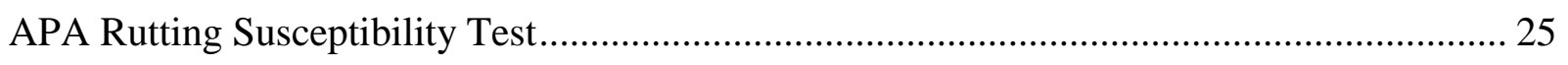

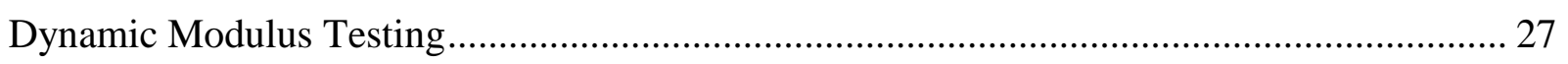

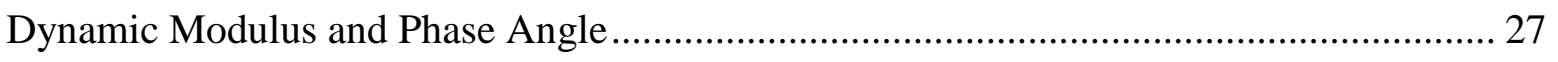

Dynamic Modulus and Phase Angle Mastersolver........................................................ 32

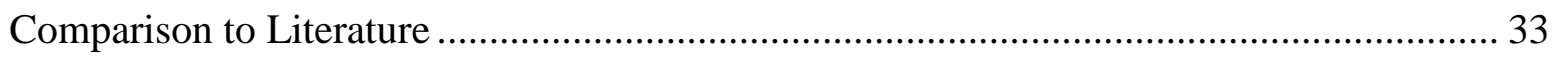

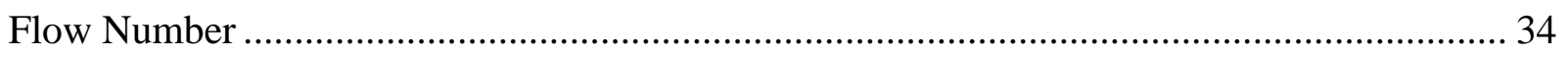

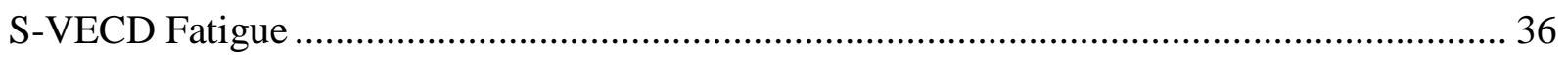

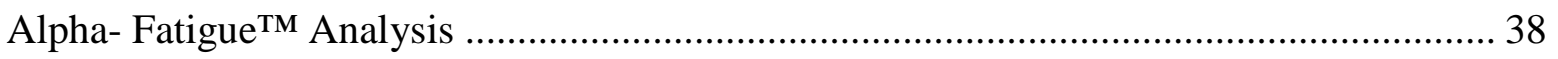

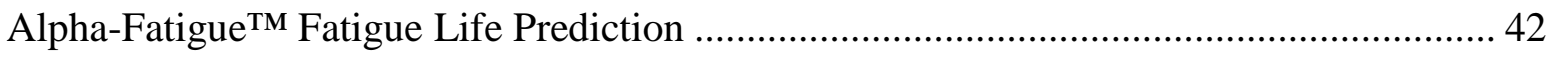

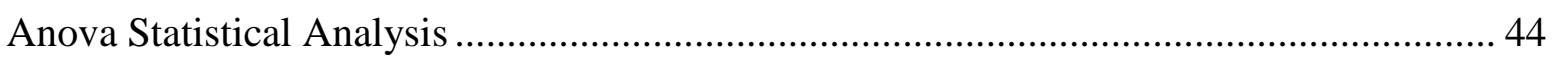

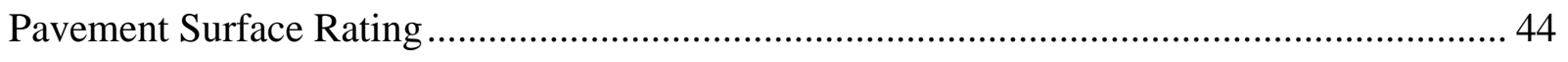

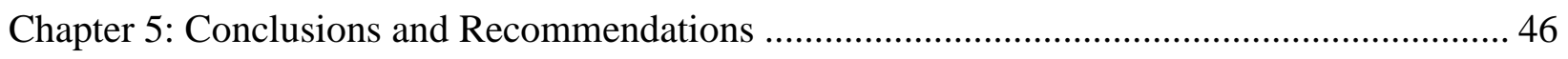

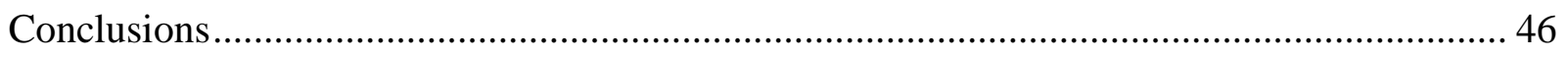

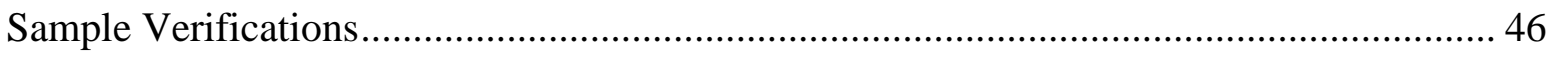

APA Rutting Susceptibility Testing .................................................................... 46

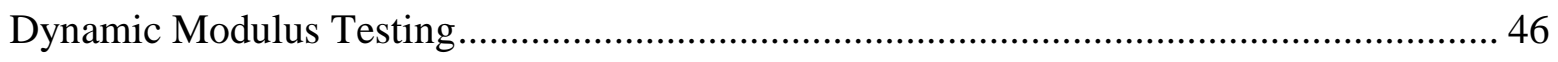

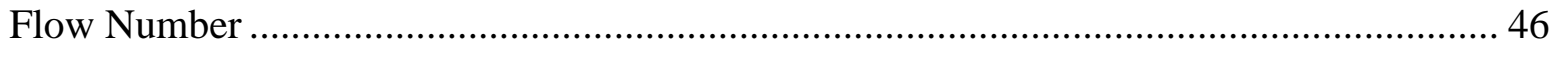

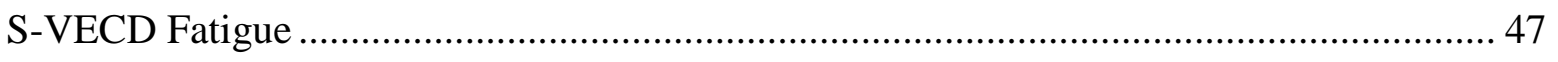

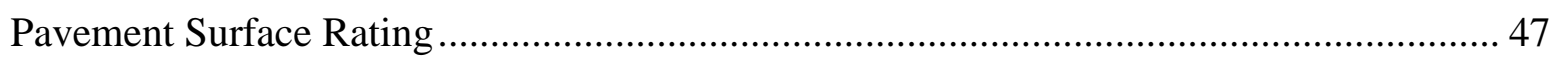

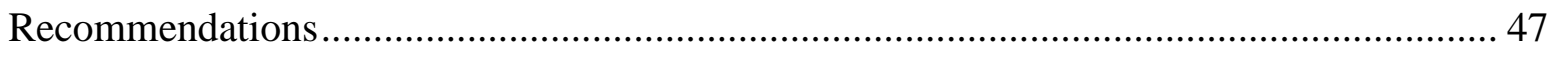




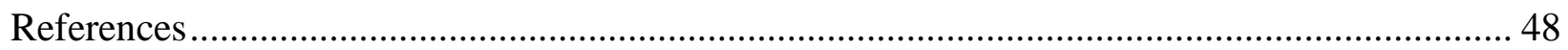

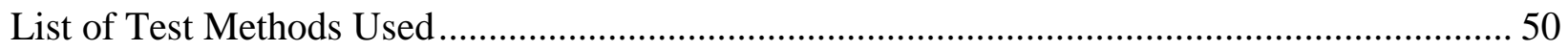

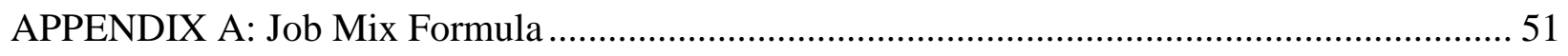

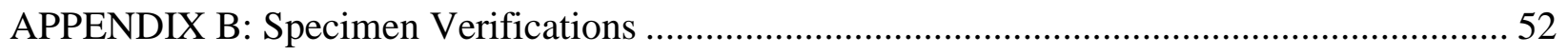

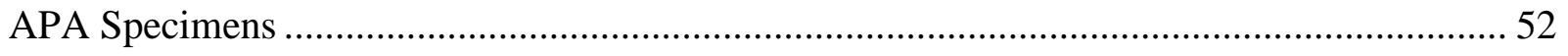

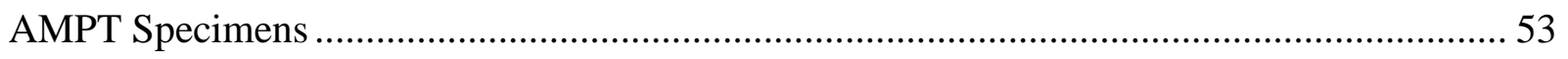

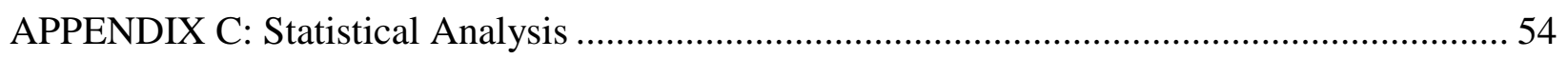

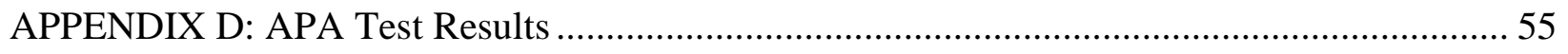

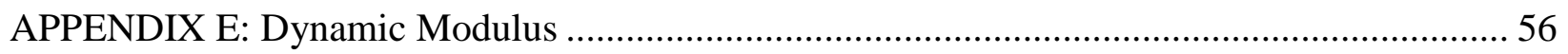

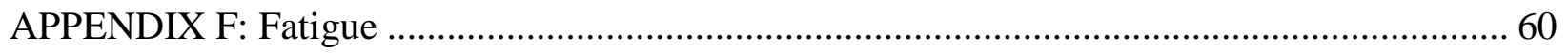

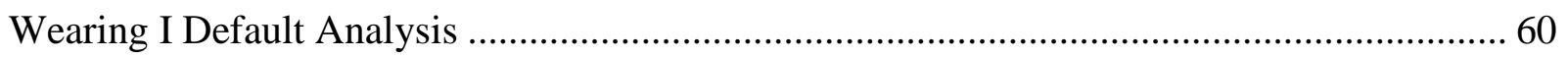

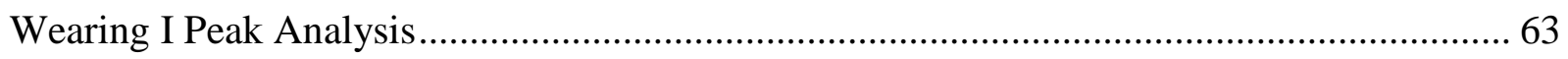

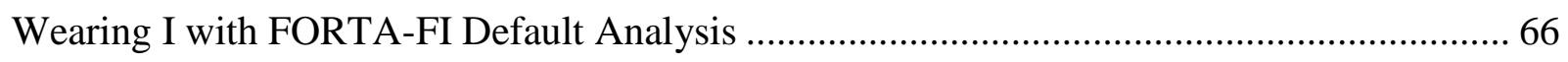

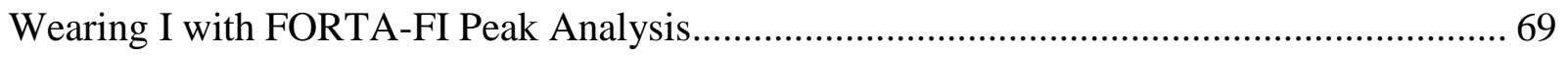

Wearing I Default Fatigue Life Prediction Analysis ............................................................. 72

Wearing I Peak Fatigue Life Prediction Analysis....................................................................... 73

Wearing I with FORTA-FI Default Fatigue Life Prediction Analysis ..................................... 74

Wearing I with FORTA-FI Peak Fatigue Life Prediction Analysis ........................................ 75 


\section{List of Figures}

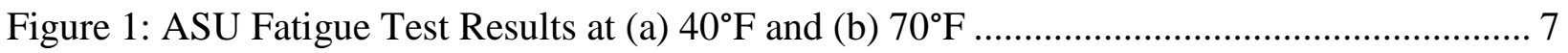

Figure 2: ASU Fatigue Life Prediction at (a) 150 microstrains and (b) 200 microstrains............. 9

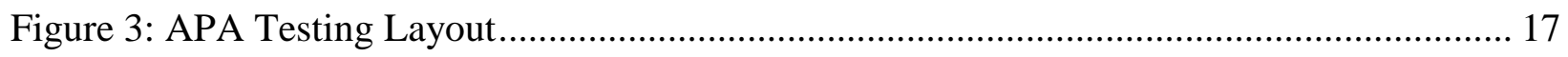

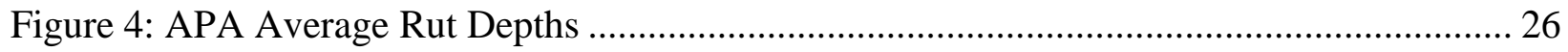

Figure 5: Average Dynamic Modulus at 4 degrees ............................................................ 31

Figure 6: Average Dynamic Modulus at 20 degrees .......................................................... 31

Figure 7: Average Dynamic Modulus at 40 degrees ......................................................... 32

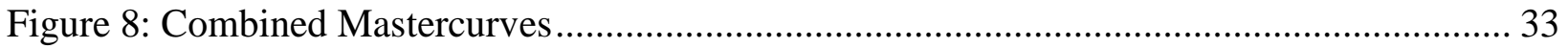

Figure 9: Comparison of Dynamic Modulus to Arizona State University Reported Values........ 34

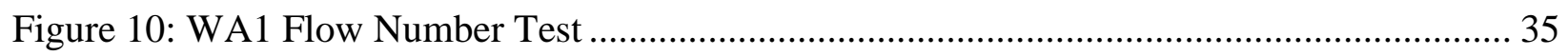

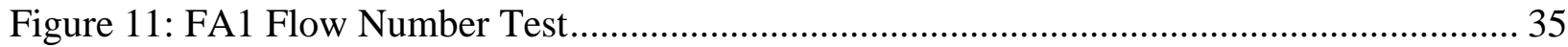

Figure 12: Fatigue Life using different K- Values.......................................................... 41

Figure 13: Peak and Default Endurance Limits ................................................................ 42

Figure 14: Edge Cracking in the Wearing I Section ............................................................. 45

Figure 15: Edge Cracking in the Wearing I with FORTA-FI Section ................................... 45 


\section{List of Tables}

Table 1: ASU Flow Number Results .............................................................................. 5

Table 2: ASU Fatigue Test K- Value Results ..................................................................... 8

Table 3: Maximum Specific Gravity Test Results ............................................................. 22

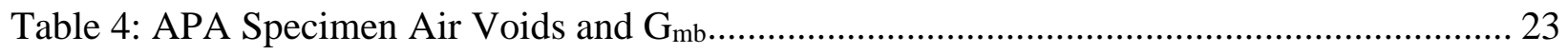

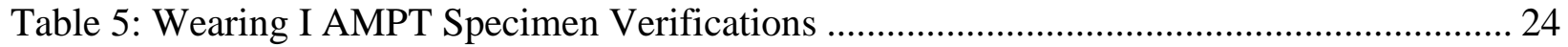

Table 6: Wearing I with FORTA-FI AMPT Specimen Verifications ...................................... 24

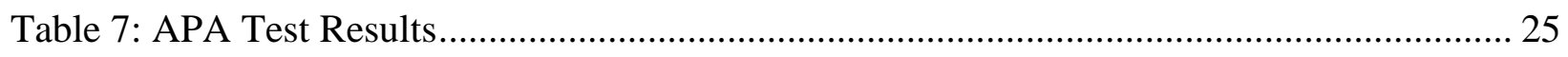

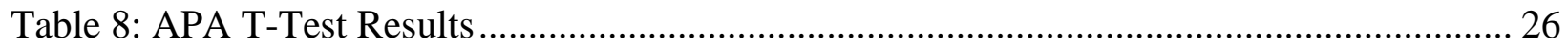

Table 9: Dynamic Modulus Test Outputs (MPa)................................................................ 28

Table 10: Dynamic Modulus Test Average, Standard Deviation, and Coefficient of Variation

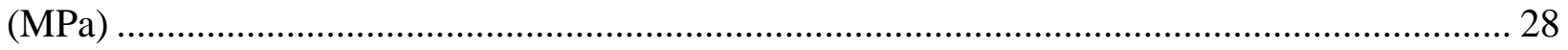

Table 11: Dynamic Modulus Test Phase Angle Results......................................................... 29

Table 12: Dynamic Modulus Test Phase Angle Average, Standard Deviation, and Coefficient of

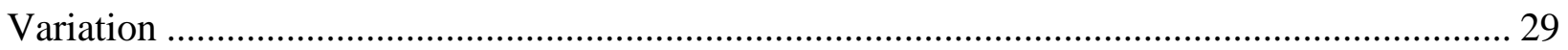

Table 13: Mastersolver Material Parameters .............................................................................. 33

Table 14: Flow Number Data Smoothing Method Results................................................... 36

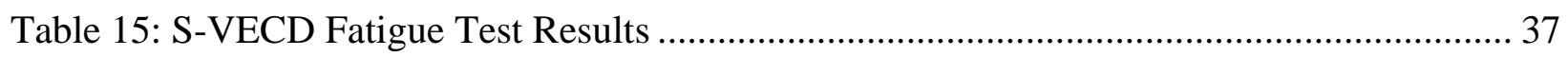

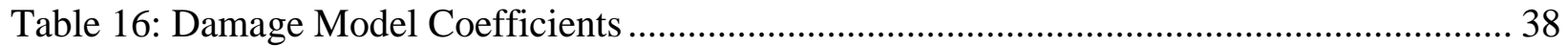

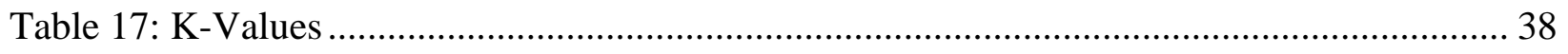

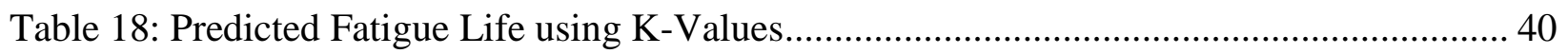

Table 19: Exponential Model Endurance Limits ................................................................. 42

Table 20: Comparison of Fatigue Life Predicted by Alpha Fatigue and Fatigue Equations ........ 43

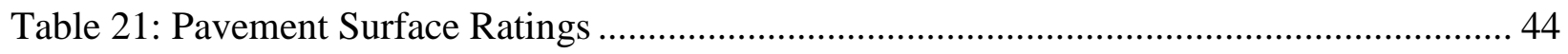




\section{Chapter 1: Introduction}

\section{Background}

Across the United States roadways are severely deteriorating, and transportation agencies are battling daily to combat the deterioration. According to the 2017 ASCE Infrastructure Report Card, the roads in the United States were given a "D" ranking. The ASCE report card states that, “one out of every five miles of highway pavement in the United States is in poor condition". It was also stated, "our roads have a significant and increasing backlog of rehabilitation needs" (American Society of Civil Engineers, 2017). One of the first means of combating pavement deterioration is to conduct a pavement inspection in order to calculate the pavement condition index. From this index, transportation agencies can rank roadways according to a number of factors. These factors can include safety, cost to repair, and time to failure. Based on the ranking, agencies can prioritize sections of roadways based on funds available.

During the pavement inspections, inspectors are looking for asphalt pavement distresses such as rutting and cracking. The cracks identified can be the result of a multitude of mechanisms. Some common types of cracks are fatigue (alligator cracks) which can be caused by things such as loading and poor drainage, block cracks which can be caused by severely oxidized mix, and edge cracks which can be caused by lack of edge support. Other types of cracking distresses are longitudinal and transverse cracks.

This research focuses on a comparison of asphalt pavement performance. This comparison was done using the analyses of the Asphalt Pavement Analyzer (APA) rutting susceptibility test, the Asphalt Pavement Analyzer (AMPT) dynamic modulus test, AMPT flow number test, and AMPT Direct Tension Cyclic Fatigue Test.

\section{Problem Statement}

Research was conducted to compare the performance of two plant produced asphalt mixtures, West Virginia DOH Wearing I, and the same West Virginia Wearing I mixture with fiber added. In October 2016, the Wearing I and Wearing I with fiber mixes were paved on 
Dorsey Avenue in Morgantown, WV. The fiber product used in the mixture was FORTA- FI® ${ }^{1}$, produced by the FORTA Corporation based out of Grove City, Pennsylvania. FORTA- FI® is a blend of aramid and polyolefin fibers. They are stated to increase the strength and durability of the asphalt mixtures in both low and high temperatures (FORTA, 2017). The performance tests were done using the APA rutting susceptibility test, the AMPT dynamic modulus test, AMPT flow number test, and AMPT Direct Tension Cyclic Fatigue Test. In total, 12 APA specimens were tested. 32 AMPT specimens were tested, 6 dynamic modulus specimens, 8 flow number rutting specimens, and 18 direct tension cyclic fatigue specimens. The Asphalt Pavement Analyzer test results were analyzed in accordance with AASHTO Specification T340, Determining the Rutting Susceptibility of Hot Mix Asphalt (HMA) using the asphalt pavement analyzer (APA). The AMPT dynamic modulus test results were analyzed using the Mastersolver Workbook published by Ramon Bonaquist (Bonaquist, Simple Performance Tester for Superpave Mix Design, 2011). The AMPT flow number results were analyzed using both the built- in data smoothing method and the Francken Model method, the latter is considered to be more stable according to researchers from Arizona State University. The Francken Model method was conducted using MATLAB based on the work of Dalton (Dalton, 2016). The AMPT direct tension cyclic fatigue results were analyzed using the InstroTek Alpha Fatigue Software.

\section{Objectives}

There were two research objectives: to compare the APA and AMPT performance test results of the two plant produced mixes, and to determine the effect of the FORTA-FI® Fibers.

\section{Scope and Limitations}

All bulk material was collected from trucks at the asphalt plant with as much randomization as possible. The mixture was separated into smaller amounts by quartering to increase randomization and to reduce bias. The specimens were prepared and the tests were conducted in accordance with the standards set forth by the American Association of State Highway and Transportation Officials (AASHTO). All recommendations made by AASHTO

\footnotetext{
${ }^{1}$ This is the specific product evaluated in this research. There is no intention to report this as a recommendation for the product compared to other fiber alternatives.
} 
were taken into consideration although not all were used. Preparation and testing was limited to the resources available to the West Virginia University Asphalt Technology Laboratory.

\section{Report Outline}

This report is composed of five chapters and additional appendices. Chapter 1 includes the background, problem statement, objectives, scope and limitations, and the report outline. Chapter 2 contains a literature review conducted on performance testing of Fiber Reinforced Asphalt Concrete. Chapter 3 includes the research methodology used including, experimental design, material preparation, specimen preparation, specimen verification, and testing. Chapter 4 contains results and discussions for the tests and analyses performed. Chapter 5 contains conclusions and recommendations for the tests, analyses, and further research needed outside of the scope of this research project. The appendices contain the data resulting from all of the verifications, testing, and analyses. 


\section{Chapter 2: Literature Review}

This literature review will explore performance testing of Fiber Reinforced Asphalt, and performance test data analysis.

\section{Performance Testing of Fiber Reinforced Asphalt}

Fiber reinforcement is not a new concept. In fact, it has been explored since the early 1960's (Abtahi et. al., 2009). The debate has been what fibers to use, their benefits, cost, and overall performance of Fiber Reinforced Asphalt Concrete. The fibers used in asphalt concrete include several categories: these categories are steel/metal, natural fiber, and synthetic fiber (Abtahi et. al., 2009). Polypropylene fibers are widely used as reinforcing agents in concrete. Several experiments have been performed to test their effects on the performance of asphalt concrete, however, there is an issue with their low melting point. Polyester fibers have also been

explored for use as a reinforcement. BoniFibers is a trade name for polyester fibers manufactured to be blended with asphalt concrete. Polyester fibers were analyzed for their benefit in overlay applications, and it was shown that the fatigue resistance of the asphalt could be improved at low stress levels (Abtahi et. al., 2009). This research tested asphalt reinforced with aramid synthetic fibers, so these will be explored in depth.

Kaloush et. al. tested a proprietary blend of polypropylene and aramid fibers at Arizona State University. The manor in which the research was conducted was similar in that the performance of the mixture reinforced with fiber was compared to that of a control consisting of the same asphalt mixture but without fiber (Kaloush et. al., 2010). The researchers had the objectives of evaluating the material properties of the two mixtures using advanced laboratory tests, including stiffness, permanent deformation, and cracking characteristics. The researchers prepared gyratory specimens, beam specimens, and disc specimens. The gyratory specimens were used for triaxial testing, the beam specimens were used for fatigue testing, and the disc specimens were used for thermal cracking evaluation.

The first test conducted was a triaxial shear strength test. The researchers conducted three tests; two tests were confined, and the third test was unconfined. The results showed that the fiber reinforced asphalt had a higher cohesion values as indicated by greater resistance to shear stress. There was little effect on the angle of internal friction which was expected because angle 
of internal friction is an aggregate property. The fiber reinforced asphalt also had a higher residual energy which means the mix has a higher resistance to crack propogation after peak stress than the non- reinforced mix (Kaloush et. al., 2010).

The next test conducted was the repeated load permanent deformation test. This test is also known as the Flow Number Test. The researchers state it has been thoroughly documented in the NCHRP Report 465 study. The researchers found the flow number results for the fiber reinforced mixture to be fifteen times higher than those of the non- reinforced mixture. The results of the flow number testing are shown in Table 1.

Table 1: ASU Flow Number Results

\begin{tabular}{|c|c|c|c|}
\hline Mix Type & $\sigma_{\mathrm{d}}(\mathrm{psi})$ & Flow Number (Cycles) & $\begin{array}{c}\text { Axial Permanent Strain } \varepsilon_{p} \\
{[\%] \text { at Failure }}\end{array}$ \\
\hline \multirow{6}{*}{ Control } & 15 & 436 & 0.84 \\
\hline & 15 & 241 & 0.56 \\
\hline & 15 & 166 & 0.95 \\
\hline & Average & 281 & 0.78 \\
\hline & Standard Deviation & 139 & 0.20 \\
\hline & $\begin{array}{l}\text { \% Coefficient of } \\
\text { Variation }\end{array}$ & 49.6 & 25.8 \\
\hline \multirow{6}{*}{$\begin{array}{c}\text { Fiber- } \\
\text { Reinforced }\end{array}$} & 15 & 3336 & 0.47 \\
\hline & 15 & 3466 & 0.60 \\
\hline & 15 & 5916 & 0.46 \\
\hline & Average & 4,239 & 0.51 \\
\hline & Standard Deviation & 1,453 & 0.08 \\
\hline & $\begin{array}{l}\text { \% Coefficient of } \\
\text { Variation } \\
\end{array}$ & 34 & 15.3 \\
\hline
\end{tabular}

The next test conducted by the researchers at Arizona State University was a Dynamic Modulus Test. The test method used by the researchers was AASHTO TP 62-03. The mixtures had a PG 70 -10 binder. The researchers tested the specimens at 14, 40, 70, 100, and 130 degrees Fahrenheit. The test frequencies used were $25,10,5,1,0.5$, and $0.1 \mathrm{~Hz}$. A master curve was constructed for a reference temperature of $70^{\circ} \mathrm{F}\left(21^{\circ} \mathrm{C}\right)$. The results of the test the fiber reinforced asphalt have a higher dynamic modulus value at all test temperatures. This especially became true at the higher temperatures, due to the reinforcing effect of the aramid fibers. The better 
performance of the fiber reinforced mixture at higher temperatures means that the mix would have better rutting resistance than the non- reinforced mix (Kaloush et. al., 2010).

The next test conducted by the researchers was a fatigue test. The tests were conducted on beam specimens per AASHTO TP 8 and SHRP M-009 (Kaloush et. al., 2010). The tests were ran at $4.4,21$, and 38.8 degrees Celsius. The fatigue life at $40^{\circ} \mathrm{F}$ of the fiber reinforced asphalt was discovered to be significantly better than the fatigue life of the control mixture. The fatigue life at $70^{\circ} \mathrm{F}$ for the non- reinforced asphalt was higher than the fiber reinforced asphalt at high strain values, and the fiber reinforced asphalt had a higher fatigue life at lower strain values. However, it was determined that the differences at $70^{\circ} \mathrm{F}$ were not statistically significant. A graphical representation of these results is shown in Figure 1.

The researchers explain the results at the two test temperatures to clarify the differences. The fiber reinforcement is a benefit when the tensile strength of the fiber is greater than the tensile strength of the asphalt. However, at higher temperatures, bond strength effects the performance of fiber reinforcement. At higher temperatures, the material is softer, and the bond strength is lower than it is when the material is cooler and stiffer. The loss of bond reduces the effect of the fibers. 

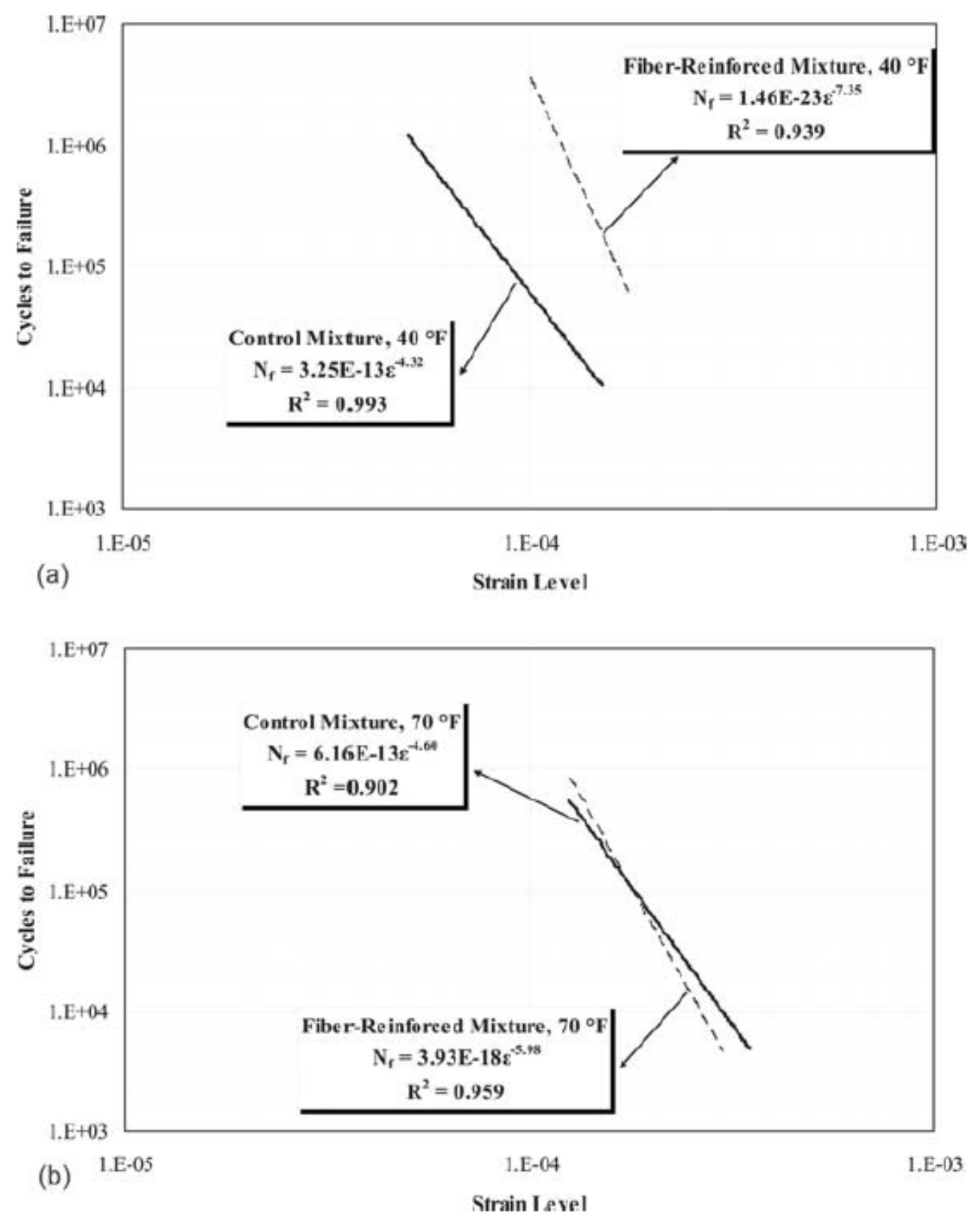

Figure 1: ASU Fatigue Test Results at (a) $40^{\circ} \mathrm{F}$ and (b) $70^{\circ} \mathrm{F}$

The K- Values for the two mixtures were reported by the researchers, and they are shown in Table 2. These K- values are transfer functions that are used in Equation 1 to calculate the fatigue life of the pavement. The fatigue life of the pavement is the number of load cycles the pavement can withstand before it fails structurally due to fatigue.

$$
N_{f}=K_{1}\left(\frac{1}{\varepsilon_{t}}\right)^{K_{2}}(E)^{K_{3}}
$$


Where:

$$
\begin{aligned}
& \mathrm{K}_{1}, \mathrm{~K}_{2}, \mathrm{~K}_{3}=\text { constants } \\
& \varepsilon_{\mathrm{t}}=\text { strain } \\
& \mathrm{E}=\text { Dynamic Modulus }
\end{aligned}
$$

At the lower strain level the fiber reinforced mix had a higher fatigue life than the nonreinforced mix, and at the higher strain level the non- reinforced mix had a higher fatigue life than the fiber reinforced mix. The researchers stated that these results indicate the fiber reinforced mix will perform better on roads with higher travel speeds, and the non- reinforced mix will perform better on roads with lower travel speeds (Kaloush et. al., 2010). The researchers graphical representation of fatigue life prediction results at all test temperatures is shown in Figure 2.

Table 2: ASU Fatigue Test $K$-Value Results

\begin{tabular}{|c|c|c|c|c||}
\hline \multirow{2}{*}{ Mixture Type } & \multicolumn{4}{|c|}{$50 \%$ of Initial Stiffness, $\mathrm{E}_{\mathrm{o}} @ \mathrm{~N}=50$ Cycles } \\
\cline { 2 - 5 } & $\mathrm{K}_{1}$ & $\mathrm{~K}_{2}$ & $\mathrm{~K}_{3}$ & $\mathrm{R}^{2}$ \\
\hline Control & 2.3496 & 2.3601 & 1.3853 & 0.914 \\
\hline Fiber-Reinforced & $6.48 \mathrm{E}-22$ & 7.8357 & 1.0839 & 0.988 \\
\hline
\end{tabular}

$$
* \mathrm{~N}_{\mathrm{f}}=\mathrm{K}_{1} *\left(1 / \varepsilon_{\mathrm{t}}\right){ }_{2}^{\mathrm{K}} *\left(1 / \mathrm{E}_{\mathrm{o}}\right) \mathrm{K}_{3}
$$



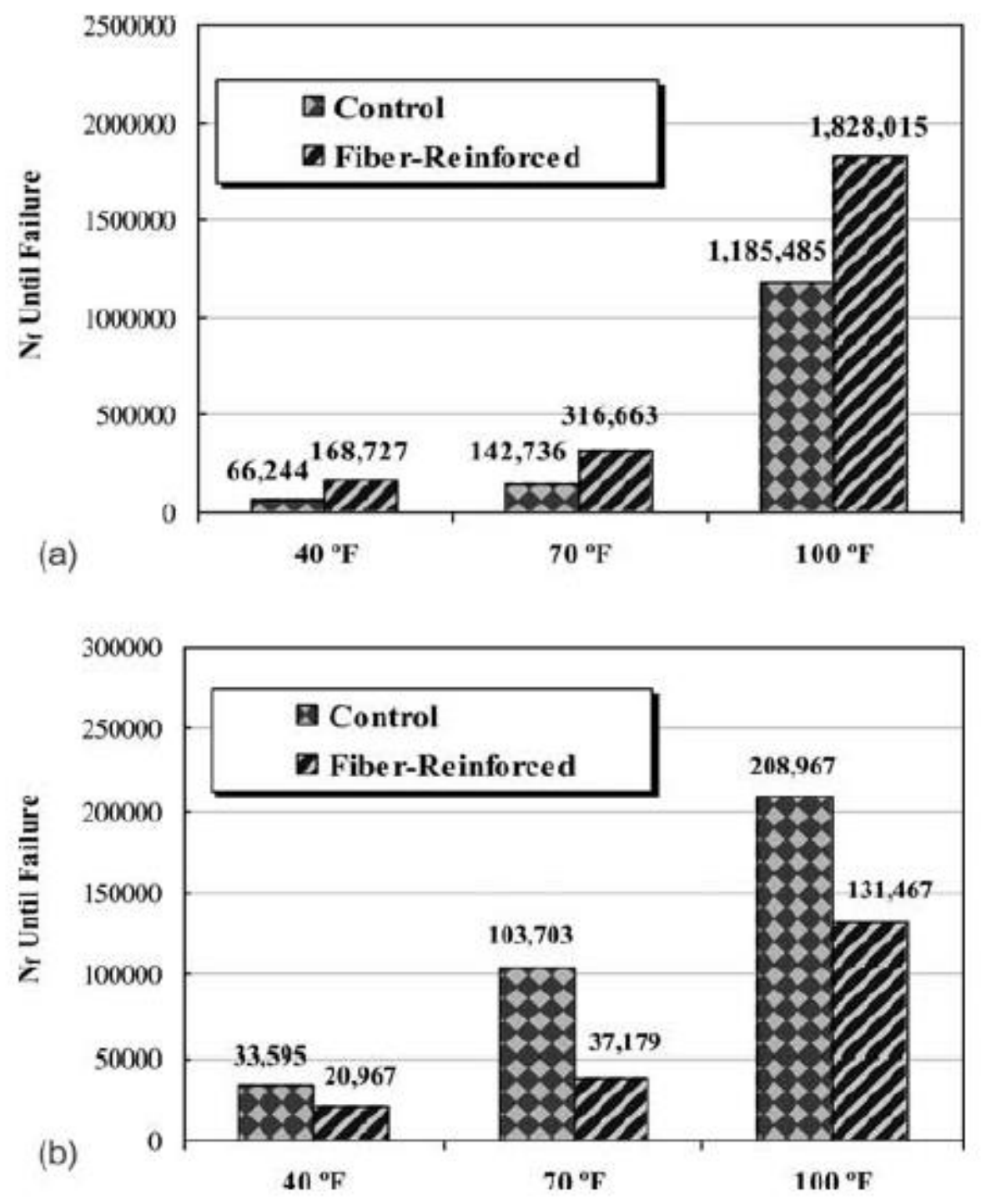

Figure 2: ASU Fatigue Life Prediction at (a) 150 microstrains and (b) 200 microstrains

A field condition survey conducted on the field application location after one year revealed that the fiber reinforced section had no visible cracks, while the non- reinforced section had a couple of low severity cracks ranging from 1 to 2 feet long (Kaloush et. al., 2010).

\section{Dynamic Modulus and Phase Angle Mastersolver}

The results produced during dynamic modulus testing on the Asphalt Mixture Performance Tester (AMPT) can be analyzed using Mastersolver version 2.2 published by Bonaquist (Bonaquist, Simple Performance Tester for Superpave Mix Design, 2011). This 
analysis yields a master curve for the material tested using reduced frequencies. These curves are based on Equation 2. This equation can generate the dynamic modulus of the material at any given reference temperature and loading frequency (Bonaquist et. al., 2005).

$$
\log \left(E^{*}\right)=\log \left(E_{\text {min }}^{*}\right)+\log \left(E_{\text {max }}^{*}\right)-\frac{\log \left(E_{\text {min }}^{*}\right)}{1+e^{\left(\beta+\gamma * \log \left(\omega_{r}\right)\right)}}
$$

Where:

$$
\begin{aligned}
& E^{*}=\text { Dynamic Modulus, }(\mathrm{ksi}) \\
& \mathrm{B}, \mathrm{\gamma}=\text { parameters describing the shape of the sigmoidal function } \\
& \omega_{\mathrm{r}}=\text { reduced frequency }
\end{aligned}
$$

Equation 3 is the equation used to solve for the reduced frequency.

$$
\omega_{r}=\omega * a(T)
$$

Where:

$$
\begin{aligned}
& \omega_{\mathrm{r}}=\text { reduced frequency } \\
& \omega=\text { loading frequency } \\
& a(T)=\text { shift factor as a function of temperature }
\end{aligned}
$$

Equation 4 is the Arrhenius equation which generates the temperature shift factor.

$$
\log (a(T))=\frac{\Delta E_{a}}{19.147143} *\left[\frac{1}{T}-\frac{1}{T_{r}}\right]
$$

Where:

$$
\begin{aligned}
& \mathrm{a}(\mathrm{T})=\text { shift factor as a function of temperature } \\
& \Delta \mathrm{E}_{\mathrm{a}}=\text { activation energy (treated as a fitting parameter) } \\
& \mathrm{T}=\text { test temperature, }{ }^{\circ} \mathrm{K} \\
& \mathrm{T}_{\mathrm{r}}=\text { reference temperature, }{ }^{\circ} \mathrm{K}
\end{aligned}
$$


For the purpose of this research, the temperature was held at the reference temperature, $15^{\circ} \mathrm{C}$, so the calculated load frequency was able to be input directly into the equation. Equation 5 was used to calculate the load duration which is the inverse of load frequency. Equation 6 shows the calculation for load frequency (Huang, 2004).

$$
d=\frac{12 * a}{s}
$$

Where:

$$
\begin{aligned}
& \mathrm{d}=\text { duration }(\mathrm{s}) \\
& \mathrm{a}=\text { tire contact radius (in.) } \\
& \mathrm{s}=\text { speed (ft. } / \mathrm{s}) \\
& \qquad \omega=\frac{1}{d}
\end{aligned}
$$

Where:

$$
\omega=\text { load frequency }(\mathrm{Hz} .)
$$

\section{Alpha-Fatigue}

The InstroTek Alpha-Fatigue ${ }^{\mathrm{TM}}$ software can be used to analyze raw fatigue data collected during testing (InstroTek, 2014). The Alpha-Fatigue software uses inputs from dynamic modulus testing as well as fatigue testing for analysis. The Alpha-Fatigue software has two modes of analysis. The first mode is the default mode in which the software picks the failure point. This point is approximately the midpoint of the phase angle curve. The second mode is the peak mode in which the user selects the peak phase angle. This is either the peak point before the phase angle drop or the peak of the phase angle curve if no phase angle drop occurred. Only one sample tested terminated before a phase angle drop could occur, and, for this sample, the peak of the phase angle curve was selected. The models used for analysis were the exponential model. This selection was for the purpose of continuity with previous research performed in the West Virginia University Asphalt Technology Laboratory. Equation 7 is used to generate the exponential damage model fatigue life.

$$
N_{f}=r\left(G^{R}\right)^{S}
$$


Where:

$$
\begin{aligned}
& \mathrm{G}^{\mathrm{R}}=\text { Stable Rate of pseudo strain energy release } \\
& \mathrm{r}, \mathrm{s}=\text { failure parameters }
\end{aligned}
$$

The exponential damage model is based on the work of Sabouri and Kim (Kim et. al., 2014). This model is the result of further development of the first stable rate of pseudo strain energy release $\left(\mathrm{G}^{\mathrm{R}}\right)$ method, which was an energy- based failure criterion (Zhang et. al., 2013). It was based on the rate of change of total pseudostrain energy. The researchers developed a failure criterion that could be applied using the viscoelastic continuum damage (VECD) model and could predict the fatigue failure that is equivalent to the drop in phase angle shown in performance tests. Prior to the development of this failure criterion the VECD model associated fatigue failure with a loss of stiffness. The $\mathrm{G}^{\mathrm{R}}$ characterizes the overall rate of damage accumulation during testing. The researchers found that failure is correlated directly to the rate at which damage accumulates. Once the rate of accumulation is known, the researchers stated that the fatigue life of the material could be accurately predicted (Zhang et.al., 2013).

The new $G^{R}$ method is still dependent on the rate of change of pseudostrain energy, but it also captures the effect of the whole loading history (Kim et. al., 2014). The development of the revised $G^{R}$ approach yielded that the characteristic curve was independent of temperature and mode of loading. This allows the characteristic curve to be developed using only one test temperature and one mode of loading. The $\mathrm{G}^{\mathrm{R}}$ failure criterion and the Simplified Viscoelastic Continuum Damage (S-VECD) model can be used to predict the fatigue life of asphalt concrete at different temperatures and strain amplitudes using the results from dynamic modulus and crosshead controlled (CX) cyclic direct tension tests (Kim et. al., 2014).

These K- values are transfer functions that are used in Equation 8 to calculate the fatigue life of the pavement. The fatigue life of the pavement is the number of load cycles the pavement can withstand before it fails structurally due to fatigue.

$$
N_{f}=K_{1}\left(\frac{1}{\varepsilon_{t}}\right)^{K_{2}}(E)^{K_{3}}
$$

Where:

$$
\mathrm{K}_{1}, \mathrm{~K}_{2}, \mathrm{~K}_{3}=\text { constants }
$$




$$
\begin{aligned}
& \varepsilon_{\mathrm{t}}=\text { strain } \\
& \mathrm{E}=\text { Dynamic Modulus }
\end{aligned}
$$

\section{Summary}

This literature review served to explore the topic of performance testing of fiber reinforced asphalt. It can be said that based on the results of the research at Arizona State University, there is a benefit to adding fiber reinforcement to hot mix asphalt.

The results of research conducted at Arizona State University showed that adding fiber can increase the dynamic modulus of the pavement, and greatly increase the resistance to permanent deformation. With regard to fatigue cracking, the fiber reinforced asphalt was found to perform better in lower strain conditions, while the non- reinforced asphalt was found to perform better in higher strain conditions. This is simplified by saying the fiber reinforced asphalt performs better on roads with higher travel speeds, and the non- reinforced asphalt performs better on roads with lower speeds.

The final review was conducted on methods of performance test data analysis. The Mastersolver workbook and Alpha- Fatigue software were explored. The exploration of these analysis methods allowed the performance test data collected through this research project to be better used. 


\section{Chapter 3: Research Methodology}

The research methodology included sample collection and preparation and testing with four methods:

- APA rutting potential

- AMPT dynamic modulus

- $\quad$ AMPT flow number

- AMPT uniaxial fatigue.

\section{Material Preparation}

The material used for the conduction of the tests was produced by Greer Asphalt located in Morgantown, WV. The material was collected from trucks at the asphalt plant. The material was shoveled into bulk storage containers, and transported to the West Virginia University Asphalt Technology Laboratory. Upon receiving the mix, the containers were labeled, weighed, and the information was recorded in master lists for the Wearing I and the Wearing I with fiber samples.

\section{Splitting}

Each master list was used to randomly select containers to be split into approximate specimen amounts. Based on the number of specimens to be compacted, the mix was randomly selected until sufficient material was available. The material was then heated to $100^{\circ} \mathrm{C}$, so that the mix could be separated and stirred. Once all of the mix reached a point in which it could be easily separated, it was poured onto a table. The mix was stirred, and then quartered. These piles were subsequently quartered into smaller amounts until the piles were small enough for boxing; each box slightly more than one half the mass of mix needed for one Gyratory shear compaction sample. These boxes were then labeled and stored. Some of the split samples were boxed into samples for maximum theoretical specific gravity tests.

\section{Maximum Specific Gravity}

Although the plant provided the maximum specific gravity $\left(\mathrm{G}_{\mathrm{mm}}\right)$ of the standard Wearing I mixture, the test was re-run in the laboratory to verify the plant result. For the Wearing I mixture with FORTA-FI@, the maximum specific gravity was unknown, so it had to 
be determined before sample preparation and testing could proceed. $G_{\mathrm{mm}}$ of the two mixtures was determined in accordance with AASHTO Specification T 209, Theoretical Maximum Specific Gravity $\left(\mathrm{G}_{\mathrm{mm}}\right)$ and Density of Hot Mix Asphalt (HMA).

\section{Specimen Preparation}

The performance tests conducted required two separate sizes of test specimens. The APA rutting susceptibility test required samples that were compacted to a height of 75 and diameter of $150 \mathrm{~mm}$ with a target air voids of $7 \pm 0.5$ percent. The APMT tests required samples to be compacted to a height of $180 \mathrm{~mm}$ and a diameter of $150 \mathrm{~mm}$. These samples were then cored and sawed to meet the size requirements of the test specifications. The target air voids was $7 \pm 0.5$ percent after coring and sawing.

\section{APA Specimen Preparation}

The APA samples were prepared in accordance with AASHTO Specification T 312, Preparing and Determining the Density of Asphalt Mixture Specimens by Means of the SuperPave Gyratory Compactor. The mixture for compaction of specimens was randomly selected from the boxes previously prepared during the splitting process for APA samples. Two boxes were randomly selected, and the mixture was placed into a pan. The pan was then place in the oven at $310^{\circ} \mathrm{F}$ which is within the compaction temperature range for the binder. The material was occasionally stirred to ensure even heating. Probe thermometers were used to monitor the temperature of the material. When the material reached the oven set temperature, it was removed from the oven and poured out onto a table. The mixture was then stirred and quartered. The mixture was placed into a separate preheated and tared pan for a final weighing. The material was selected from alternating quarters, and then subsequently re-quartered and selected until the pan contained the amount of material needed to compact a specimen. The material was returned to the oven until the compaction temperature was reached. The material was transferred into a preheated SuperPave Gyratory Compactor Mold with the use of a preheated transfer funnel. The filled mold was placed into the compactor, and the compaction height was set on the machine. The compactor compacted the material to the specified height of $75 \mathrm{~mm}$. The mold was removed from the compactor, and allowed to cool until the specimen reached a temperature of approximately $80^{\circ} \mathrm{C}$. The specimen was then extracted from the mold and allowed to cool to room temperature. 


\section{AMPT Specimen Preparation}

The AMPT samples were prepared in accordance with AASHTO Specification PP 60- 14, Preparation of Cylindrical Performance Test Specimens Using the Superpave Gyratory Compactor (SGC). The sample preparation process was the same as described as above with the exceptions that more material was added to the mold and the compaction height was $180 \mathrm{~mm}$.

The $G_{m b}$ of the full size specimens was found, and then the specimens were cored and sawed to the final specimen size. For the AMPT dynamic modulus, and the AMPT flow number rutting tests, the specimens were cored to a diameter of $100 \mathrm{~mm}$ and cut to a height of $150 \mathrm{~mm}$ in accordance with PP60. For the AMPT direct tension cyclic fatigue tests, the samples were cored to a diameter of $100 \mathrm{~mm}$ and cut to a height of $130 \mathrm{~mm}$. The cored and sawed specimens were tested using AASHTO Specification T 331, Bulk Specific Gravity $\left(\mathrm{G}_{\mathrm{mb}}\right)$ and Density of Compacted Hot Mix Asphalt (HMA) Using Automatic Vacuum Sealing Method to determine the $\mathrm{G}_{\mathrm{mb}}$. They were then stored in airtight bags to reduce the effect of oxidation prior to testing. All samples were tested within two weeks of being cored and trimmed.

\section{Specimen Air Voids}

AASHTO Specification T 331, Bulk Specific Gravity $\left(\mathrm{G}_{\mathrm{mb}}\right)$ and Density of Compacted Hot Mix Asphalt (HMA) Using Automatic Vacuum Sealing Method was used to determine $\mathrm{G}_{\mathrm{mb}}$ of each test specimen and the air void content was computed. All of the specimens met the criteria of $7.0 \pm 0.5 \%$ air voids.

\section{APA Rutting Susceptibility Test}

The APA testing was performed in accordance with AASHTO Specification T 340, Determining Rutting Susceptibility of Hot Mix Asphalt (HMA) Using the Asphalt Pavement Analyzer (APA). The only exception made was the use of AASHTO T 331 instead of AASHTO $\mathrm{T} 166$ to determine the air voids of the specimens. The loading hose pressure was 100psi. The test temperature as per the test specification was set at the high temperature of the standard Superpave performance graded (PG) binder, $64^{\circ} \mathrm{C}$.

The 6 replicate specimens used for each mix, per Figure 3 were alternated between the different positions; three replicates of each mix were tested for each of the two runs of the 
machine. For one run, one mixture occupied positions 1, 4, and 5, and the other mixture occupied positions 2,3 , and 6 . For the second run, the positions were reversed.

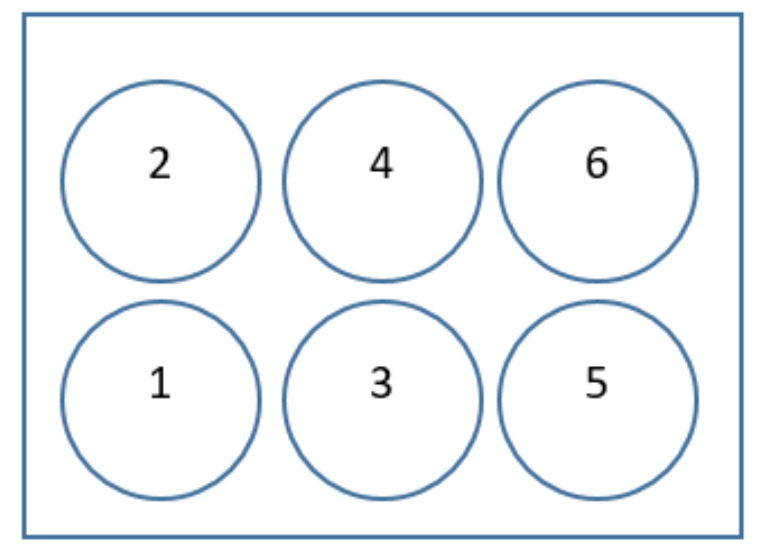

Figure 3: APA Testing Layout

The samples were placed in the molds and placed in an oven to preheat for a minimum of 6 hours, but not longer than 24 hours. At least 2 hours prior to testing, the machine was turned on to allow the test chamber to stabilize at the set test temperature of $64^{\circ} \mathrm{C}$. When the temperature stabilized, the conditioned samples in the molds were quickly placed into the APA. The temperature was then allowed to stabilize again for a minimum of 10 minutes.

25 load cycles were applied as a seating load. The holding tray was then removed from the machine and initial rut was measured within $6 \pm 0.5$ minutes. The tray was returned to the locked position, and the chamber was once again allowed to stabilize for at least 10 minutes. The test was started and 8000 load cycles were applied. Upon completion the rut depth was measured. The total rut depths were calculated from the initial and final measurements. The averages of the rut depth measurement for each specimen was calculated. The specimen average rut depths were then averaged to calculate the average rut depth of each material type.

\section{AMPT Dynamic Modulus Test}

Dynamic Modulus Testing was done in accordance with AASHTO Specification T 79, Determining the Dynamic Modulus and Flow Number for Asphalt Mixtures Using the Asphalt Mixture Performance Tester. The tests were performed at three temperatures, $4^{\circ} \mathrm{C}, 20^{\circ} \mathrm{C}$, and 
$40^{\circ} \mathrm{C}$. The tests were performed at frequencies of 10,1 , and $0.1 \mathrm{~Hz}$ for the 4 and 20 degree tests. The 40 degree tests were performed at 10, 1, 0.1, and $0.01 \mathrm{~Hz}$. Three replicate tests of each mixture type were performed.

The air voids and geometry of each sample was measured and met the requirements of $\mathrm{T}$ 79. The gauge points for attaching the linear variable differential transformers were glued to the samples using Devcon 5 minute epoxy. The jig included with the AMPT was used to ensure proper positioning of the gauge points.

The prepared specimens were placed into a conditioning chamber along with a dummy specimen. The dummy specimen contained a temperature probe inserted into the middle of the specimen to be able to monitor the internal temperature. The specimens remained in the chamber until the target temperature was reached by the dummy specimen. This process took at least 2 hours. The AMPT was turned on, and the test chamber temperature was set and allowed to equalize for at least 1 hour.

The three replicates of each of the two mixes were tested at the lowest temperature. The tests were performed at each frequency starting at the highest frequency and transitioning to the lowest frequency. All six samples were tested for one temperature in a day. The samples were returned to the conditioning chamber and left overnight to bring them to the next highest test temperature.

For each sample, the test specimen was quickly moved from the conditioning chamber and placed into the test chamber. Teflon friction reducers were placed between the top and bottom of the sample and the respective end platens. The LVDT's were attached and adjusted to zero displacement using the level tool in the InstroTek Software. The test chamber was closed and the temperature was allowed to equalize again. During the equalizing period the specimen geometry and other required data were logged into the software. Once the temperature equalized, the test was started. The temperature was monitored throughout the duration of the test. The software automatically stopped the test upon completion. The data were recorded, and the procedure was repeated for each subsequent sample and temperature. 


\section{AMPT Flow Number Test}

Flow Number Testing was done in accordance with AASHTO Specification T 79, Determining the Dynamic Modulus and Flow Number for Asphalt Mixtures Using the Asphalt Mixture Performance Tester. Procedure B was followed which was the procedure for the flow number test. Appendix X2 was used to evaluate the data. The test method requires four replicates. In this research, the four samples included three samples used for the dynamic modulus test and an additional sample that was fabricated for the flow number test.

Per T 79 Appendix X2 the test temperature was determined using the LTPP Bind software. For Morgantown, WV the required test temperature is $51^{\circ} \mathrm{C}$.

The four test specimens as well as a dummy specimen were placed into a calibrated oven at the test temperature to condition. The temperature was monitored as the specimens were warming. The AMPT was turned on, and the test chamber, along with the end platens to be used were allowed to heat to the test temperature and stabilize.

When the specimens and the test chamber were stable at the test temperature, the chamber was opened, and the first test specimen was quickly placed into the chamber. The specimen was placed between two end platens. Teflon friction reducers were placed between the specimen and the end platens. The chamber was closed and the temperature was allowed to stabilize. The top loading platen was prevented from rotating during loading. The test was performed with a contact stress of $30 \mathrm{kPa}$ and a deviator stress of $600 \mathrm{kPa}$ as per $\mathrm{T} 79$. The test was run unconfined. The results were analyzed using both the built- in data smoothing method, and also using the Francken model computation method discussed in section 10 of the test specification.

\section{AMPT Direct Tension Cyclic Fatigue Test}

Fatigue testing was done in accordance with AASHTO Specification TP 107, Determining the Damage Characteristic Curve of Asphalt Mixtures from Direct Tension Cyclic Fatigue Tests. The test specimens for the direct tension fatigue testing were prepared in accordance with AASHTO Specification PP60, with the only exception being that the specimens were cut to a height of $130 \mathrm{~mm}$ instead of $150 \mathrm{~mm}$. The average diameter of the specimens tested was to be within the range of 100 to $104 \mathrm{~mm}$ with a standard deviation of less than $0.5 \mathrm{~mm}$. The 
average height of the specimens tested was to be between 127.5 and $132.5 \mathrm{~mm}$. When cutting the specimens, the specification was followed in that the first $25 \mathrm{~mm}$ was cut off of the bottom of the specimen with the remaining material being cut from the top of the specimen. The specimens were prepared in a manner that they would be tested within 2 weeks of coring and sawing. They were stored in sealed plastic bags. There were 9 specimens of each mixture type prepared for fatigue testing. The $\mathrm{G}_{\mathrm{mb}}$ was calculated in the same manner as the Flow Number Samples.

Gauge points were attached to the specimens in the same manner as they were for the dynamic modulus testing, with the only difference being a thicker base plate on the gluing jig was used for proper alignment.

The end plates were thoroughly cleaned with a wire wheel, and then they were wiped down with acetone to remove any residual material. Next, they were heated in an oven at $40^{\circ} \mathrm{C}$. This heating process allowed for better bonding of the end plates to the specimens. Devcon 10110, steel putty, was used to attach the end plates to the specimens. The steel putty was mixed per the manufacturer's instructions. The specification recommended $120 \mathrm{~g}$ of steel putty would be sufficient, but it has been found, through other research conducted in the West Virginia University Asphalt Technology Laboratory, that $60 \mathrm{~g}$ of steel putty is sufficient for the gluing procedure. The end plates were attached using a gluing jig following the test specification gluing procedure. The specimens were kept in the gluing jig for 4 hours to allow the putty to set. They were then removed, and the putty was allowed to cure for 12 additional hours before conditioning.

Using the LTTPBind software, the $98 \%$ reliability climatic performance grade (PG) was determined to be PG 58-22. Based on this performance grade and the procedure listed in the test specification, the testing temperature was determined to be $15^{\circ} \mathrm{C}$. The temperature of the conditioning chamber was set to $15^{\circ} \mathrm{C}$, and after curing the test specimens were placed in the chamber along with a dummy specimen that had a temperature probe inserted into its center. The specimens were left to condition at least until the temperature of the dummy specimen equalized. The AMPT was turned on, and the test chamber was set to the test temperature and allowed to equalize. When the chamber and the specimen were at temperature the specimen was quickly placed into the chamber. The bottom specimen plate was attached using three screws which were torqued using a torque wrench to $6 \mathrm{lb}-\mathrm{ft}$. A ball was placed on the top plate to reduce 
eccentricity, and a seating load of $0.09 \mathrm{kN}$ (20 lbs.) was applied. The top plate was then attached with three screws to the same torque. The load was then reduced to $0 \mathrm{kN} \pm 0.01 \mathrm{kN}$. The LVDT's were attached, and they were adjusted to zero displacement using the software's leveling tool. This process was completed within 5 minutes, and the chamber was closed and allowed to equalize for another hour before testing.

A fingerprint dynamic modulus test was run at $10 \mathrm{~Hz}$ at $15^{\circ} \mathrm{C}$ in the tension- compression mode of loading. A target strain range of 50 to 75 microstrains was entered into the equipment control software. The software automatically performed the dynamic modulus test per the instructions listed in the specification. The specimen then underwent a rest period of 20 minutes. After the rest period the cyclic fatigue test was started. Three specimen tests were required to produce the single test result. The first test was run with a peak- to- peak on- specimen strain amplitude of 300 microstrains. The second and third test were based on the results of the 300 microstrain test. The strain levels were determined using Table 4 in AASHTO Specification TP 107. All of the samples testsed at 300 microstrains failed at a cycle greater than 20,000 . Therefore, all of the second tests were tested at 400 microstrains, and the third tests were tested at 350 microstrains per the specification.

After testing, each specimen was removed from the test chamber. The gauge points were removed and cleaned with acetone to be reused. The specimens were placed in an oven at $100^{\circ} \mathrm{C}$ to soften the asphalt and weaken the bond of the steel putty. The putty was scraped from the end plates. The plates were then cleaned with a wire wheel, wiped down with acetone to remove residue, and they were reused for subsequent test. Upon completion of testing, the cleaned end plates were coated in a thin layer of oil and placed into storage for future testing. 


\section{Chapter 4: Results and Discussion}

This chapter presents the results of performance testing and analyses of the results.

\section{Maximum Specific Gravity}

The maximum specific gravity testing was done in accordance with AASHTO Specification T 209 as discussed in the methodology section. The job mix formula listed the Gmm of the Wearing I mixture as 2.484. The date of acceptance of the mix design was 9 March 2004, so it was decided to rerun this test on the Wearing I mixture to accurately determine the $\mathrm{G}_{\mathrm{mm}}$. The test was also run for the Wearing I mixture containing FORTA-FI®, as it was expected that the fibers would possible alter the $G_{\mathrm{mm}}$ of the material. The results are shown in Table 3 . The sample type W1 is the standard Wearing I mixture, and the sample type FF1 is the Wearing I mixture with FORTA-FI®.

Table 3: Maximum Specific Gravity Test Results

\begin{tabular}{|c|c|c|c|c|c|c|}
\hline Sample Type & $\begin{array}{c}\text { Container } \\
\text { Dry }\end{array}$ & $\begin{array}{c}\text { Sample } \\
\& \\
\text { Container } \\
\text { Dry }\end{array}$ & $\begin{array}{c}\text { Submerged } \\
\text { Weight }\end{array}$ & $\begin{array}{l}\text { Container } \\
\text { Submerged }\end{array}$ & $\mathrm{Gmm}$ & $\begin{array}{c}\text { Average } \\
\text { Gmm }\end{array}$ \\
\hline W1 & 2057.3 & 3658 & 2275.5 & 1316.8 & 2.493 & \multirow{2}{*}{2.491} \\
\hline W1 & 2057.3 & 3648.1 & 2268.4 & 1316.8 & 2.489 & \\
\hline FF1 & 2057.3 & 3652 & 2269.4 & 1316.8 & 2.484 & \multirow{2}{*}{2.484} \\
\hline FF1 & 2057.3 & 3649.6 & 2268.1 & 1316.8 & 2.484 & \\
\hline
\end{tabular}

The $\mathrm{G}_{\mathrm{mm}}$ of the Wearing I mixture was, in fact, different than the value provided on the job mix formula. The provided value was stated was 2.484 , and the laboratory calculated value was 2.491. The $\mathrm{G}_{\mathrm{mm}}$ for the Wearing I mixture with FORTA-FI@ was determined to be 2.484.

\section{APA Specimen Air Voids}

The APA specimens were prepared in accordance with AASHTO Specification T 312 as stated in the methodology. $\mathrm{G}_{\mathrm{mb}}$ was calculated with AASHTO Specification T331, the automatic vacuum sealing method, CoreLok®. The specimens were prepared and cooled to room temperature before testing. 
Table 4: APA Specimen Air Voids and $G_{m b}$

\begin{tabular}{|c|l|c|c|c|c|c|c|}
\hline & & Sample 1 & Sample 2 & Sample 3 & Sample 4 & Sample 5 & Sample 6 \\
\hline \multirow{2}{*}{ W1 } & Gmb & 2.310 & 2.313 & 2.308 & 2.306 & 2.306 & 2.305 \\
\cline { 2 - 8 } & Air Voids & 7.3 & 7.2 & 7.3 & 7.4 & 7.4 & 7.5 \\
\hline \multirow{2}{*}{ FF1 } & Gmb & 2.311 & 2.309 & 2.312 & 2.307 & 2.313 & 2.314 \\
\cline { 2 - 8 } & Air Voids & 6.9 & 7.0 & 6.9 & 7.1 & 6.9 & 6.8 \\
\hline
\end{tabular}

The results of specimens used for testing are shown in Table 4. The results of all specimens are $7 \pm 0.5 \%$. All of the specimens used for testing were within the specified air void limits.

\section{AMPT Specimen Air Voids}

The AMPT specimens were prepared in accordance with AASHTO Specification T 312, as stated in the methodology. The $\mathrm{G}_{\mathrm{mb}}$ was calculated the same as above. The specimens were tested before and after coring and sawing; the data from before coring and sawing was recorded to be added to similar data collected in the West Virginia University Asphalt Technology Laboratory. The data from after coring and sawing was used to verify the specimens for testing. The data for the Wearing I specimens $\left(\mathrm{WA}_{\mathrm{i}}\right)$ from before and after the coring and sawing procedure are presented in Table 5. The data for the Wearing I with FORTA-FI® specimens $\left(\mathrm{FA}_{\mathrm{i}}\right)$ from before and after the coring and sawing procedure are presented in Table 6. 
Table 5: Wearing I AMPT Specimen Verifications

\begin{tabular}{|c|c|c|c|c|c|c|c|c|c|c|c|c|c|}
\hline Sample & WA1 & WA2 & WA3 & WA4 & WA5 & WA6 & WA7 & WA8 & WA9 & WA10 & WA11 & WA12 & WA13 \\
\hline \multicolumn{10}{|c|}{ Before } \\
\hline Gmm & 2.491 & 2.491 & 2.491 & 2.491 & 2.491 & 2.491 & 2.491 & 2.491 & 2.491 & 2.491 & 2.491 & 2.491 & 2.491 \\
\hline Gmb & 2.253 & 2.281 & 2.282 & 2.280 & 2.281 & 2.281 & 2.278 & 2.281 & 2.278 & 2.280 & 2.281 & 2.280 & 2.278 \\
\hline VTM & $\mathbf{9 . 6 \%}$ & $\mathbf{8 . 4 \%}$ & $\mathbf{8 . 4 \%}$ & $\mathbf{8 . 5} \%$ & $\mathbf{8 . 4 \%}$ & $\mathbf{8 . 4 \%}$ & $\mathbf{8 . 5 \%}$ & $\mathbf{8 . 4 \%}$ & $\mathbf{8 . 6 \%}$ & $\mathbf{8 . 5 \%}$ & $\mathbf{8 . 4 \%}$ & $\mathbf{8 . 5 \%}$ & $\mathbf{8 . 5 \%}$ \\
\hline \multicolumn{10}{|c|}{ After } \\
\hline Gmm & 2.491 & 2.491 & 2.491 & 2.491 & 2.491 & 2.491 & 2.491 & 2.491 & 2.491 & 2.491 & 2.491 & 2.491 & 2.491 \\
\hline Gmb & 2.316 & 2.314 & 2.318 & 2.312 & 2.312 & 2.327 & 2.319 & 2.311 & 2.322 & 2.320 & 2.324 & 2.322 & 2.320 \\
\hline VTM & $\mathbf{7 . 0} \%$ & $\mathbf{7 . 1 \%}$ & $\mathbf{7 . 0 \%}$ & $\mathbf{7 . 2 \%}$ & $\mathbf{7 . 2 \%}$ & $\mathbf{6 . 6 \%}$ & $\mathbf{6 . 9 \%}$ & $\mathbf{7 . 2 \%}$ & $\mathbf{6 . 8} \%$ & $\mathbf{6 . 9 \%}$ & $\mathbf{6 . 7 \%}$ & $\mathbf{6 . 8} \%$ & $\mathbf{6 . 9 \%}$ \\
\hline
\end{tabular}

Table 6: Wearing I with FORTA-FI AMPT Specimen Verifications

\begin{tabular}{|c|c|c|c|c|c|c|c|c|c|c|c|c|c|}
\hline Sample & FA1 & FA2 & FA3 & FA4 & FA5 & FA6 & FA7 & FA8 & FA9 & FA10 & FA11 & FA12 & FA13 \\
\hline \multicolumn{10}{|c|}{ Before } \\
\hline Gmm & 2.484 & 2.484 & 2.484 & 2.484 & 2.484 & 2.484 & 2.484 & 2.484 & 2.484 & 2.484 & 2.484 & 2.484 & 2.484 \\
\hline Gmb & 2.270 & 2.275 & 2.266 & 2.270 & 2.264 & 2.265 & 2.264 & 2.267 & 2.267 & 2.270 & 2.269 & 2.265 & 2.263 \\
\hline VTM & $\mathbf{8 . 6 \%}$ & $\mathbf{8 . 4 \%}$ & $\mathbf{8 . 8} \%$ & $\mathbf{8 . 6 \%}$ & $\mathbf{8 . 9 \%}$ & $\mathbf{8 . 8} \%$ & $\mathbf{8 . 8} \%$ & $\mathbf{8 . 7 \%}$ & $\mathbf{8 . 7 \%}$ & $\mathbf{8 . 6 \%}$ & $\mathbf{8 . 7 \%}$ & $\mathbf{8 . 8 \%}$ & $\mathbf{8 . 9 \%}$ \\
\hline \multicolumn{10}{|c|}{ After } \\
\hline Gmm & 2.484 & 2.484 & 2.484 & 2.484 & 2.484 & 2.484 & 2.484 & 2.484 & 2.484 & 2.484 & 2.484 & 2.484 & 2.484 \\
\hline Gmb & 2.307 & 2.298 & 2.302 & 2.304 & 2.311 & 2.310 & 2.299 & 2.307 & 2.314 & 2.314 & 2.317 & 2.298 & 2.303 \\
\hline VTM & $\mathbf{7 . 1 \%}$ & $\mathbf{7 . 5 \%}$ & $\mathbf{7 . 3 \%}$ & $\mathbf{7 . 3 \%}$ & $\mathbf{7 . 0 \%}$ & $\mathbf{7 . 0 \%}$ & $\mathbf{7 . 4 \%}$ & $\mathbf{7 . 1 \%}$ & $\mathbf{6 . 8} \%$ & $\mathbf{6 . 8} \%$ & $\mathbf{6 . 7 \%}$ & $\mathbf{7 . 5 \%}$ & $\mathbf{7 . 3 \%}$ \\
\hline
\end{tabular}


The specimens are listed in the order in which they were tested. All of the specimens tested were within the air void limit of $7.0 \pm 0.5 \%$. It should again be noted that specimens 1 through 4 of both mixture types were used for both dynamic modulus and flow number testing.

\section{APA Rutting Susceptibility Test}

The APA testing was performed using 6 replicate tests of each material. Each run of the test contained 3 replicates of each material, and the test positions of the mixtures were alternated between the two runs to reduce bias. The APA requires manual calibration (so even if the calibration is within specified tolerances there can still be slight differences). Alternating the position of the specimens between replicates was a way to verify that each mixture was exposed to the same set of conditions. The total results of each replicate are presented in Appendix D. For discussion purposes, the average rut depth at each test position for each replicate, and the total average rut depth of each mixture will be presented. These are shown in Table 7.

Table 7: APA Test Results

\begin{tabular}{|c|c|c|c|}
\hline \multirow{2}{*}{$\begin{array}{c}\text { Mixture } \\
\text { Type }\end{array}$} & \multirow{2}{*}{ Replicate } & \multicolumn{2}{|c|}{ Run } \\
\hline & & 1 & 2 \\
\hline \multirow{3}{*}{ W1 } & 1 & 5.00 & 4.82 \\
\hline & 2 & 4.25 & 4.19 \\
\hline & 3 & 5.03 & 5.37 \\
\hline \multicolumn{2}{|c|}{ Avg. } & 4.76 & 4.79 \\
\hline \multicolumn{2}{|c|}{ Total Rut } & \multicolumn{2}{|c|}{4.78} \\
\hline \multirow{3}{*}{ FF1 } & $\begin{array}{l}1 \\
\end{array}$ & 4.53 & 4.62 \\
\hline & 2 & 5.45 & 4.70 \\
\hline & 3 & 5.28 & 5.00 \\
\hline \multicolumn{2}{|c|}{ Avg. } & 5.09 & 4.77 \\
\hline \multicolumn{2}{|c|}{ Total Rut } & \multicolumn{2}{|c|}{4.93} \\
\hline
\end{tabular}

The results of the testing initially showed that the total average rut depths of the two mixture types were very similar. The Wearing I with FORTA-FI® had a total average rut depth that was only about two tenths of a millimeter more than that of the Wearing I mixture. A graphical representation of the rut depths provides a visual aid to recognize the slight differences. 
Figure 4 shows the average rut depths of the two mixtures. This figure shows average rut depths that are very similar.

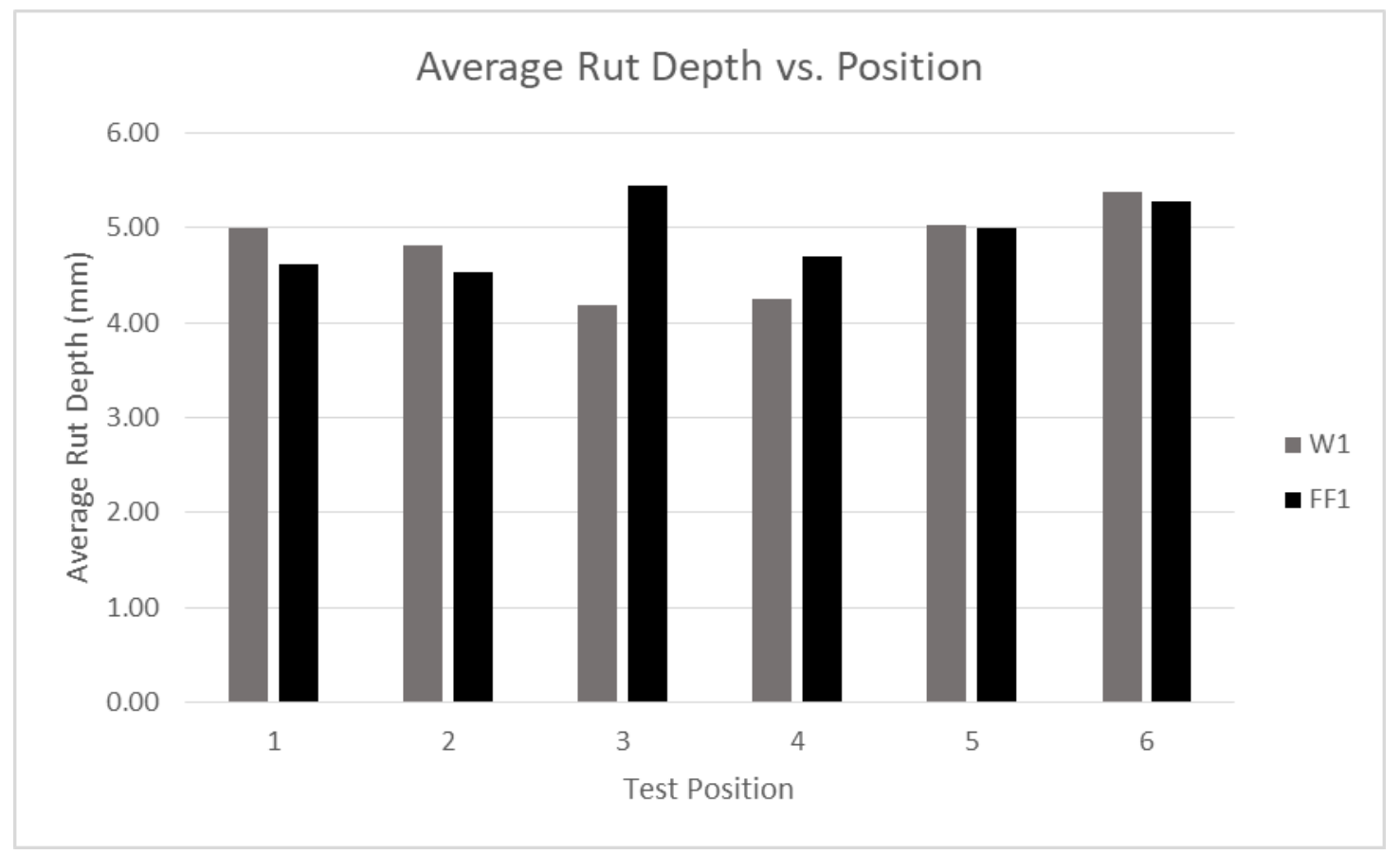

Figure 4: APA Average Rut Depths

A two- sample assuming equal variances t- test was performed on the combined results of the APA test. This t- test was used to analyze the result and to see if there was a significant difference in the average rut depths of the two mixtures. The results of the t- test are shown in Table 8.

Table 8: APA T-Test Results

\begin{tabular}{|l|c|c|}
\hline $\mathrm{t}$-Test: Two-Sample Assuming Equal Variances $(\alpha=0.05)$ & W 1 & $F F 1$ \\
\hline Mean & 4.77 & 4.93 \\
\hline Variance & 0.22 & 0.14 \\
\hline Observations & 6 & 6 \\
\hline Pooled Variance & \multicolumn{2}{|c|}{0.18} \\
\hline Hypothesized Mean Difference & \multicolumn{2}{|c|}{0} \\
\hline $\mathrm{df}$ & \multicolumn{2}{|c|}{10} \\
\hline $\mathrm{t}$ Stat & \multicolumn{2}{|c|}{-0.63} \\
\hline $\mathrm{P}(\mathrm{T}<=\mathrm{t})$ one-tail & \multicolumn{2}{|c|}{0.27} \\
\hline $\mathrm{t}$ Critical one-tail & \multicolumn{2}{|c|}{1.81} \\
\hline $\mathrm{P}(\mathrm{T}<=\mathrm{t})$ two-tail & \multicolumn{2}{|c|}{0.54} \\
\hline $\mathrm{t}$ Critical two-tail & \multicolumn{2}{|c|}{2.23} \\
\hline
\end{tabular}


The total average rut depths were $4.93 \mathrm{~mm}$ for the Wearing I with FORTA-FI® mixture and 4.78 $\mathrm{mm}$ for the Wearing I mixture. The t- test showed insufficient evidence to reject the null hypothesis of equal means. It can be concluded at the $95 \%$ confidence level that there is no significant difference in the average rut depths of the Wearing I and the Wearing I with FORTAFI® mixtures when tested in the Asphalt Pavement Analyzer. This result means that the rutting potential, when tested with the APA, of the two mixtures is statistically the same. The specification lists no criteria for interpretation of the results other than a comparison of average rut depths. The APA has been used at WVU ATL for many years. The limit used to identify rutting resistant mixes is $8 \mathrm{~mm}$ (Zaniewski and Patino, 2005). There is no correlation to field performance of these two mixtures.

\section{Dynamic Modulus Testing}

Dynamic Modulus Testing was done in accordance with AASHTO Specification T 79 using an InstroTek AMPT. The data were analyzed using both the AMPT outputs and Bonaquist's Mastersolver. The Mastersolver outputs are provided in Appendix E.

\section{Dynamic Modulus and Phase Angle}

The dynamic modulus values output from the AMPT are provided in Table 9. The average, standard deviation, and coefficient of variance $(\%)$ are provided in Table 10. The phase angle values output by the AMPT are provided in Table 11. The average, standard deviation, and coefficient of variation $(\mathrm{MPa})(\%)$ are provided in Table 12. Three specimens of each mix type were tested at all test temperatures and frequencies. 
Table 9: Dynamic Modulus Test Outputs (MPa)

\begin{tabular}{|c|c|c|c|c|c|c|c|c|c|c|c|}
\hline \multirow[b]{2}{*}{ Mix Type } & \multirow[b]{2}{*}{ Specimen } & \multicolumn{3}{|c|}{$4^{\circ} \mathrm{C}$} & \multicolumn{3}{|c|}{$20^{\circ}$} & \multicolumn{4}{|c|}{$40^{\circ}$} \\
\hline & & $10 \mathrm{~Hz}$ & $1.0 \mathrm{~Hz}$ & $0.1 \mathrm{~Hz}$ & $10 \mathrm{~Hz}$ & $1.0 \mathrm{~Hz}$ & $0.1 \mathrm{~Hz}$ & $10 \mathrm{~Hz}$ & $1.0 \mathrm{~Hz}$ & $0.1 \mathrm{~Hz}$ & $0.01 \mathrm{~Hz}$ \\
\hline \multirow{3}{*}{ Wearing I } & WA1 & 15435.0 & 11567.0 & 7978.0 & 7008.0 & 4020.0 & 2085.0 & 1615.0 & 689.9 & 303.5 & 164.6 \\
\hline & WA2 & 13343.0 & 10229.0 & 7211.0 & 6016.0 & 3476.0 & 1800.0 & 1472.0 & 634.9 & 286.8 & 158.6 \\
\hline & WA3 & 14449.0 & 11066.0 & 7820.0 & 5669.0 & 3816.0 & 1992.0 & 1553.0 & 662.2 & 297.4 & 168.6 \\
\hline \multirow{3}{*}{$\begin{array}{l}\text { Wearing I } \\
\text { w/ } \\
\text { FORTA-FI }\end{array}$} & FA1 & 12940.0 & 10176.0 & 7545.0 & 6323.0 & 3929.0 & 2242.0 & 1706.0 & 813.6 & 395.5 & 226.8 \\
\hline & FA2 & 12869.0 & 9858.0 & 7010.0 & 5990.0 & 3508.0 & 1877.0 & 1560.0 & 708.8 & 330.7 & 181.0 \\
\hline & FA3 & 13862.0 & 10667.0 & 7616.0 & 6219.0 & 3639.0 & 1950.0 & 1655.0 & 755.8 & 350.5 & 184.6 \\
\hline
\end{tabular}

Table 10: Dynamic Modulus Test Average, Standard Deviation, and Coefficient of Variation (MPa)

\begin{tabular}{|c|c|c|c|c|c|c|c|c|c|c|c|}
\hline \multirow[b]{2}{*}{ Mix Type } & \multirow[b]{2}{*}{ Specimen } & \multicolumn{3}{|c|}{$4^{\circ} \mathrm{C}$} & \multicolumn{3}{|c|}{$20^{\circ}$} & \multicolumn{4}{|c|}{$40^{\circ}$} \\
\hline & & $10 \mathrm{~Hz}$ & $1.0 \mathrm{~Hz}$ & $0.1 \mathrm{~Hz}$ & $10 \mathrm{~Hz}$ & $1.0 \mathrm{~Hz}$ & $0.1 \mathrm{~Hz}$ & $10 \mathrm{~Hz}$ & $1.0 \mathrm{~Hz}$ & $0.1 \mathrm{~Hz}$ & $0.01 \mathrm{~Hz}$ \\
\hline \multirow{3}{*}{ Wearing I } & Avg. & 14409.0 & 10954.0 & 7669.7 & 6231.0 & 3770.7 & 1959.0 & 1546.7 & 662.3 & 295.9 & 163.9 \\
\hline & SD & 1046.6 & 676.0 & 405.0 & 694.9 & 274.8 & 145.3 & 71.7 & 27.5 & 8.5 & 5.0 \\
\hline & CV & $7.26 \%$ & $6.17 \%$ & $5.28 \%$ & $11.15 \%$ & $7.29 \%$ & $7.42 \%$ & $4.64 \%$ & $4.15 \%$ & $2.86 \%$ & $3.07 \%$ \\
\hline \multirow{3}{*}{$\begin{array}{l}\text { Wearing I } \\
\text { w/ } \\
\text { FORTA-FI }\end{array}$} & Avg. & 13223.7 & 10233.7 & 7390.3 & 6177.3 & 3692.0 & 2023.0 & 1640.3 & 759.4 & 358.9 & 197.5 \\
\hline & SD & 554.0 & 407.6 & 331.3 & 170.4 & 215.4 & 193.1 & 74.1 & 52.5 & 33.2 & 25.5 \\
\hline & $C V$ & $4.19 \%$ & $3.98 \%$ & $4.48 \%$ & $2.76 \%$ & $5.84 \%$ & $9.55 \%$ & $4.52 \%$ & $6.91 \%$ & $9.25 \%$ & $12.90 \%$ \\
\hline
\end{tabular}


Table 11: Dynamic Modulus Test Phase Angle Results

\begin{tabular}{|c|c|c|c|c|c|c|c|c|c|c|c|}
\hline \multirow[b]{2}{*}{ Mix Type } & \multirow[b]{2}{*}{ Specimen } & \multicolumn{3}{|c|}{$4^{\circ} \mathrm{C}$} & \multicolumn{3}{|c|}{$20^{\circ}$} & \multicolumn{4}{|c|}{$40^{\circ}$} \\
\hline & & $10 \mathrm{~Hz}$ & $1.0 \mathrm{~Hz}$ & $0.1 \mathrm{~Hz}$ & $10 \mathrm{~Hz}$ & $1.0 \mathrm{~Hz}$ & $0.1 \mathrm{~Hz}$ & $10 \mathrm{~Hz}$ & $1.0 \mathrm{~Hz}$ & $0.1 \mathrm{~Hz}$ & $0.01 \mathrm{~Hz}$ \\
\hline \multirow{3}{*}{ Wearing I } & WA1 & 9.9 & 13.3 & 17.9 & 20.6 & 25.9 & 29.9 & 34.5 & 33.3 & 29.7 & 25.0 \\
\hline & WA2 & 9.5 & 12.6 & 17.0 & 20.9 & 26.3 & 29.9 & 34.2 & 32.7 & 28.9 & 24.5 \\
\hline & WA3 & 9.5 & 12.6 & 17.1 & 19.8 & 27.0 & 34.6 & 34.1 & 32.6 & 28.9 & 25.1 \\
\hline \multirow{3}{*}{$\begin{array}{l}\text { Wearing I } \\
\text { w/ } \\
\text { FORTA-FI }\end{array}$} & FA1 & 8.7 & 11.1 & 14.5 & 18.3 & 23.1 & 27.4 & 31.9 & 32.1 & 29.5 & 26.0 \\
\hline & FA2 & 9.6 & 12.5 & 16.7 & 20.2 & 25.5 & 29.5 & 33.3 & 32.7 & 28.9 & 24.6 \\
\hline & FA3 & 9.3 & 12.2 & 16.3 & 20.2 & 25.6 & 29.6 & 33.0 & 32.8 & 29.9 & 25.3 \\
\hline
\end{tabular}

Table 12: Dynamic Modulus Test Phase Angle Average, Standard Deviation, and Coefficient of Variation

\begin{tabular}{|c|c|c|c|c|c|c|c|c|c|c|c|}
\hline \multirow[b]{2}{*}{ Mix Type } & \multirow[b]{2}{*}{ Specimen } & \multicolumn{3}{|c|}{$4^{\circ} \mathrm{C}$} & \multicolumn{3}{|c|}{$20^{\circ}$} & \multicolumn{4}{|c|}{$40^{\circ}$} \\
\hline & & $10 \mathrm{~Hz}$ & $1.0 \mathrm{~Hz}$ & $0.1 \mathrm{~Hz}$ & $10 \mathrm{~Hz}$ & $1.0 \mathrm{~Hz}$ & $0.1 \mathrm{~Hz}$ & $10 \mathrm{~Hz}$ & $1.0 \mathrm{~Hz}$ & $0.1 \mathrm{~Hz}$ & $0.01 \mathrm{~Hz}$ \\
\hline \multirow{3}{*}{ Wearing I } & Avg. & 9.6 & 12.8 & 17.3 & 20.4 & 26.4 & 31.5 & 34.3 & 32.9 & 29.2 & 24.9 \\
\hline & SD & 0.2 & 0.4 & 0.5 & 0.6 & 0.6 & 2.7 & 0.2 & 0.4 & 0.5 & 0.3 \\
\hline & CV & $2.40 \%$ & $3.15 \%$ & $2.85 \%$ & $2.78 \%$ & $2.11 \%$ & $8.62 \%$ & $0.61 \%$ & $1.15 \%$ & $1.58 \%$ & $1.29 \%$ \\
\hline \multirow{3}{*}{$\begin{array}{l}\text { Wearing I } \\
\mathrm{w} / \\
\text { FORTA-FI }\end{array}$} & Avg. & 9.2 & 11.9 & 15.8 & 19.6 & 24.7 & 28.8 & 32.7 & 32.5 & 29.4 & 25.3 \\
\hline & SD & 0.5 & 0.7 & 1.2 & 1.1 & 1.4 & 1.2 & 0.7 & 0.4 & 0.5 & 0.7 \\
\hline & CV & $4.98 \%$ & $6.18 \%$ & $7.40 \%$ & $5.61 \%$ & $5.72 \%$ & $4.31 \%$ & $2.25 \%$ & $1.16 \%$ & $1.71 \%$ & $2.77 \%$ \\
\hline
\end{tabular}


The results provided fit well within expected outcomes. As the temperature increased, the average dynamic modulus decreased as expected. As the load frequency decreased the average dynamic modulus decreased as expected. The standard deviation and coefficient of variation of the dynamic modulus also decreased as the load frequency decreased. These are trends that have been observed in past testing conducted in the West Virginia University Asphalt Technology Laboratory (Dalton, 2016). The standard deviation of the dynamic modulus values tended to decrease as the load frequency decreased. This shows an increase in accuracy for the lower frequency tests. The coefficient of variation showed no trends, and it never exceeded $13 \%$.

The average phase angle of the two mixtures tended to increase as the load frequency was decreased. As the temperature was increased, the average phase angle tended to increase. These results are once again similar to past testing conducted in the laboratory. Specifically, they are similar to research conducted by Dalton (Dalton, 2016). The standard deviation of the phase angle test results yielded no trend. The coefficient of variation never exceeded $12.5 \%$. No trends were observed with respect to the coefficient of variance.

Plots of the average dynamic modulus values of the two mixture types provide a visual aid in which the trends can be observed with regard to temperature and load frequency. These plots are shown in Figures 5-7. It can be observed at the $4^{\circ} \mathrm{C}$ test temperature that the Wearing I mixture out performs the Wearing I with FORTA-FI@ mixture at all test frequencies. The results for the $20^{\circ} \mathrm{C}$ test temperature show almost equal performance of the mixtures at all test frequencies. The $40^{\circ} \mathrm{C}$ test temperature shows that the Wearing I with FORTA-FI® outperforms the Wearing I mixture at all test frequencies. The plots show that for all mixtures, the average dynamic modulus values decrease as test temperature is increased. The plots also show the increase in average dynamic modulus, for all mixtures, as the load frequency is increased. 


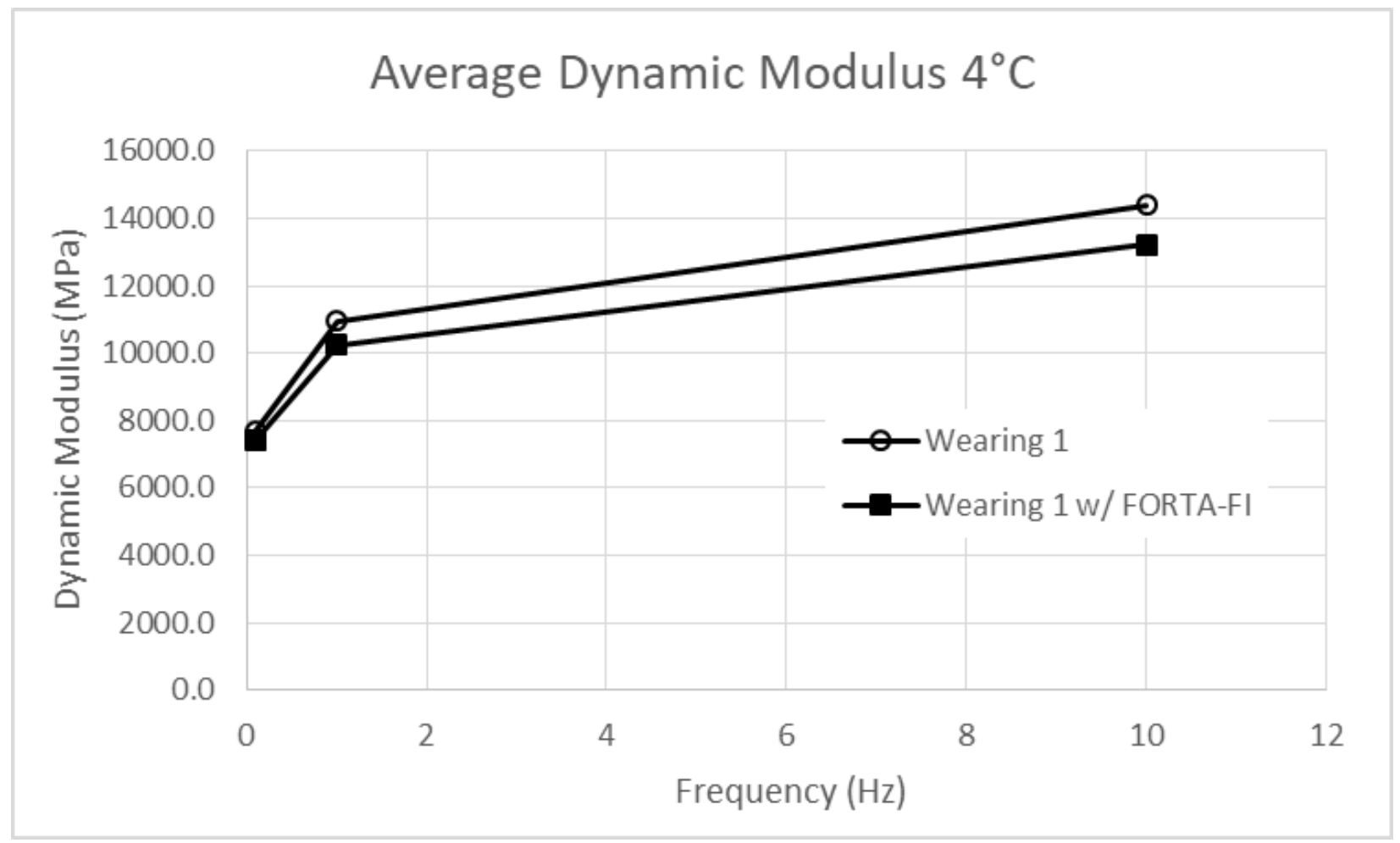

Figure 5: Average Dynamic Modulus at 4 degrees

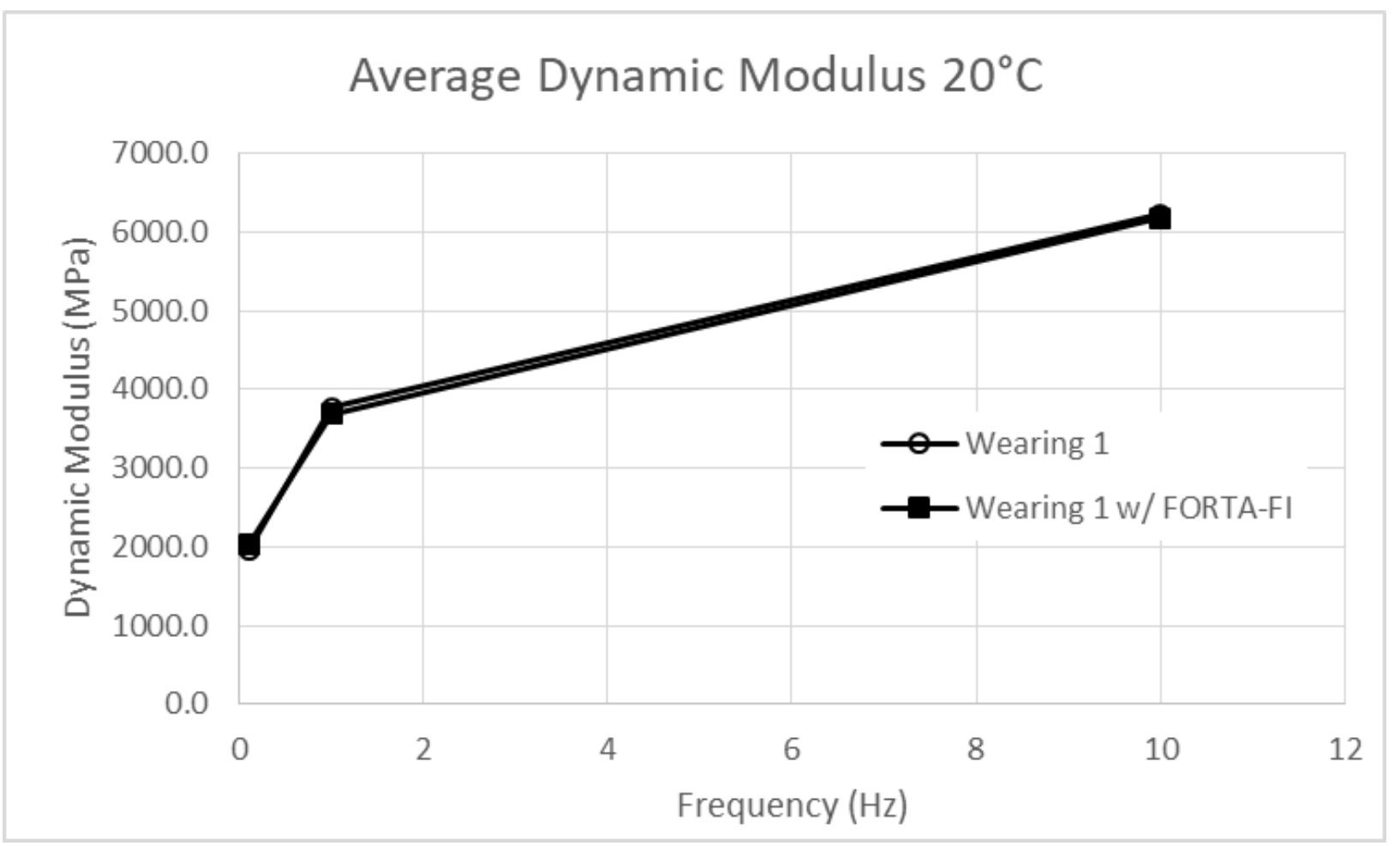

Figure 6: Average Dynamic Modulus at 20 degrees 


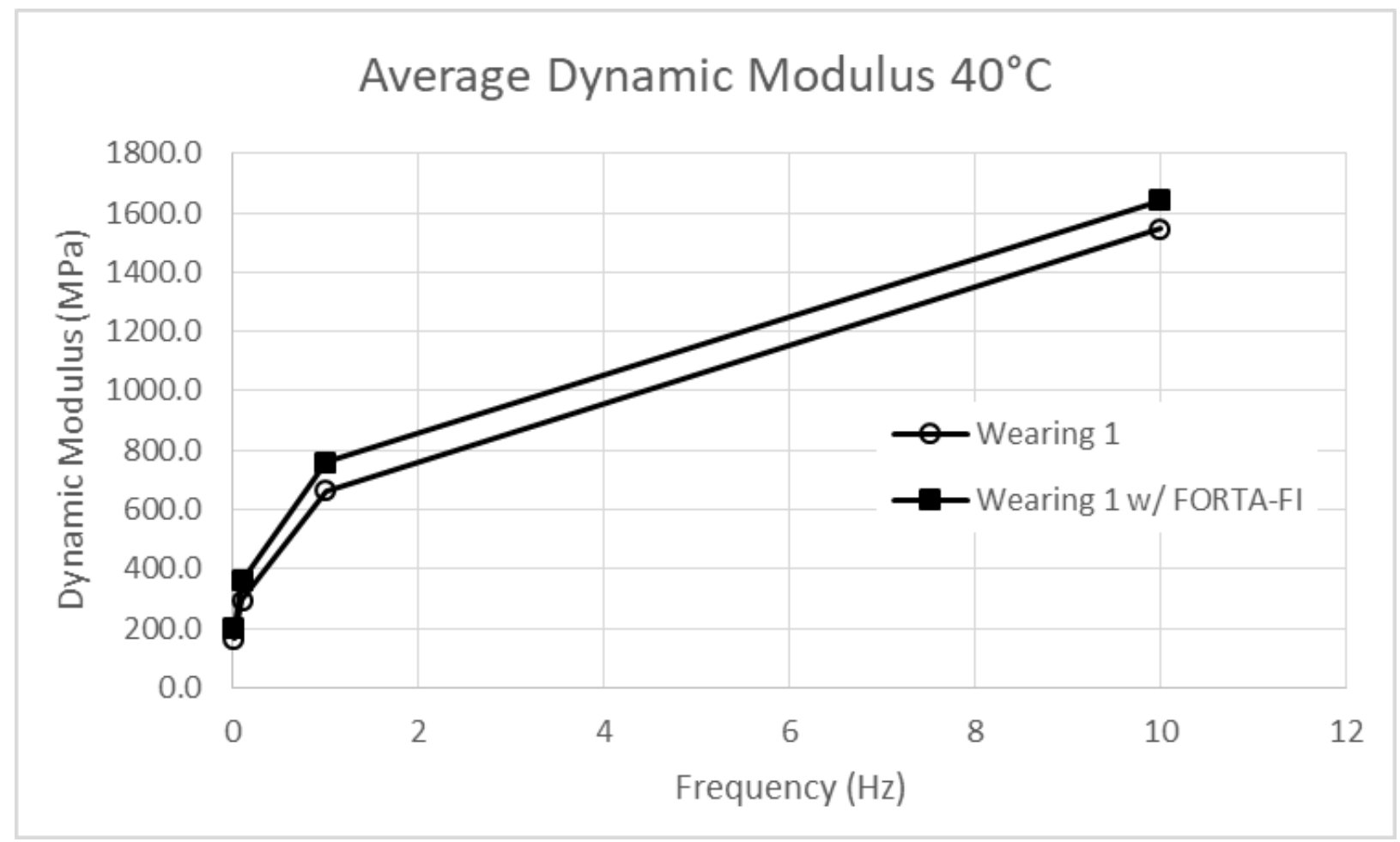

Figure 7: Average Dynamic Modulus at 40 degrees

\section{Dynamic Modulus and Phase Angle Mastersolver}

The results produced during dynamic modulus testing on the AMPT were further analyzed using Mastersolver version 2.2 published by Bonaquist (Bonaquist, Simple Performance Tester for Superpave Mix Design, 2011). The master curves produced by the Mastersolver used a reference temperature of $15^{\circ} \mathrm{C}$. Figure 8 shows the master curves generated by the Mastersolver for the two materials. The material parameters calculated by the Mastersolver and goodness of fit values for the master curves are shown in Table 13. Again, all Mastersolver outputs are given in Appendix E. 


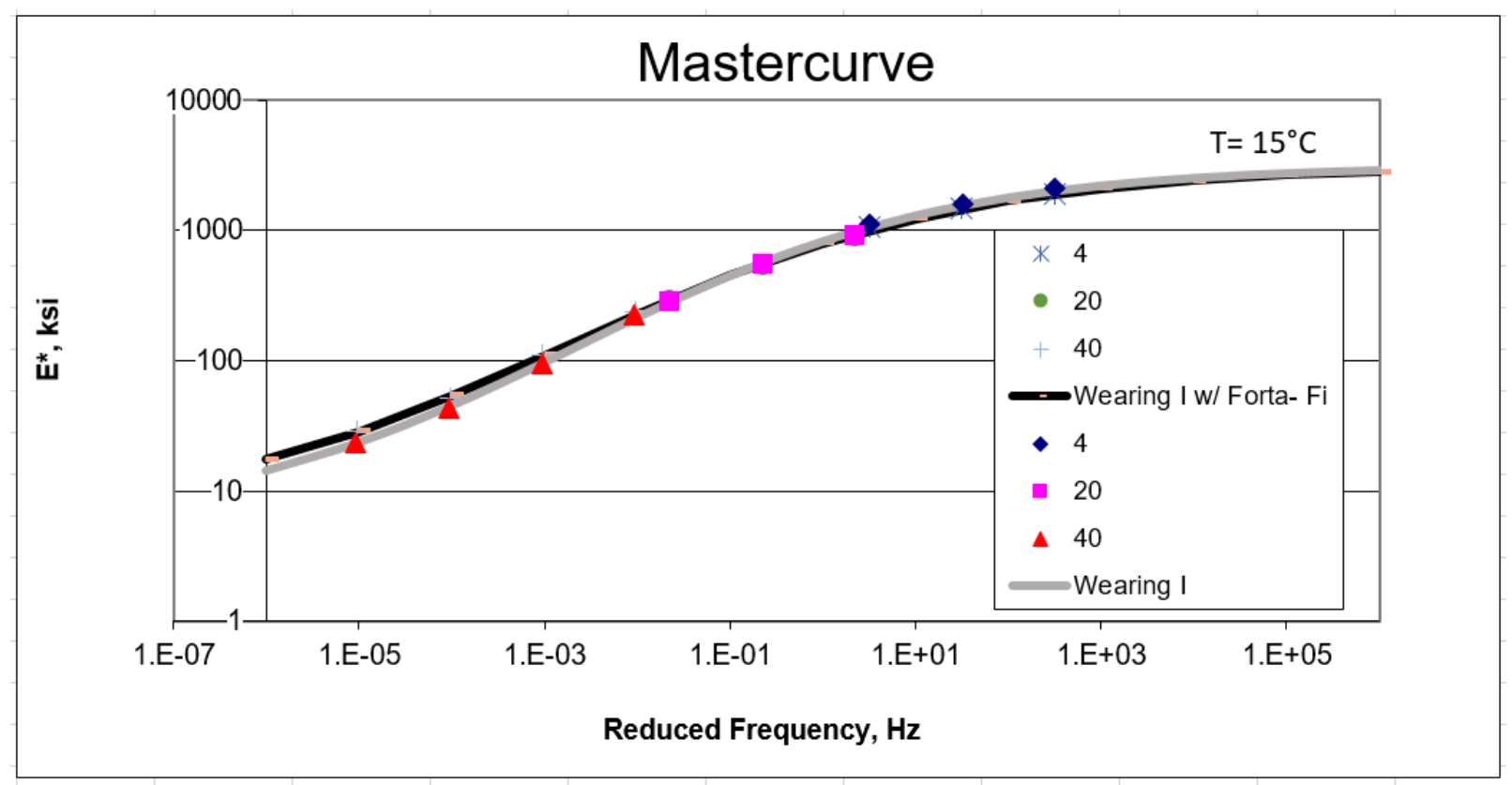

Figure 8: Combined Mastercurves

Table 13: Mastersolver Material Parameters

\begin{tabular}{|c|c|c|c|c|c|c|c|}
\hline \multicolumn{4}{|c|}{ Material Parameters } & \multicolumn{2}{c|}{ Goodness of Fit } \\
\hline Mixture Type & Max E* & Min E* & $\beta$ & $\gamma$ & $\Delta \mathrm{E}_{\mathrm{a}}$ & $\mathrm{R}^{2}$ & $\mathrm{~S}_{\mathrm{e}} / \mathrm{S}_{\mathrm{y}}$ \\
\hline Wearing I & 3148.3 & 5.3 & -1.32988 & -0.50195 & 209497 & 0.997 & 0.036 \\
\hline Wearing I w/ FORTA-FI & 3121.2 & 5.5 & -1.29457 & -0.46777 & 208879 & 0.998 & 0.031 \\
\hline
\end{tabular}

An analysis of the Mastersolver results, for the two mixtures, once again shows almost identical behavior. This is contrary to the results obtained at Arizona State University in which the fiber reinforced mixture outperformed the non- reinforced mixture at all temperatures.

The results of the Mastersolver can be used to calculate and compare the dynamic modulus of the two mixtures at any given temperature and loading frequency. This is a great tool to use for designing pavement structures using these mixes.

\section{Comparison to Literature}

Figure 9 shows the dynamic modulus at a frequency of $10 \mathrm{~Hz}$ from this research and the values reported by Kaloush et. al. (2010). The modulus values determined in this research are 
considerably lower than Kaloush et al. There is no direct explanation for these differences but factors would include differences in the testing protocol, differences in the mix types and aggregates, 3/8" and 3/4" NMAS for WV and Kaloush et al. respectively, and differences in binder grade, PG 64-22 and PG 70-10 for WV and Kaloush et al. respectively. With respect to the differences attributed to the fiber, the West Virginia mix contained one pound of fiber per ton of mix. Kaloush et al. did not report the fiber dosage rate.

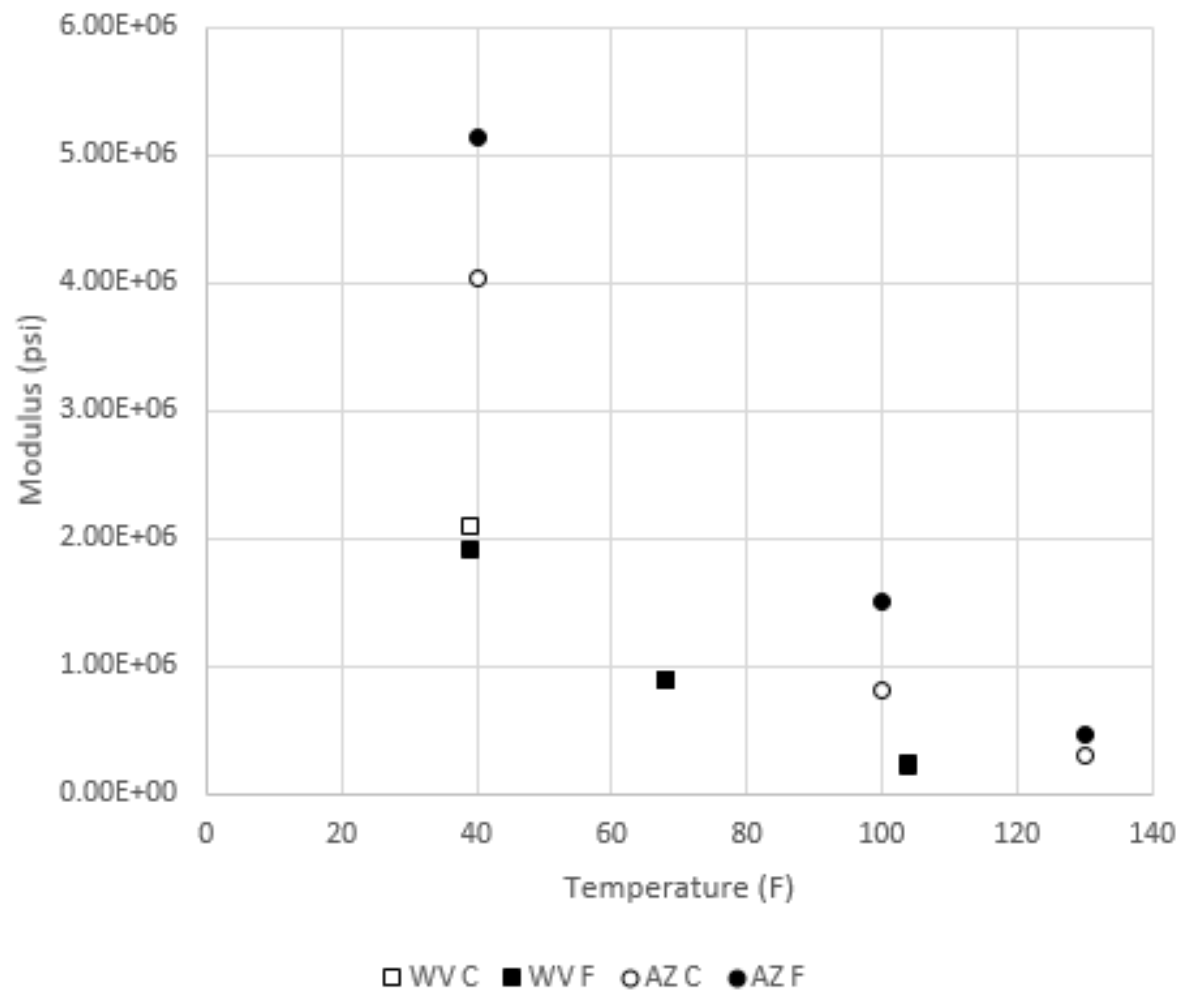

Figure 9: Comparison of Dynamic Modulus to Arizona State University Reported Values

\section{Flow Number}

Figure 10 and 11 show examples of the flow number test for a Wearing I and Wearing I with Forta- Fi specimen. The graphs have two lines indicating the flow number by the Data Smoothing Method and by the Francken Model Method. The data smoothing method defines the flow number as the point where the permanent strain rate reaches a minimum value. The Francken Model Method computes the flow number as the inflection point of the permanent strain graph. 


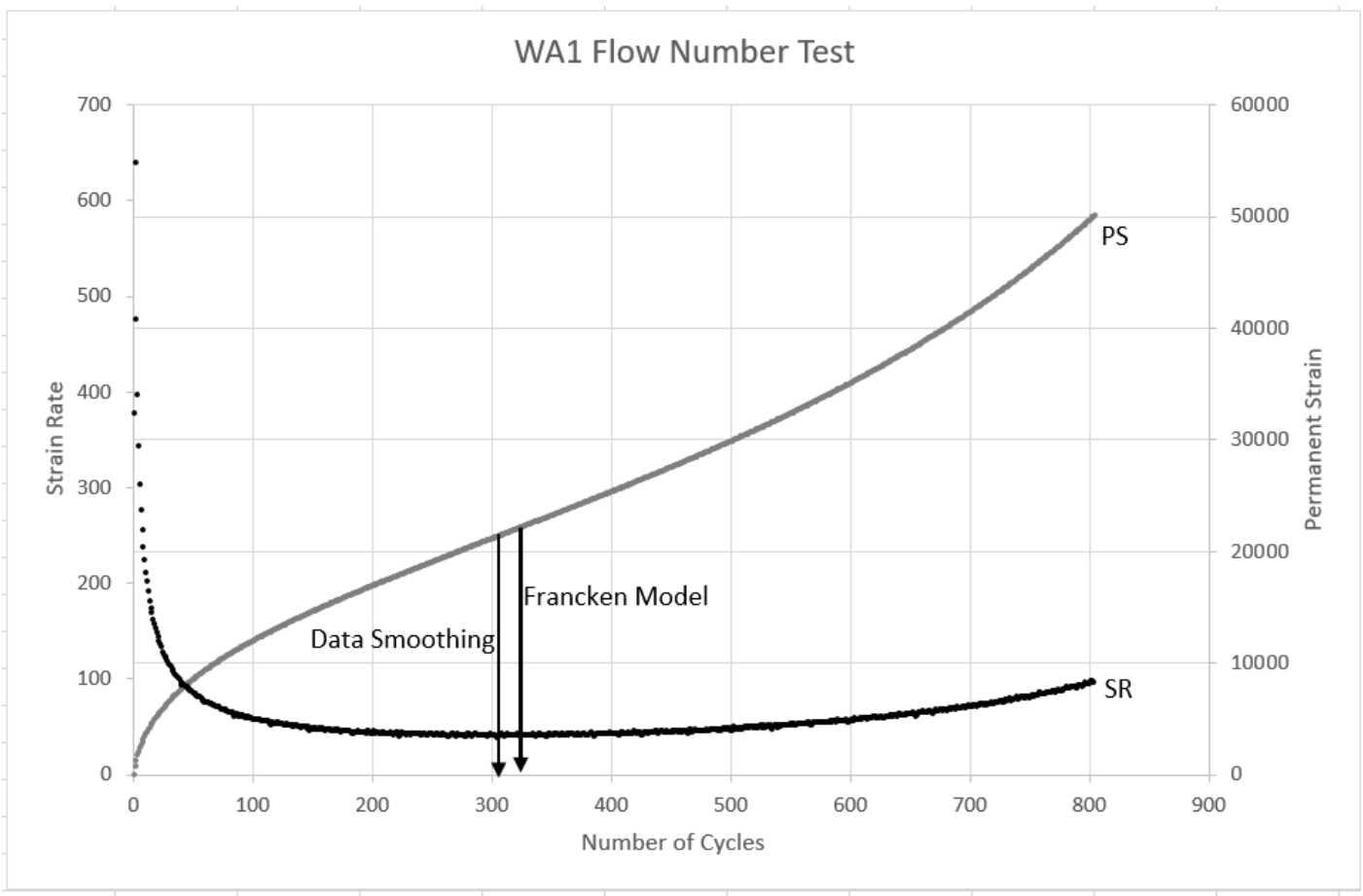

Figure 10: WA1 Flow Number Test

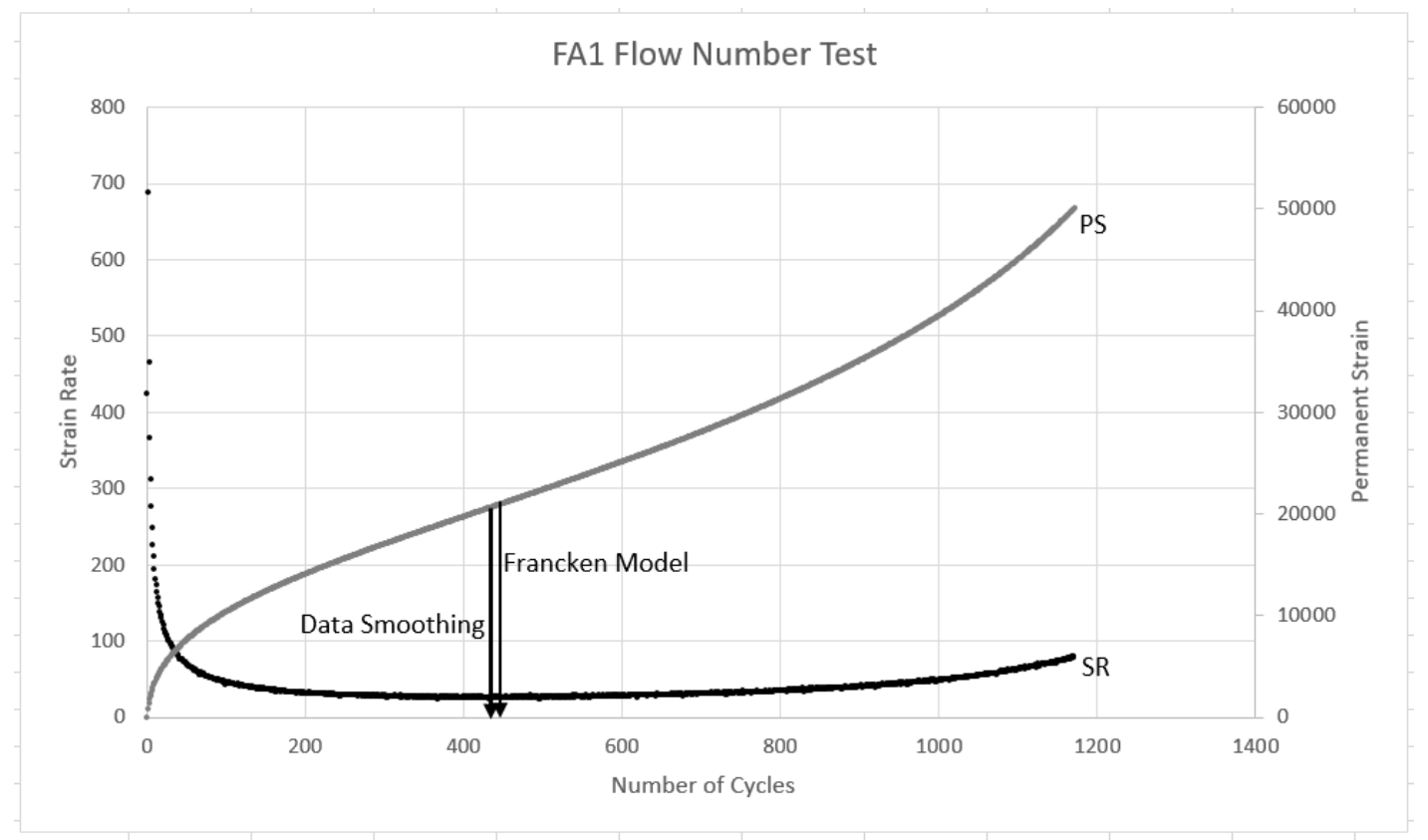

Figure 11: FAl Flow Number Test

The Francken Model method was stated to be more stable by researchers at Arizona State University. MATLAB was used to fit the data to the Francken Model using nonlinear regression. 
The flow number results are presented in Table 14. Both of the mixtures met the specification's acceptable range for replicates. The Wearing I with FORTA-FI® was found to have a higher flow number than the Wearing I mix using both analysis methods. The average flow numbers were 273 and 240 for the data smoothing method, and 288 and 266 for the Francken Model method.

Table 14: Flow Number Data Smoothing Method Results

\begin{tabular}{|c|c|c|c|c|c|c|c|c|}
\hline \multirow[b]{2}{*}{ Specimen } & \multicolumn{4}{|c|}{ Data Smoothing } & \multicolumn{4}{|c|}{ Francken Model } \\
\hline & $\begin{array}{l}\text { Flow } \\
\text { Number }\end{array}$ & Avg & SD & $\begin{array}{c}\text { Range } \\
\text { as \% Avg. }\end{array}$ & $\begin{array}{c}\text { Flow } \\
\text { Number }\end{array}$ & Avg & SD & $\begin{array}{c}\text { Range } \\
\text { as \% Avg }\end{array}$ \\
\hline WA1 & 305 & \multirow{4}{*}{240} & \multirow{4}{*}{48} & \multirow{4}{*}{$47.9 \%$} & 323 & \multirow{4}{*}{266} & \multirow{4}{*}{48} & \multirow{4}{*}{$43.94 \%$} \\
\hline WA2 & 234 & & & & 275 & & & \\
\hline WA3 & 232 & & & & 261 & & & \\
\hline WA4 & 190 & & & & 206 & & & \\
\hline FA1 & 432 & \multirow{4}{*}{273} & \multirow{4}{*}{106} & \multirow{4}{*}{$81.3 \%$} & 448 & \multirow{4}{*}{288} & \multirow{4}{*}{107} & \multirow{4}{*}{$76.17 \%$} \\
\hline FA2 & 210 & & & & 229 & & & \\
\hline FA3 & 223 & & & & 241 & & & \\
\hline FA4 & 227 & & & & 232 & & & \\
\hline
\end{tabular}

*The range as percent of average shall be $<118 \%$

The flow number results compare to the results found at Arizona State University in that the fiber reinforced asphalt had a higher flow number. However, the results of the research at Arizona State showed the fiber reinforced mixture having a performance 15 times that of the non- reinforced mixture.

\section{S-VECD Fatigue}

Table 15 shows the results for all of the fatigue tests. These tests were automatically terminated based on one of three criteria for failure: 1) 10 percent of the initial dynamic modulus was reached, 2) a sudden phase angle drop after an increase in phase angle, and 3) the number of cycles exceeded 100,000. All of the specimens tested reached one of these. One sample had an LVDT read error, but the error occurred after both the phase angle dropped, and $10 \%$ of the initial dynamic modulus. Two samples terminated before $10 \%$ of the initial dynamic modulus was reached due to a sudden phase angle drop. Fifteen samples terminated as a result of $10 \%$ of the initial dynamic modulus being reached. No sample tested exceeded 100,000 cycles. 
Table 15: S-VECD Fatigue Test Results

\begin{tabular}{|c|c|c|c|c|c|c|c|c|}
\hline $\begin{array}{l}\text { Mixture } \\
\text { Type }\end{array}$ & $\begin{array}{l}\text { Specimen } \\
\text { ID }\end{array}$ & Replicate & $\begin{array}{l}\text { VTM } \\
(\%)\end{array}$ & Strain & $\begin{array}{c}\text { Failure } \\
\text { Cycle }\end{array}$ & $\begin{array}{c}\text { Initial } \\
\text { Dynamic } \\
\text { Modulus }\end{array}$ & $\begin{array}{c}\text { Final } \\
\text { Dynamic } \\
\text { Modulus }\end{array}$ & Failure Criteria \\
\hline \multirow{9}{*}{ 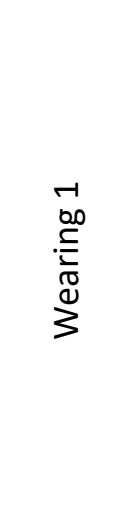 } & WA5 & 1 & $7.2 \%$ & 300 & 21620 & 8118.2 & 799.5 & $10 \%$ modulus \\
\hline & WA6 & 2 & $6.6 \%$ & 300 & 24830 & 8220.4 & 818.6 & $10 \%$ modulus \\
\hline & WA7 & 3 & $6.9 \%$ & 300 & 22680 & 8308.0 & 908.8 & Phase Angle Drop \\
\hline & WA8 & 1 & $7.2 \%$ & 400 & 3610 & 6799.3 & 668.2 & $10 \%$ modulus \\
\hline & WA9 & 2 & $6.8 \%$ & 400 & 5830 & 6879.9 & 677.2 & $10 \%$ modulus \\
\hline & WA10 & 3 & $6.9 \%$ & 400 & 3060 & 6828.1 & 1168.6 & Phase Angle Drop \\
\hline & WA11 & 1 & $6.7 \%$ & 350 & 8160 & 7553.5 & 721.9 & $10 \%$ modulus \\
\hline & WA12 & 2 & $6.8 \%$ & 350 & 10090 & 7489.6 & 720.2 & $10 \%$ modulus \\
\hline & WA13 & 3 & $6.9 \%$ & 350 & 4570 & 7523.5 & 738.7 & $10 \%$ modulus \\
\hline \multirow{9}{*}{ 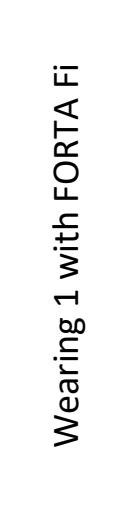 } & FA5 & 1 & $7.0 \%$ & 300 & 30400 & 7311.6 & 729.5 & $10 \%$ modulus \\
\hline & FA6 & 2 & $7.0 \%$ & 300 & 21450 & 7466.2 & 736.2 & Phase Angle Drop* \\
\hline & FA7 & 3 & $7.4 \%$ & 300 & 30510 & 7219.7 & 718.5 & $10 \%$ modulus \\
\hline & FA8 & 1 & $7.1 \%$ & 400 & 3710 & 6457.8 & 632.7 & $10 \%$ modulus \\
\hline & FA9 & 2 & $6.8 \%$ & 400 & 4710 & 6475.6 & 642.1 & $10 \%$ modulus \\
\hline & FA10 & 3 & $6.8 \%$ & 400 & 3480 & 6563.7 & 630.0 & $10 \%$ modulus \\
\hline & FA11 & 1 & $6.7 \%$ & 350 & 4140 & 7183.5 & 708.8 & $10 \%$ modulus \\
\hline & FA12 & 2 & $7.5 \%$ & 350 & 10200 & 6954.2 & 681.6 & $10 \%$ modulus \\
\hline & FA13 & 3 & $7.3 \%$ & 350 & 8420 & 6808.7 & 670.3 & $10 \%$ modulus \\
\hline
\end{tabular}

* LVDT Error after test complete 


\section{Alpha- Fatigue ${ }^{\mathrm{TM}}$ Analysis}

Table 16: Damage Model Coefficients

\begin{tabular}{|c|c|c|c|c|c|c|c|c|c|}
\hline $\begin{array}{c}\text { Damage } \\
\text { Model } \\
\text { Coefficients }\end{array}$ & \multicolumn{2}{|c|}{$\mathrm{a}$} & \multicolumn{2}{c|}{$\mathrm{b}$} & $\alpha$ & \multicolumn{3}{c|}{$\mathrm{r}$} & \multicolumn{2}{c|}{$\mathrm{s}$} \\
\cline { 2 - 10 } & Default & Peak & Default & Peak & Both & Default & Peak & Default & Peak \\
\hline $\begin{array}{c}\text { Wearing I } \\
\text { Wearing I } \\
\text { w/ FORTA- } \\
\text { FI }\end{array}$ & $-5.75 \mathrm{E}-04$ & $-3.26 \mathrm{E}-04$ & 0.628 & 0.683 & 3.831 & $1.41 \mathrm{E}+05$ & $5.54 \mathrm{E}+05$ & -0.593 & -0.702 \\
\hline
\end{tabular}

The exponential damage model coefficient values are listed in Table 16. The damage model coefficients vary between the default and peak analyses. For the a, $b$, and $r$ coefficients, the peak value is larger for both material types. For the $s$ coefficient the peak value is smaller for both material types. The $(\alpha)$ coefficient, however, is the same for both default and peak.

Compared to previous research conducted in the WVU Asphalt Technology Laboratory done by Dalton, the $(r)$ coefficients are more similar. Dalton found the coefficients to vary by an order of magnitude between the default and peak values. The K-values in units of (psi) calculated by Alpha-Fatigue ${ }^{\mathrm{TM}}$ for both the default and peak analysis are given in Table 17 as well as the Asphalt Institute, Shell K-values, Arizona State University Control K-Values, and Arizona State University Fiber Reinforced K-Values. The Asphalt Institute $\mathrm{K}_{1}$ values are field calibrated, and they are reported in units of pounds per square inch (Huang, 2004). The analyses ran are reported in Appendix F.

Table 17: K-Values

\begin{tabular}{|l|c|c|c|c|c|c|}
\hline \multirow{2}{*}{\multicolumn{1}{c|}{$\begin{array}{c}\text { K- Values } \\
\text { (psi) }\end{array}$}} & \multicolumn{2}{|c|}{ K1 } & \multicolumn{2}{c|}{ K2 } & \multicolumn{2}{c|}{ K3 } \\
\cline { 2 - 7 } & Default & Peak & Default & Peak & Default & Peak \\
\hline Wearing 1 & $1.47 \mathrm{E}+08$ & $9.96 \mathrm{E}+12$ & 3.654 & 5.171 & -2.865 & -4.410 \\
\hline Wearing 1 w/ FORTA- & $3.03 \mathrm{E}+07$ & $1.07 \mathrm{E}+13$ & 3.684 & 5.486 & -2.780 & -4.611 \\
\hline Asphalt Institute & \multicolumn{2}{|c|}{0.0796} & \multicolumn{2}{c|}{3.291} & -0.854 \\
\hline Shell & \multicolumn{2}{|c|}{0.0685} & \multicolumn{2}{c|}{5.671} & -2.363 \\
\hline ASU Control & \multicolumn{2}{|c|}{2.3496} & \multicolumn{2}{c|}{2.3601} & -1.3853 \\
\hline ASU Fiber Reinforced & \multicolumn{2}{|c|}{$6.48 \mathrm{E}-22$} & \multicolumn{2}{c|}{7.8357} & 1.0839 \\
\hline
\end{tabular}

The $\mathrm{K}_{1}$ - values vary several orders of magnitude. The values calculated by Alpha-Fatigue ${ }^{\mathrm{TM}}$ also vary from those values published by Shell and the Asphalt Institute. To compare to the literature the K- values reported by Kaloush et. al. (2010) were input into the traditional fatigue equation. The K- values for the ASU control mixture were used for the Wearing I mix, and the K-values 
for the Arizona fiber reinforced mixture were used for the Wearing I with FORTA-FI@. The predicted fatigue life values using the differing K- values are shown in Table 18 and Figure 12. The dynamic modulus values were calculated using the Mastersolver master curve equations at $15^{\circ} \mathrm{C}$ and $0.6 \mathrm{~Hz}$. 
Table 18: Predicted Fatigue Life using K-Values

\begin{tabular}{|c|c|c|c|c|c|c|c|c|c|c|}
\hline \multirow[b]{2}{*}{$\begin{array}{l}\text { Frequency } \\
(\mathrm{Hz})\end{array}$} & \multirow[b]{2}{*}{ Material } & \multirow[b]{2}{*}{$\begin{array}{l}\text { K-Value } \\
\text { Type }\end{array}$} & \multirow[b]{2}{*}{$\mathrm{K}_{1}$} & \multirow[b]{2}{*}{$K_{2}$} & \multirow[b]{2}{*}{$\mathrm{K}_{3}$} & \multirow[b]{2}{*}{$\begin{array}{l}\text { Dynamic } \\
\text { Modulus }\end{array}$} & \multicolumn{4}{|c|}{$\mathrm{N}_{\mathrm{f}}$ at Strain $(\mu \varepsilon)$} \\
\hline & & & & & & & 100 & 200 & 300 & 400 \\
\hline \multirow{10}{*}{0.60} & \multirow{5}{*}{ 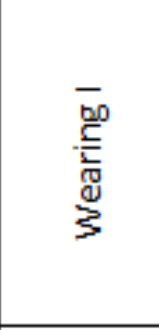 } & Default & $1.47 \mathrm{E}+08$ & 3.654 & -2.865 & 733000 & $9.57 E+05$ & $7.60 E+04$ & $1.73 E+04$ & $6.04 \mathrm{E}+03$ \\
\hline & & Peak & $9.96 \mathrm{E}+12$ & 5.171 & -4.410 & 733000 & $6.58 \mathrm{E}+07$ & $1.83 E+06$ & $2.24 E+05$ & $5.07 E+04$ \\
\hline & & $\begin{array}{l}\text { Asphalt } \\
\text { Institute }\end{array}$ & 0.0796 & 3.291 & -0.854 & 733000 & $1.14 \mathrm{E}+07$ & $1.16 \mathrm{E}+06$ & $3.06 \mathrm{E}+05$ & $1.19 E+05$ \\
\hline & & Shell & 0.0685 & 5.671 & -2.363 & 733000 & $4.58 E+07$ & $8.99 \mathrm{E}+05$ & $9.02 E+04$ & $1.76 \mathrm{E}+04$ \\
\hline & & ASU & 2.3496 & 2.3601 & -1.3853 & 733000 & $6.96 \mathrm{E}+05$ & $1.36 \mathrm{E}+05$ & $5.21 \mathrm{E}+04$ & $2.64 E+04$ \\
\hline & \multirow{5}{*}{ 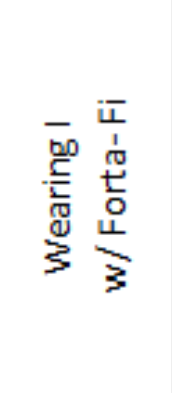 } & Default & $3.03 E+07$ & 3.684 & -2.78 & 711000 & $8.89 E+05$ & $6.92 E+04$ & $1.55 E+04$ & $5.38 \mathrm{E}+03$ \\
\hline & & Peak & $1.07 \mathrm{E}+13$ & 5.486 & -4.611 & 711000 & $9.73 E+07$ & $2.17 E+06$ & $2.35 \mathrm{E}+05$ & $4.84 E+04$ \\
\hline & & $\begin{array}{l}\text { Asphalt } \\
\text { Institute }\end{array}$ & 0.0796 & 3.291 & -0.854 & 711000 & $1.17 E+07$ & $1.19 E+06$ & $3.14 E+05$ & $1.22 \mathrm{E}+05$ \\
\hline & & Shell & 0.0685 & 5.671 & -2.363 & 711000 & $4.91 \mathrm{E}+07$ & $9.64 E+05$ & $9.67 E+04$ & $1.89 E+04$ \\
\hline & & ASU & $6.48 \mathrm{E}-22$ & 7.8357 & 1.0839 & 711000 & $1.16 E+07$ & $5.06 \mathrm{E}+04$ & $2.11 E+03$ & $2.22 \mathrm{E}+02$ \\
\hline
\end{tabular}




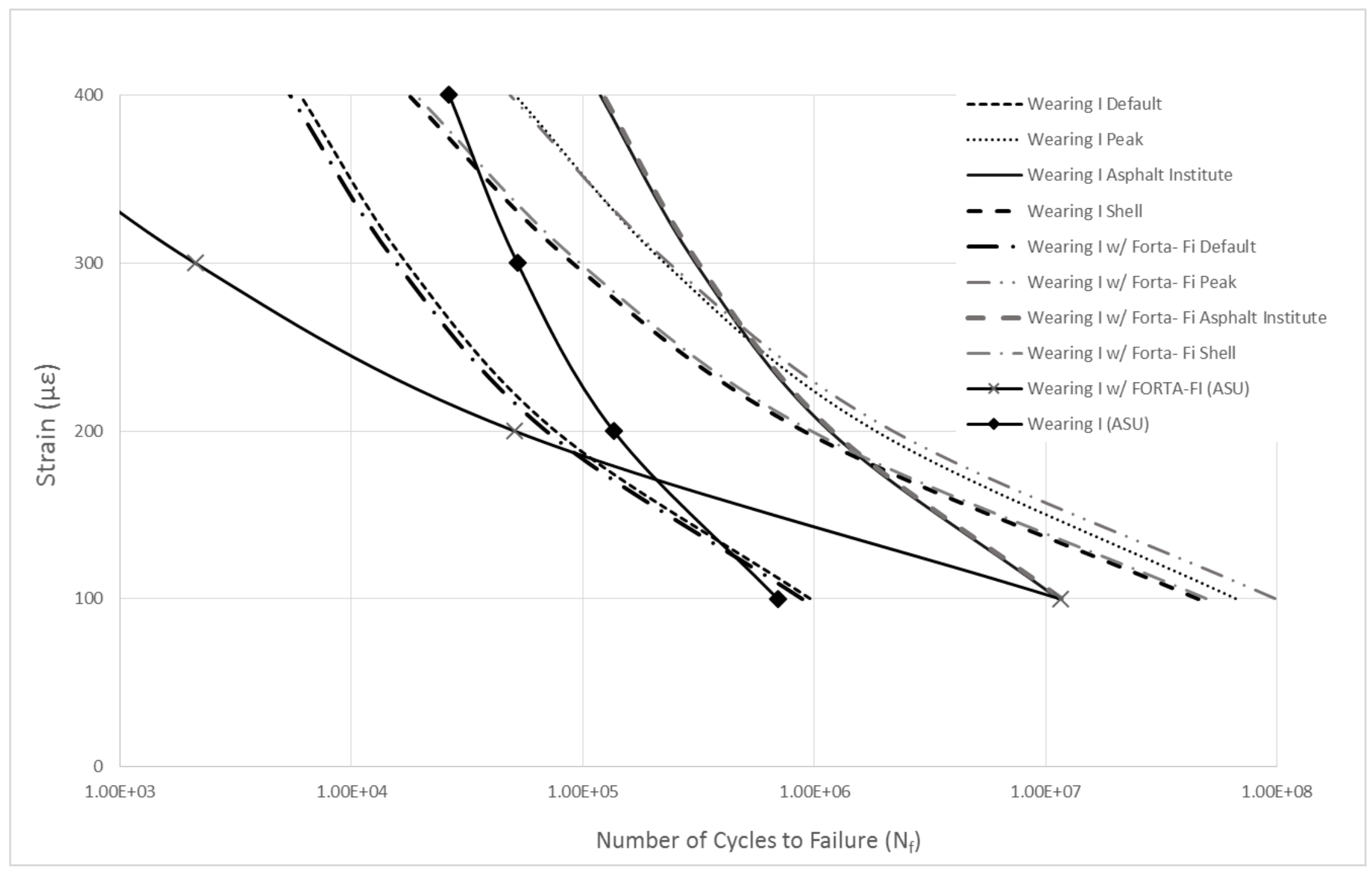

Figure 12: Fatigue Life using different $K$-Values 
The Alpha-Fatigue ${ }^{\mathrm{TM}}$ software provided endurance limit values for the two materials tested. The endurance limit is defined as the strain level at which the pavement fails at 50 million cycles. These limits are computed using transfer functions for temperatures of 5, 10, 15, 20, and 25 degrees Celsius. The endurance limit results are shown in Table 19 and Figure 13. The endurance limits of the Wearing I with Fort- Fi® are only slightly higher than those of the Wearing I mixture.

Table 19: Exponential Model Endurance Limits

\begin{tabular}{|c|c|c|c|c|c|c|c|c|c|c|}
\hline \multirow{2}{*}{$\begin{array}{c}\text { Endurance } \\
\text { Limits }\end{array}$} & \multicolumn{2}{|c|}{$5^{\circ} \mathrm{C}$} & \multicolumn{2}{c|}{$10^{\circ} \mathrm{C}$} & \multicolumn{2}{c|}{$15^{\circ} \mathrm{C}$} & \multicolumn{2}{c|}{$20^{\circ} \mathrm{C}$} & \multicolumn{2}{c|}{$25^{\circ} \mathrm{C}$} \\
\cline { 2 - 10 } & Default & Peak & Default & Peak & Default & Peak & Default & Peak & Default & Peak \\
\hline Wearing 1 & 19 & 51 & 21 & 57 & 25 & 67 & 29 & 82 & 39 & 112 \\
\hline $\begin{array}{c}\text { Wearing 1 } \\
\text { with } \\
\text { FORTA-FI }\end{array}$ & 21 & 57 & 23 & 64 & 26 & 75 & 31 & 90 & 40 & 121 \\
\hline
\end{tabular}

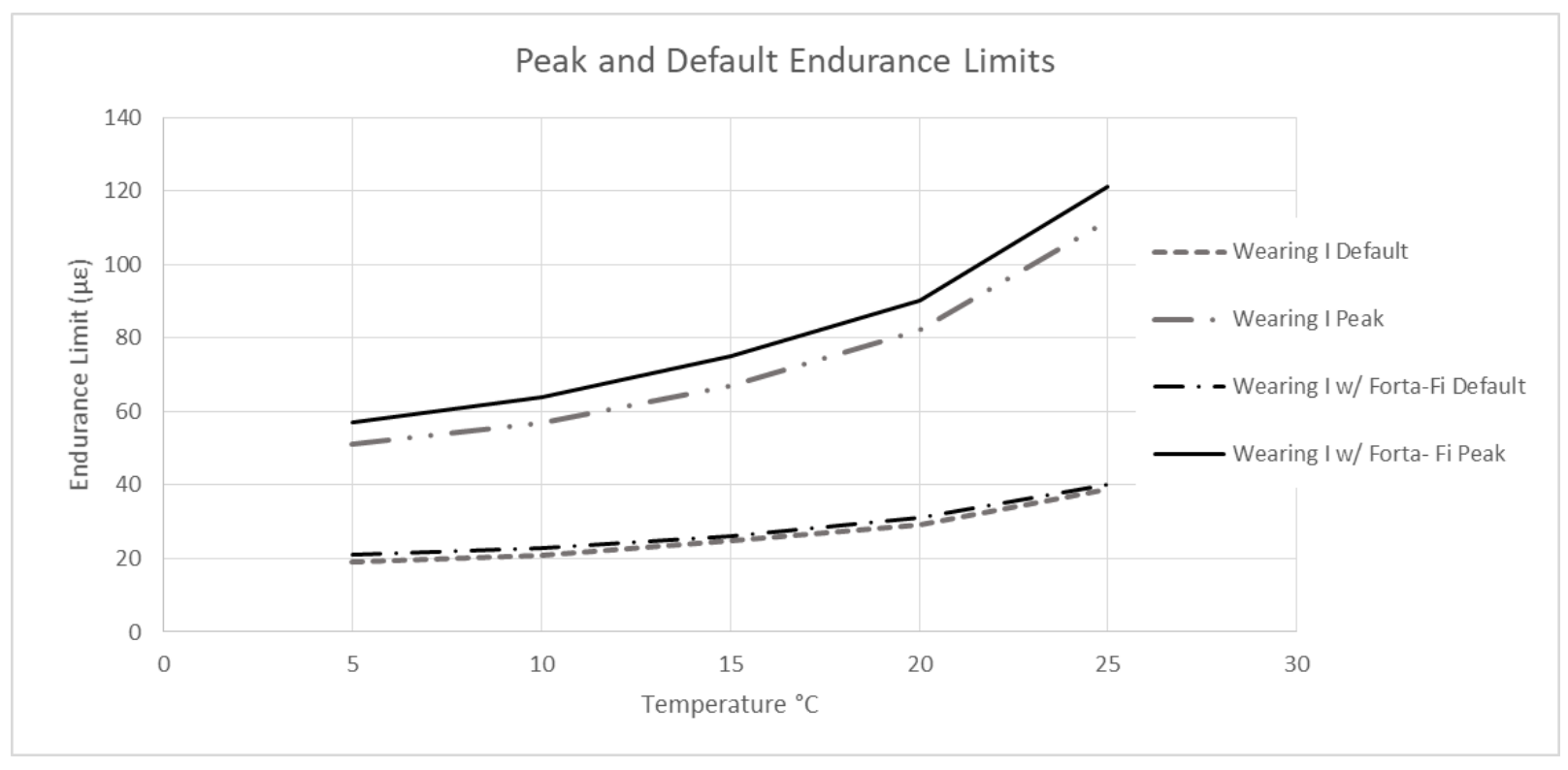

Figure 13: Peak and Default Endurance Limits

\section{Alpha-Fatigue ${ }^{\mathrm{TM}}$ Fatigue Life Prediction}

The Alpha-Fatigue ${ }^{\mathrm{TM}}$ program has the capability to compute the fatigue life of the pavement based on test data and user input variables (InstroTek, 2014). This analysis also uses both a peak and default analysis method in which the phase angle is either selected by the program or the user. The analysis presents the number of cycles to failure of the material 
analyzed. For purposes of this analysis, the temperature was kept constant at $15^{\circ} \mathrm{C}$. The load frequency of $0.60 \mathrm{~Hz}$ is representative of an 18,000 pound single axle with a 110 psi tire pressure traveling at $25 \mathrm{mph}$. The strain levels analyzed were 100, 200, 300, and 400 microstrains. The software calculated the fatigue life and the endurance limits for both materials. The endurance limits were the same as shown in Table 19. The results of the Alpha- Fatigue prediction are compared to computations using the resultant K- values and fatigue equations in Table 20.

Table 20: Comparison of Fatigue Life Predicted by Alpha Fatigue and Fatigue Equations

\begin{tabular}{|c|c|c|c|}
\hline $\begin{array}{c}\text { Material } \\
\text { Type }\end{array}$ & Strain $(\mu \varepsilon)$ & $\begin{array}{c}\mathrm{N}_{\mathrm{f}} \\
\text { Alpha- Fatigue }\end{array}$ & $\begin{array}{c}\mathrm{N}_{\mathrm{f}} \\
\text { Fatigue Equation }\end{array}$ \\
\hline \multirow{3}{*}{$\begin{array}{c}\text { Wearing I } \\
\text { Default }\end{array}$} & 100 & $1.76 \mathrm{E}+07$ & $9.57 \mathrm{E}+05$ \\
\cline { 2 - 4 } & 200 & $1.16 \mathrm{E}+06$ & $7.60 \mathrm{E}+04$ \\
\cline { 2 - 4 } & 300 & $2.48 \mathrm{E}+05$ & $1.73 \mathrm{E}+04$ \\
\hline \multirow{3}{*}{$\begin{array}{c}\text { Wearing I } \\
\text { Peak }\end{array}$} & 100 & $8.53 \mathrm{E}+04$ & $6.04 \mathrm{E}+03$ \\
\cline { 2 - 4 } & 200 & $3.49 \mathrm{E}+09$ & $6.58 \mathrm{E}+07$ \\
\cline { 2 - 4 } & 300 & $9.43 \mathrm{E}+07$ & $1.83 \mathrm{E}+06$ \\
\hline Wearing I +06 & $2.24 \mathrm{E}+05$ \\
\cline { 2 - 4 } W/ & 100 & $2.22 \mathrm{E}+06$ & $5.07 \mathrm{E}+04$ \\
\cline { 2 - 4 } Forta- Fi & $1.88 \mathrm{E}+07$ & $8.89 \mathrm{E}+05$ \\
\cline { 2 - 4 } Default & 200 & $1.12 \mathrm{E}+06$ & $6.92 \mathrm{E}+04$ \\
\cline { 2 - 4 } Wearing I & 300 & $2.31 \mathrm{E}+05$ & $1.55 \mathrm{E}+04$ \\
\cline { 2 - 4 } w/ & 100 & $7.83 \mathrm{E}+04$ & $5.38 \mathrm{E}+03$ \\
\cline { 2 - 4 } Forta- Fi & 200 & $1.19 \mathrm{E}+09$ & $9.73 \mathrm{E}+07$ \\
\cline { 2 - 4 } Peak & 300 & $1.34 \mathrm{E}+08$ & $2.17 \mathrm{E}+06$ \\
\cline { 2 - 4 } & 400 & $2.73 \mathrm{E}+06$ & $2.35 \mathrm{E}+05$ \\
\hline
\end{tabular}

The results of the Alpha- Fatigue prediction and the fatigue equation prediction are not the same. The difference is the result of different computations for dynamic modulus. The Alpha- Fatigue equation formulates its own Mastercurve and derives the value based on the temperature used for calculation. The equation uses dynamic modulus values derived from Bonaquist's Mastersolver.

The peak performance results compare to those of the researchers at Arizona State University in that the fiber reinforced mixture performed better at lower strain levels, while the non- reinforced mixture performed better at higher strain levels. It should be noted that the test 
specification note of increased accuracy of the peak phase angle selection method was suggested by researchers at Arizona State University.

\section{Anova Statistical Analysis}

An Anova analysis was ran on the raw data collected during fatigue testing. The Anova analysis results are in Appendix C. The F- statistic of 1.14 was less than the F- critical statistic of 4.75 , so at the $95 \%$ confidence level it can be concluded that there is no significant difference in the fatigue test performance of the two materials.

\section{Pavement Surface Rating}

Two $528 \mathrm{ft}$. long sections of each mix paved on Dorsey Avenue were surveyed in April 2018 to evaluate the pavement surface rating (PSR). Figures 14 and 15 show the Wearing I and Wearing I with FORTA-FI respectively. The two lanes of each section were surveyed separately with respect to the direction traveled while surveying. They are designated northwest (NW) and southeast (SE). The survey was conducted using the 2012 WVDOH PSR criteria (West Virginia Department of Transportation, 2012). The results of the PSR survey are shown in Table 21. The pavement condition is virtually the same for the control and mix with fiber.

Table 21: Pavement Surface Ratings

\begin{tabular}{|r|l|c|c|}
\hline \multicolumn{2}{|c|}{ PSR } & NW & SE \\
\hline FORTA-FI & $0-528 \mathrm{ft}$ & 83.5 & 81.9 \\
\hline FORTA-FI & $528-1056 \mathrm{ft}$ & 83.2 & 82.2 \\
\hline \multicolumn{2}{|r|}{ Section Average } & 83.4 & 82.1 \\
\hline \multicolumn{2}{|c|}{ Average } & \multicolumn{2}{c|}{82.7} \\
\hline Wearing I & $0-528 \mathrm{ft}$ & 82.8 & 81.7 \\
\hline Wearing I & $528-1056 \mathrm{ft}$ & 83.3 & 80.3 \\
\hline \multicolumn{2}{|c|}{ Section Average } & 83.1 & 81.0 \\
\hline \multicolumn{2}{|c|}{ Average } & \multicolumn{2}{|c|}{82.0} \\
\hline
\end{tabular}

The average PSR value of the Wearing I section was 82.0 and the average PSR value of the Wearing I with FORTA-FI@ section was 82.7. The PSR of both sections are given a satisfactory rating (Zaniewski et. al., 2016). These values are the condition of the pavement sections 18 months after paving. There is very little difference in the PSR of the two sections. 


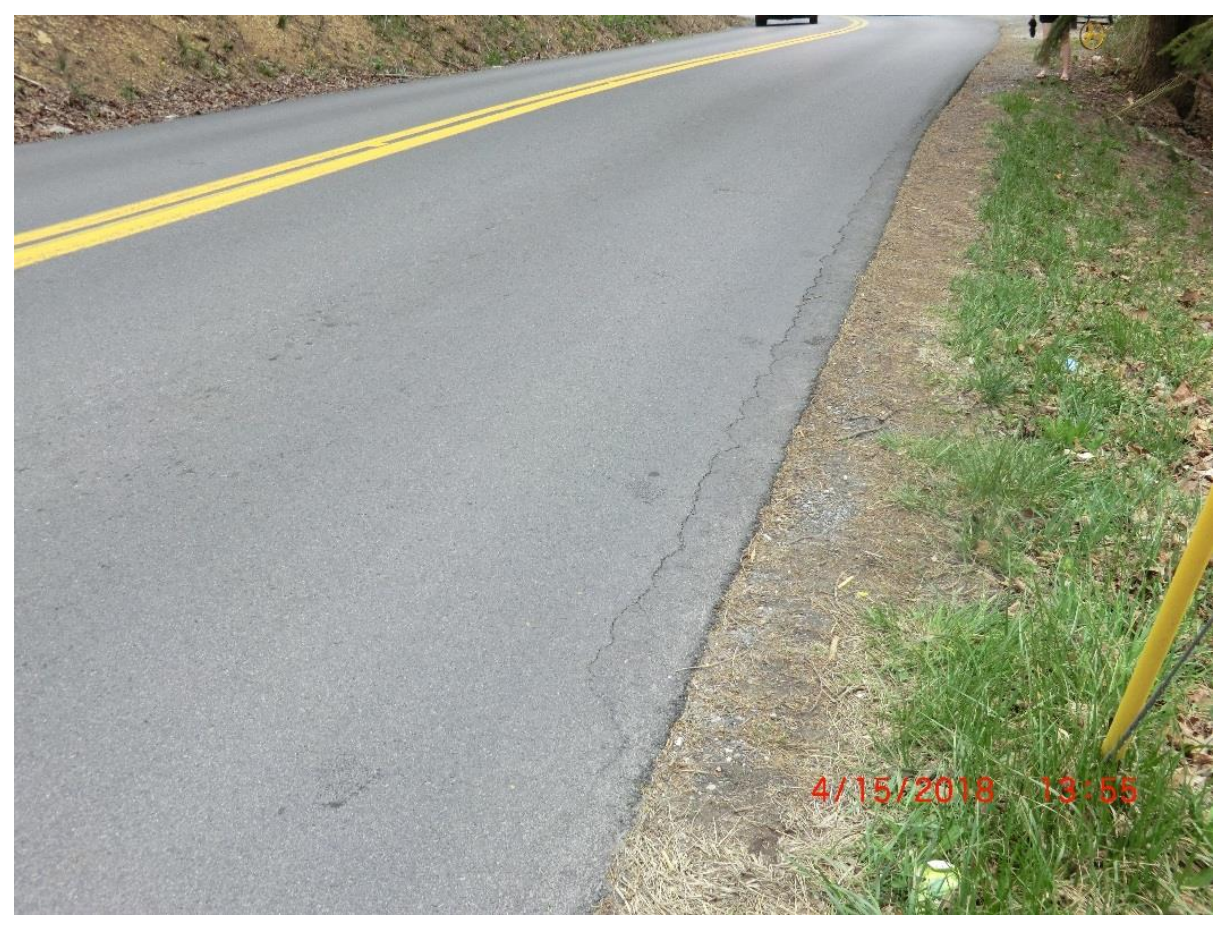

Figure 14: Edge Cracking in the Wearing I Section

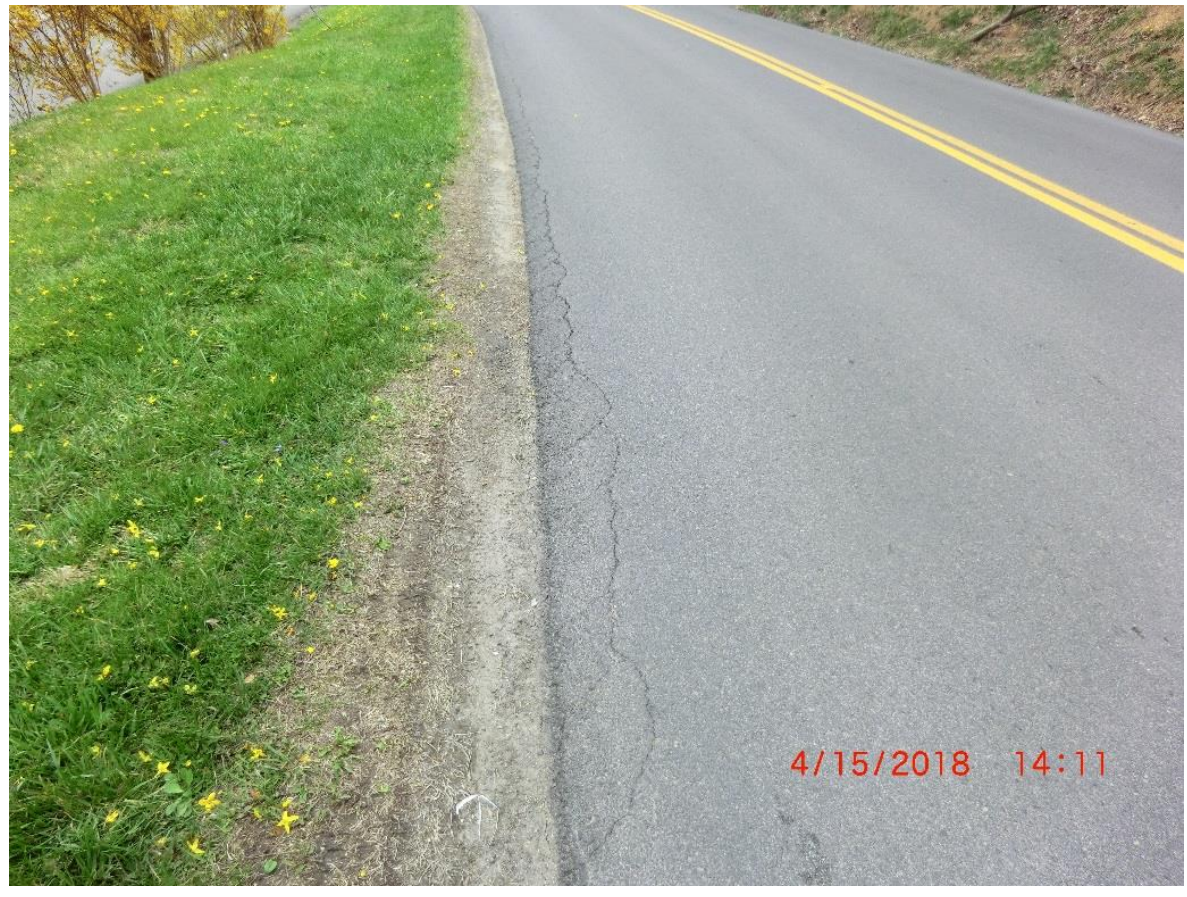

Figure 15: Edge Cracking in the Wearing I with FORTA-FI Section 


\section{Chapter 5: Conclusions and Recommendations}

\section{Conclusions}

\section{Sample Verifications}

All of the samples used for testing were within the guidelines of the test specifications. The air void content raised no flags for concern.

\section{APA Rutting Susceptibility Testing}

The results of the APA testing showed the average rut depth of the Wearing I mixture was $4.78 \mathrm{~mm}$ and the average rut depth of the Wearing I with FORTA-FI® mixture was 4.93 $\mathrm{mm}$. Even though the Wearing I mixture outperformed the Wearing I with FORTA- FI ${ }^{\circledR}$, the results of the APA testing showed that there was inconclusive evidence to reject the null hypothesis of equal means. Therefore, with $95 \%$ confidence it can be stated that there is no significant difference in the rutting susceptibility of the two mixtures tested.

\section{Dynamic Modulus Testing}

The dynamic modulus testing produced results that fell within expected outcomes. As the temperature increased, the average dynamic modulus decreased. As the load frequency decreased the average dynamic modulus decreased. The average phase angle increased as the load frequency was decreased, and it increased as temperature increased. These results compared to past laboratory testing in the WVU Asphalt Technology Laboratory (Dalton, 2016). At the $4^{\circ} \mathrm{C}$ test temperature, the Wearing I mixture outperformed the Wearing I with FORTA-FI@ mixture at all frequencies. At the $20^{\circ} \mathrm{C}$ test temperature, results show almost equal performance of the two mixtures at all frequencies. At the $40^{\circ} \mathrm{C}$ test temperature, results show that the Wearing I with FORTA-FI@ mixture outperforms the Wearing I mixture at all frequencies. The results from Bonaquist's Mastersolver analysis showed almost equal performance of the mixtures at the $15^{\circ} \mathrm{C}$ reference temperature.

\section{Flow Number}

Both of the mixtures tested met the requirements for acceptable range for replicates. Using both analysis methods, the Wearing I with FORTA- FI® mixture had a higher flow number. The results of the Francken Model Method were higher than those produced by the data 
smoothing method. Based on the guidelines of the test specification, both mixtures were determined to be rut resistant.

\section{S-VECD Fatigue}

All of the samples tested terminated according to set criteria, therefore, the results of the tests are all valid. The InstroTek Alpha Fatigue software was used to analyze the raw data using two methods. The first method was to use the default phase angle value as selected by the software, and the second method was to use a peak phase angle value selected by the user. The user manual lists the peak method as the more accurate analysis. The analysis produced damage model coefficients, k-values, and endurance limits for the two mixtures. These were input into the fatigue equations to compare the fatigue life of the two mixtures.

A second analysis was done using the Alpha Fatigue Software. This method used built- in features of the software to predict the fatigue life and the endurance limits of the two mixtures using default and peak phase angle values. User defined variables and constants were used. The temperature was held constant at $15^{\circ} \mathrm{C}$. The variable was the strain level.

An ANOVA statistical analysis conducted on the raw performance data showed that at the $95 \%$ confidence level there is no significant difference in the fatigue life of the two mixtures.

\section{Pavement Surface Rating}

The PSR of the Wearing I and Wearing I with FORTA-FI® sections showed very little difference 18 months after paving. Both sections are performing satisfactorily.

\section{Recommendations}

More testing needs to be done on these two materials. Specifically, the materials tested need to be laboratory produced, so that the mixture process can be tightly controlled to reduce variation. There was a marked difference in the results of this research and the results of research conducted on similar material at Arizona State University. The fiber reinforced material did not make nearly the difference in performance that the researchers at Arizona State observed. It is possible that mix temperature may have affected the properties of the FORTA-FI® fibers. There is no way to determine this without further testing. It would be highly beneficial to repeat this research with laboratory produced mixtures. This was not possible within the scope of this research. 


\section{References}

Abtahi, S. M., Sheikhzadeh, M., \& Hejazi, S. M. (2009). Fiber- reinforced asphalt- concrete- A review. Construction and Building Materials, 24(6), 871-877.

American Society of Civil Engineers. (2017). 2017 Infrastructure Report Card.

Bonaquist , R., \& Christensen, D. W. (2005). Practical Procedure for Developing Dynamic Modulus Master Curves for Pavment Structural Design. Transportation Research Board, $1929,208-217$.

Bonaquist, R. (2011, March 31). Simple Performance Tester for Superpave Mix Design. Retrieved from Transportation Research Board: http://apps.trb.org/cmsfeed/TRBNetProjectDisplay.asp?ProjectID=963

Dalton, L. (2016). Evaluating the Protocol of the Spectrum of Hot Mix Asphalt Mixes Produced in West Virginia. West Virginia University, Department of Civil Engineering. Ann Arbor: Proquest.

FORTA. (2017). Fact Data FORTA-FI. Grove City: FORTA.

Huang, Y. H. (2004). Pavement Analysis and Design (Second ed.). Upper Saddle River: Pearson Prentice Hall.

InstroTek. (2014). Asphalt Pavment Hierachical Analysis Toolbox- Fatigue Program. Raleigh: InstroTek Inc.

Kaloush, K., Biligiri, K. P., Zeiada, W. A., Rodenzo, M. C., \& Reed, J. X. (2010). Evaluation of fiber- reinforced asphalt mixtures using advanced material characterization tests. ASTM International- Journal of Testing and Evaluation, 38(4).

Sabouri, M., \& Kim, Y. R. (2014). Development of a Failure Criterion for Asphalt Mixtures Under Different Modes of Fatigue Loading. Transportation Research Record( 2447), 117-125.

West Virginia Department of Transportation Division of Highways Special Provision. (2012). Section 490 Nine Year Pavement Performance Criteria. Charleston, WV. 
Zaniewski, J. P., \& Patino, G. (2005). Evaluation of Superpave Mixtures in West Virginia Using the Asphalt Pavement Analyzer. West Virginia University, Department of Civil and Environmental Engineering, Morgantown, WV.

Zaniewski, J. P., Taverna, F., \& Pentz , J. (2016). Asphalt and Concrete Pavement Condition Analysis for the WVDOH. Morgantown, WV.

Zhang, J., Sabouri, M., Guddati, M. N., \& Kim, Y. R. (2013). Development of a failure criterion for asphalt mixtures under fatigue loading. Road Materials and Pavement Design, 14(S2), 1-15. 


\section{List of Test Methods Used}

AASHTO PP 60: Preparation of Cylindrical Performance Test Specimens Using the Superpave Gyratory Compactor. Washington, DC: American Association of State Highway and Transportation Officials, 2015.

AASHTO TP 79: Standard Method of Test for Determining the Dynamic Modulus and Flow Number for Asphalt Mixture Performance Tester (AMPT) Washington, DC: American Association of State Highway and Transportation Officials, 2013.

AASHTO TP 107: Determining the Damage Characteristics Curve of Asphalt Mixtures from Direct Tension Cyclic Fatigue Tests. Washington, DC: American Association of State Highway and Transportation Officials, 2015.

AASHTO T 209: Theoretical Maximum Specific Gravity (Gmm) and Density of Hot Mix Asphalt (HMA). Washington, DC: American Association of State Highway and Transportation Officials, 2015.

AASHTO T 312: Preparing and Determining the Density of Hot Mix Asphalt (HMA) by Means of the Superpave Gyratory Compactor. Washington, DC: American Association of State Highway Transportation Officials, 2015.

AASHTO T 331: Bulk Specific Gravity and Density of Compacted Hot Mix Asphalt (HMA) Using Automatic Vacuum Sealing Method. Washington, DC: American Association of State Highway and Transportation Officials, 2015.

AASHTO T 340: Determining Rutting Susceptibility of Hot Mix Asphalt (HMA) Using the Asphalt Pavement Analyzer (APA). Washington, DC: American Association of State Highway and Transportation Officials, 2015. 


\section{APPENDIX A: Job Mix Formula}

T400

03-00

WEST VIRGINIA DIVISION OF HIGHWAYS

JOB MIX FORMULA FOR HOT-MIX ASPHALT

\begin{tabular}{|lc|lc|}
\hline Report Number: & 1360465 & Date Accepted: & March 9, 2004 \\
\hline HMA Type: & Wearing-1 & HMA Code: & 13966 \\
\hline Producer: & Greer Asphalt & Plant Location: & Greer, WV \\
\hline Designed By: & Rich Nuzum & Design Lab: & Clarksburg Asphalt \\
\hline Plant Type: & Batch & Plant Make: & McCarter \\
\hline Plant Code: & G012A & Traffic Type: & Heavy \\
\hline
\end{tabular}

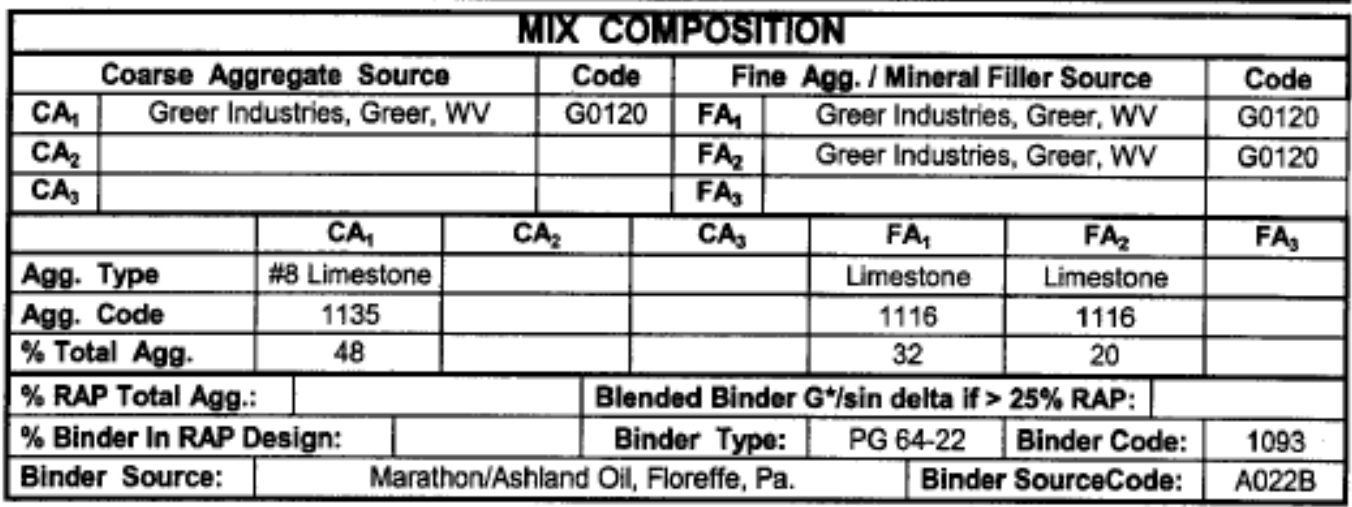

\begin{tabular}{|c|c|c|c|c|c|c|c|c|c|c|}
\hline \multicolumn{8}{|c|}{ Sieve Fraction } & \multirow{3}{*}{\begin{tabular}{|c|}
$\begin{array}{l}\text { Voids filled with } \\
\text { Asphalt"VFA"(\%) }\end{array}$ \\
75 \\
\end{tabular}} & \multirow{3}{*}{\multicolumn{2}{|c|}{\begin{tabular}{|c|}
$\begin{array}{c}\text { Fines to } \\
\text { Asphalt Ratio }\end{array}$ \\
0.8 \\
\end{tabular}}} \\
\hline \multirow{2}{*}{$\begin{array}{c}\text { Sieve } \\
\text { Size } \\
\end{array}$} & \multirow[b]{2}{*}{ Target } & \multicolumn{2}{|c|}{ Allowable } & \multirow{2}{*}{$\begin{array}{l}\text { Sieve } \\
\text { Size }\end{array}$} & \multirow[b]{2}{*}{ Target } & \multicolumn{2}{|c|}{ Allowable } & & & \\
\hline & & Min. & Max. & & & Min. & Max. & & & \\
\hline 2" $(50 \mathrm{~mm})$ & & & & $\# 4(4.75 \mathrm{~mm})$ & 60 & & 80 & \multirow{2}{*}{\multicolumn{3}{|c|}{$\begin{array}{l}\text { Temperature Range } \\
\text { Completed Mixture }\left({ }^{\circ} \mathrm{F}\right)\end{array}$}} \\
\hline $1.5^{\mathrm{\prime \prime}}(37.5 \mathrm{~mm})$ & & & & $\# 8(2.36 \mathrm{~mm})$ & 39 & 33 & 45 & & & \\
\hline $1^{\prime \prime}(25 \mathrm{~mm})$ & & & & \#16 $(1.18 \mathrm{~mm})$ & 23 & & & \multirow{2}{*}{$\begin{array}{c}\text { Desirable } \\
\text { Mean Temp. }\end{array}$} & \multicolumn{2}{|c|}{ Temp. Range } \\
\hline $3 / 4^{\prime \prime}(19 \mathrm{~mm})$ & & & & \#30 (600 um) & 12 & & & & Min. & Max. \\
\hline $1 / 2^{\prime \prime}(12.5 \mathrm{~mm})$ & 100 & 100 & 100 & $\# 50(300 \mu \mathrm{m})$ & 7 & & & & & \\
\hline $3 / 8^{n}(9.5 \mathrm{~mm})$ & 95 & 85 & 100 & $\# 200(75 \mu \mathrm{m})$ & 4.4 & 2.0 & 9.0 & 295 & 270 & 320 \\
\hline
\end{tabular}

\section{JOB MIX FORMULA VALUES}

\begin{tabular}{|c|c|c|c|c|}
\hline \multicolumn{5}{|c|}{ JOB MIX FORMULA VALUES } \\
\hline \multicolumn{3}{|c|}{ Job Mix Formula Targets } & \multicolumn{2}{|c|}{ Job Mix Formula Tolerances } \\
\hline Speciflc gravity stone & Design Property & Accepted Target & Minimum & Maximum \\
\hline bulk (Gsb): $\quad 2.662$ & Asphalt (\%) & 5.7 & 5.3 & 6.1 \\
\hline \multirow{2}{*}{$\begin{array}{c}\text { Maximum } \\
\text { Density }\left(\mathrm{kg} / \mathrm{m}^{3}\right)\end{array}$} & Air Voids (\%) & 4.0 & 2.5 & 5.5 \\
\hline & VMA (\%) & 15.7 & 14.7 & 16.7 \\
\hline \multirow[b]{2}{*}{2476} & Stability (N) & 10400 & 8000 & NA \\
\hline & Flow $(0.25 \mathrm{~mm})$ & 11 & 8 & 14 \\
\hline
\end{tabular}

Remarks: 


\section{APPENDIX B: Specimen Verifications}

APA Specimens

\begin{tabular}{|c|c|c|c|c|c|c|c|c|c|}
\hline & APA 1 & APA 2 & APA 3 & APA 4 & APA 5 & APA 6 & APA 7 & APA 8 & APA 9 \\
\hline Mass Sample & 3020.2 & 3020.3 & 3018.4 & 3021.6 & 3020.5 & 3020.2 & 3019.1 & 3020.7 & 3020.9 \\
\hline Mass Bag & 24.6 & 24.6 & 24.5 & 24.5 & 24.5 & 24.3 & 24.6 & 24.7 & 24.8 \\
\hline Mass Sample in Bag & 3044.8 & 3044.9 & 3042.9 & 3046.1 & 3045 & 3044.5 & 3043.7 & 3045.4 & 3045.7 \\
\hline Mass Submerged & 1707.8 & 1709.8 & 1706.1 & 1711.5 & 1708.4 & 1709.1 & 1708.5 & 1709.7 & 1710.1 \\
\hline Mass After Opening & 3020.2 & 3020.3 & 3018.7 & 3021.7 & 3020.4 & 3020.2 & 3019.0 & 3020.8 & 3020.9 \\
\hline $\mathrm{Gmm}$ & 2.484 & 2.484 & 2.484 & 2.484 & 2.484 & 2.484 & 2.484 & 2.484 & 2.484 \\
\hline $\mathrm{Gmb}$ & 2.309 & 2.313 & 2.307 & 2.314 & 2.310 & 2.311 & 2.312 & 2.312 & 2.313 \\
\hline VTM & $7.0 \%$ & $6.9 \%$ & $7.1 \%$ & $6.8 \%$ & $7.0 \%$ & $6.9 \%$ & $6.9 \%$ & $6.9 \%$ & $6.9 \%$ \\
\hline
\end{tabular}




\section{AMPT Specimens}

\begin{tabular}{|c|c|c|c|c|c|c|c|c|c|c|c|c|c|c|c|c|c|c|c|c|c|}
\hline \multirow{3}{*}{ Mix Type } & \multirow{3}{*}{ Sample\# } & \multirow{3}{*}{$\begin{array}{c}\text { Test } \\
\text { Type } \\
(\mathrm{DM}, \mathrm{FN}, \mathrm{FA})\end{array}$} & \multirow{3}{*}{ Gmm } & \multirow{3}{*}{ Gmb } & \multirow{3}{*}{ VMA } & \multirow{3}{*}{ VFA } & \multirow{3}{*}{ \% Air Voids } & \multicolumn{8}{|c|}{ Diameter $(\mathrm{mm})$} & \multicolumn{6}{|c|}{ Height (mm) } \\
\hline & & & & & & & & \multicolumn{2}{|c|}{ Top $1 / 3$} & \multicolumn{2}{|c|}{ Center } & \multicolumn{2}{|c|}{ Bottom $1 / 3$} & \multirow{2}{*}{ Average } & \multirow{2}{*}{$\begin{array}{l}\text { Standard } \\
\text { Deviation } \\
\end{array}$} & \multirow{2}{*}{0} & \multirow{2}{*}{90} & \multirow{2}{*}{180} & \multirow{2}{*}{270} & \multirow{2}{*}{ Average } & \multirow{2}{*}{$\begin{array}{l}\text { Standard } \\
\text { Deviation }\end{array}$} \\
\hline & & & & & & & & 0 & 90 & 0 & 90 & 0 & 90 & & & & & & & & \\
\hline \multirow{13}{*}{ W1 } & 1 & $\mathrm{DM}, \mathrm{FN}$ & 2.491 & 2.316 & 18.0 & 61.0 & $7.0 \%$ & 100.45 & 100.46 & 100.43 & 100.43 & 100.44 & 100.46 & 100.45 & 0.014 & 150.32 & 150.50 & 149.92 & 149.24 & 150.00 & 0.559 \\
\hline & 2 & $\mathrm{DM}, \mathrm{FN}$ & 2.491 & 2.314 & 18.0 & 60.6 & $7.1 \%$ & 100.43 & 100.42 & 100.49 & 100.43 & 100.44 & 100.43 & 100.44 & 0.025 & 149.42 & 149.42 & 149.13 & 149.73 & 149.43 & 0.245 \\
\hline & 3 & $\mathrm{DM}, \mathrm{FN}$ & 2.491 & 2.318 & 17.9 & 60.9 & $7.0 \%$ & 100.44 & 100.42 & 100.47 & 100.43 & 100.42 & 100.42 & 100.43 & 0.020 & 149.70 & 149.97 & 149.35 & 149.47 & 149.62 & 0.273 \\
\hline & 4 & $\mathrm{FN}$ & 2.491 & 2.312 & 18.1 & 60.2 & $7.2 \%$ & 100.46 & 100.46 & 100.46 & 100.44 & 100.44 & 100.42 & 100.45 & 0.016 & 150.94 & 150.53 & 150.19 & 150.50 & 150.54 & 0.308 \\
\hline & 5 & $\mathrm{FA}$ & 2.491 & 2.312 & 18.1 & 60.2 & $7.2 \%$ & 100.44 & 100.46 & 100.43 & 100.44 & 100.41 & 100.45 & 100.44 & 0.017 & 129.94 & 130.05 & 129.70 & 129.58 & 129.82 & 0.215 \\
\hline & 6 & $\mathrm{FA}$ & 2.491 & 2.327 & 17.6 & 62.4 & $6.6 \%$ & 100.46 & 100.43 & 100.42 & 100.45 & 100.46 & 100.41 & 100.44 & 0.021 & 129.65 & 129.55 & 129.54 & 129.02 & 129.44 & 0.284 \\
\hline & 7 & $\mathrm{FA}$ & 2.491 & 2.319 & 17.9 & 61.3 & $6.9 \%$ & 100.40 & 100.44 & 100.42 & 100.49 & 100.45 & 100.43 & 100.44 & 0.031 & 129.93 & 130.14 & 130.10 & 129.64 & 129.95 & 0.227 \\
\hline & 8 & $F A$ & 2.491 & 2.311 & 18.1 & 60.3 & $7.2 \%$ & 100.44 & 100.40 & 100.40 & 100.40 & 100.42 & 100.41 & 100.41 & 0.016 & 129.80 & 129.22 & 129.04 & 129.37 & 129.36 & 0.324 \\
\hline & 9 & $\mathrm{FA}$ & 2.491 & 2.322 & 17.7 & 61.7 & $6.8 \%$ & 100.48 & 100.48 & 100.42 & 100.41 & 100.45 & 100.40 & 100.44 & 0.035 & 129.68 & 130.62 & 130.35 & 129.83 & 130.12 & 0.440 \\
\hline & 10 & $\mathrm{FA}$ & 2.491 & 2.320 & 17.8 & 61.3 & $6.9 \%$ & 100.45 & 100.44 & 100.45 & 100.44 & 100.42 & 100.43 & 100.44 & 0.012 & 130.55 & 130.60 & 130.05 & 130.11 & 130.33 & 0.288 \\
\hline & 11 & $\mathrm{FA}$ & 2.491 & 2.324 & 17.7 & 62.1 & $6.7 \%$ & 100.41 & 100.42 & 100.43 & 100.41 & 100.42 & 100.45 & 100.42 & 0.015 & 130.54 & 131.00 & 130.80 & 130.66 & 130.75 & 0.198 \\
\hline & 12 & $\mathrm{FA}$ & 2.491 & 2.322 & 17.7 & 61.7 & $6.8 \%$ & 100.43 & 100.44 & 100.44 & 100.45 & 100.43 & 100.44 & 100.44 & 0.008 & 130.31 & 130.86 & 130.87 & 130.29 & 130.58 & 0.326 \\
\hline & 13 & FA & 2.491 & 2.320 & 17.8 & 61.3 & $6.9 \%$ & 100.46 & 100.40 & 100.42 & 100.46 & 100.40 & 100.44 & 100.43 & 0.028 & 130.47 & 130.23 & 130.17 & 130.34 & 130.30 & 0.132 \\
\hline \multirow{13}{*}{ FF1 } & 1 & $\mathrm{DM}, \mathrm{FN}$ & 2.484 & 2.307 & 18.3 & 61.2 & $7.1 \%$ & 100.44 & 100.43 & 100.41 & 100.43 & 100.44 & 100.43 & 100.43 & 0.011 & 150.01 & 150.33 & 150.25 & 149.61 & 150.05 & 0.323 \\
\hline & 2 & $\mathrm{DM}, \mathrm{FN}$ & 2.484 & 2.298 & 18.6 & 59.7 & $7.5 \%$ & 100.44 & 100.43 & 100.41 & 100.42 & 100.42 & 100.41 & 100.42 & 0.012 & 150.30 & 149.92 & 149.78 & 150.27 & 150.07 & 0.258 \\
\hline & 3 & $\mathrm{DM}, \mathrm{FN}$ & 2.484 & 2.302 & 18.5 & 60.4 & $7.3 \%$ & 100.43 & 100.42 & 100.44 & 100.45 & 100.41 & 100.40 & 100.43 & 0.019 & 150.08 & 149.81 & 149.42 & 149.40 & 149.68 & 0.328 \\
\hline & 4 & $\mathrm{FN}$ & 2.484 & 2.304 & 18.4 & 60.3 & $7.3 \%$ & 100.44 & 100.43 & 100.45 & 100.45 & 100.43 & 100.44 & 100.44 & 0.009 & 150.25 & 149.50 & 149.50 & 150.07 & 149.83 & 0.388 \\
\hline & 5 & $\mathrm{FA}$ & 2.484 & 2.311 & 18.1 & 61.4 & $7.0 \%$ & 100.47 & 100.42 & 100.42 & 100.43 & 100.40 & 100.40 & 100.42 & 0.026 & 130.22 & 131.02 & 131.12 & 130.18 & 130.64 & 0.504 \\
\hline & 6 & $\mathrm{FA}$ & 2.484 & 2.310 & 18.2 & 61.5 & $7.0 \%$ & 100.43 & 100.45 & 100.41 & 100.45 & 100.41 & 100.41 & 100.43 & 0.020 & 129.58 & 129.47 & 129.72 & 129.83 & 129.65 & 0.158 \\
\hline & 7 & $\mathrm{FA}$ & 2.484 & 2.299 & 18.6 & 60.1 & $7.4 \%$ & 100.44 & 100.44 & 100.42 & 100.41 & 100.43 & 100.43 & 100.43 & 0.012 & 130.30 & 130.96 & 130.76 & 130.16 & 130.55 & 0.377 \\
\hline & 8 & FA & 2.484 & 2.307 & 18.3 & 61.2 & $7.1 \%$ & 100.47 & 100.45 & 100.45 & 100.41 & 100.46 & 100.41 & 100.44 & 0.026 & 130.79 & 130.16 & 130.17 & 130.07 & 130.30 & 0.331 \\
\hline & 9 & FA & 2.484 & 2.314 & 18.0 & 62.3 & $6.8 \%$ & 100.40 & 100.46 & 100.43 & 100.41 & 100.45 & 100.42 & 100.43 & 0.023 & 130.15 & 130.32 & 130.47 & 130.60 & 130.39 & 0.194 \\
\hline & 10 & $F A$ & 2.484 & 2.314 & 18.0 & 62.3 & $6.8 \%$ & 100.43 & 100.46 & 100.41 & 100.43 & 100.43 & 100.44 & 100.43 & 0.016 & 130.57 & 130.84 & 130.93 & 130.34 & 130.67 & 0.268 \\
\hline & 11 & $\mathrm{FA}$ & 2.484 & 2.317 & 17.9 & 62.6 & $6.7 \%$ & 100.46 & 100.44 & 100.42 & 100.40 & 100.41 & 100.40 & 100.42 & 0.024 & 131.02 & 130.71 & 130.93 & 130.63 & 130.82 & 0.183 \\
\hline & 12 & $\mathrm{FA}$ & 2.484 & 2.298 & 18.6 & 59.7 & $7.5 \%$ & 100.47 & 100.47 & 100.46 & 100.45 & 100.48 & 100.43 & 100.46 & 0.018 & 130.80 & 130.75 & 130.55 & 130.64 & 130.69 & 0.112 \\
\hline & 13 & $F A$ & 2.484 & 2.303 & 18.4 & 60.4 & $7.3 \%$ & 100.43 & 100.47 & 100.46 & 100.43 & 100.45 & 100.44 & 100.45 & 0.016 & 131.08 & 131.53 & 131.31 & 131.25 & 131.29 & 0.186 \\
\hline
\end{tabular}




\section{APPENDIX C: Statistical Analysis}

\begin{tabular}{|c|c|c|c|c|c|c|}
\hline \multicolumn{5}{|c|}{ Anova: Comparing Fatigue Life of the Two Materials } & & \\
\hline SUMMARY & $300(\mu \varepsilon)$ & $350(\mu \varepsilon)$ & $400(\mu \varepsilon)$ & Total & & \\
\hline \multicolumn{7}{|l|}{ Wearing 1} \\
\hline Count & 3 & 3 & 3 & 9 & & \\
\hline Sum & 67740 & 22440 & 12160 & 102340 & & \\
\hline Average & 22580 & 7480 & 4053 & 11371 & & \\
\hline Variance & $2.53 E+06$ & $7.67 \mathrm{E}+06$ & $2.23 E+06$ & $7.60 \mathrm{E}+07$ & & \\
\hline \multicolumn{7}{|c|}{ Wearing I with Forta- Fi } \\
\hline Count & 3 & 3 & 3 & 9 & & \\
\hline Sum & 81430 & 21990 & 11630 & 115050 & & \\
\hline Average & 27143 & 7330 & 3877 & 12783 & & \\
\hline Variance & $2.54 \mathrm{E}+07$ & $9.09 E+06$ & $5.23 E+05$ & $1.27 E+08$ & & \\
\hline \multicolumn{7}{|l|}{ Total } \\
\hline Count & 6 & 6 & 6 & & & \\
\hline Sum & 149170 & 44430 & 23790 & & & \\
\hline Average & 24862 & 7405 & 3965 & & & \\
\hline Variance & $1.74 \mathrm{E}+07$ & $6.71 E+06$ & $1.11 E+06$ & & & \\
\hline \multicolumn{7}{|l|}{ ANOVA } \\
\hline Source of Variation & SS & $d f$ & $M S$ & $F$ & P-value & F crit \\
\hline Sample & $8.97 E+06$ & 1 & $8.97 E+06$ & 1.14 & 0.31 & 4.75 \\
\hline Columns & $1.51 E+09$ & 2 & $7.53 E+08$ & 95.32 & 0.00 & 3.89 \\
\hline Interaction & $2.23 E+07$ & 2 & $1.12 \mathrm{E}+07$ & 1.41 & 0.28 & 3.89 \\
\hline Within & $9.48 \mathrm{E}+07$ & 12 & $7.90 E+06$ & & & \\
\hline Total & $1.63 E+09$ & 17 & & & & \\
\hline
\end{tabular}




\section{APPENDIX D: APA Test Results}

\begin{tabular}{|c|c|c|c|c|c|}
\hline \multicolumn{2}{|c|}{2} & \multicolumn{2}{|c|}{4} & \multicolumn{2}{|c|}{6} \\
\hline \multicolumn{2}{|c|}{ FF1- Sample 1} & \multicolumn{2}{|c|}{ W1- Sample 2} & \multicolumn{2}{|c|}{ FF1- Sample 3} \\
\hline \multicolumn{2}{|c|}{ Position 2} & \multicolumn{2}{|c|}{ Position 2} & \multicolumn{2}{|c|}{ Position 2} \\
\hline Initial & 11.35 & Initial & 10.61 & Initial & 11.41 \\
\hline Final & 6.83 & Final & 6.51 & Final & 5.99 \\
\hline Rut & 4.52 & Rut & 4.10 & Rut & 5.42 \\
\hline \multicolumn{2}{|c|}{ Position 1} & \multicolumn{2}{|c|}{ Position 1} & \multicolumn{2}{|c|}{ Position 1} \\
\hline Initial & 11.57 & Initial & 11.41 & Initial & 11.32 \\
\hline Final & 7.03 & Final & 7.02 & Final & 6.18 \\
\hline Rut & 4.54 & Rut & 4.39 & Rut & 5.14 \\
\hline Average & 4.53 & Average & 4.25 & Average & 5.28 \\
\hline \multicolumn{2}{|c|}{1} & \multicolumn{2}{|c|}{3} & \multicolumn{2}{|c|}{5} \\
\hline \multicolumn{2}{|c|}{ W1- Sample 1} & \multicolumn{2}{|c|}{ FF1- Sample 2} & \multicolumn{2}{|c|}{ W1- Sample 3} \\
\hline \multicolumn{2}{|c|}{ Position 2} & \multicolumn{2}{|c|}{ Position 2} & \multicolumn{2}{|c|}{ Position 2} \\
\hline Initial & 11.44 & Initial & 11.28 & Initial & 11.54 \\
\hline Final & 6.48 & Final & 6.25 & Final & 6.02 \\
\hline Rut & 4.96 & Rut & 5.03 & Rut & 5.52 \\
\hline \multicolumn{2}{|c|}{ Position 1} & \multicolumn{2}{|c|}{ Position 1} & \multicolumn{2}{|c|}{ Position 1} \\
\hline Initial & 11.68 & Initial & 11.72 & Initial & 11.73 \\
\hline Final & 6.65 & Final & 5.86 & Final & 7.20 \\
\hline Rut & 5.03 & Rut & 5.86 & Rut & 4.53 \\
\hline Average & 5.00 & Average & 5.45 & Average & 5.03 \\
\hline
\end{tabular}

\begin{tabular}{|c|c|c|c|c|c|}
\hline \multicolumn{2}{|c|}{2} & \multicolumn{2}{|c|}{4} & \multicolumn{2}{|c|}{6} \\
\hline \multicolumn{2}{|c|}{ W1- Sample 4} & \multicolumn{2}{|c|}{ FF1- Sample 5} & \multicolumn{2}{|c|}{ W1- Sample 6} \\
\hline \multicolumn{2}{|c|}{ Position 2} & \multicolumn{2}{|c|}{ Position 2} & \multicolumn{2}{|c|}{ Position 2} \\
\hline Initial & 11.09 & Initial & 11.22 & Initial & 9.70 \\
\hline Final & 6.69 & Final & 6.20 & Final & 5.21 \\
\hline Rut & 4.40 & Rut & 5.02 & Rut & 4.49 \\
\hline \multicolumn{2}{|c|}{ Position 1} & \multicolumn{2}{|c|}{ Position 1} & \multicolumn{2}{|c|}{ Position 1} \\
\hline Initial & 11.01 & Initial & 11.18 & Initial & 11.06 \\
\hline Final & 5.78 & Final & 6.81 & Final & 4.81 \\
\hline Rut & 5.23 & Rut & 4.37 & Rut & 6.25 \\
\hline Average & 4.82 & Average & 4.70 & Average & 5.37 \\
\hline \multicolumn{2}{|c|}{1} & \multicolumn{2}{|c|}{3} & \multicolumn{2}{|c|}{5} \\
\hline \multicolumn{2}{|c|}{ FF1- Sample 4} & \multicolumn{2}{|c|}{ W1- Sample 5} & \multicolumn{2}{|c|}{ FF1- Sample 6} \\
\hline \multicolumn{2}{|c|}{ Position 2} & \multicolumn{2}{|c|}{ Position 2} & \multicolumn{2}{|c|}{ Position 2} \\
\hline Initial & 10.93 & Initial & 11.02 & Initial & 11.34 \\
\hline Final & 6.12 & Final & 6.81 & Final & 6.14 \\
\hline Rut & 4.81 & Rut & 4.21 & Rut & 5.20 \\
\hline \multicolumn{2}{|c|}{ Position 1} & \multicolumn{2}{|c|}{ Position 1} & \multicolumn{2}{|c|}{ Position 1} \\
\hline Initial & 10.77 & Initial & 11.34 & Initial & 11.36 \\
\hline Final & 6.34 & Final & 7.17 & Final & 6.56 \\
\hline Rut & 4.43 & Rut & 4.17 & Rut & 4.80 \\
\hline Average & 4.62 & Average & 4.19 & Average & 5.00 \\
\hline
\end{tabular}

\begin{tabular}{|c|c|}
\hline \multicolumn{2}{|c|}{ Average Rut (mm) } \\
\hline FF1 & W1 \\
\hline 5.09 & 4.76 \\
\hline
\end{tabular}

\begin{tabular}{|c|c|}
\hline \multicolumn{2}{|c|}{ Average Rut (mm) } \\
\hline FF1 & W1 \\
\hline 4.93 & 4.78 \\
\hline
\end{tabular}

\begin{tabular}{|c|c|}
\hline \multicolumn{2}{|c|}{ Average Rut (mm) } \\
\hline FF1 & W1 \\
4.77 & 4.79 \\
\hline
\end{tabular}

\begin{tabular}{|l||c|c|}
\hline \multicolumn{2}{|c|}{} & \multicolumn{2}{|c|}{ Average Rut (mm) } \\
\hline & FF1 & W1 \\
\hline 4.93 & 4.78 \\
\hline
\end{tabular}




\section{APPENDIX E: Dynamic Modulus}

\begin{tabular}{|c|c|c|c|c|c|c|c|c|c|c|c|c|c|}
\hline Project: & \multicolumn{8}{|c|}{ Forta- Fi } & & & & & \\
\hline Mix Identification: & \multicolumn{8}{|c|}{ Wearing- 1 Mix } & & & & & \\
\hline Date: & \multicolumn{8}{|c|}{42886} & & & & & \\
\hline Technician: & \multicolumn{8}{|c|}{ Elbert Rohrbough } & & & & & \\
\hline Sample Description: & \multicolumn{8}{|c|}{ Plant Produced Wearing- 1 Mix } & & & & & \\
\hline Notes: & \multicolumn{8}{|c|}{ Testing Completed for Forta Project } & & & & & \\
\hline Shift Factors: & \multicolumn{8}{|c|}{ Arrhenius $\log 10(a(T))=E A / 19.147143^{*}(1 / T-1 / T r)$} & & & & & \\
\hline Master Curve Model: & \multicolumn{8}{|c|}{$\left.\log \left(E^{*}\right)=\log M i n\right)+(\log ($ Max $)-\log ($ Min $)) /(1+E X P($ Beta + Gamma* $\log (w r)))$} & & & & & \\
\hline Reference Temperature: & 15 & C & & & & & & & & & & & \\
\hline \multirow{2}{*}{\multicolumn{14}{|c|}{ Data: }} \\
\hline & & & & & & & & & & & & & \\
\hline & VMA: & 18.0 & $\%$ & & & & & & & & & & \\
\hline & VFA: & 60.8 & $\%$ & & & & & & & & & & \\
\hline & \multirow{2}{*}{\begin{tabular}{|l|} 
Temp \\
\end{tabular}} & & WA1 & & WA2 & & WA3 & & Average & Modulus & Average & Std Dev & Fitted \\
\hline & & Frequency & Modulus & Phase & Modulus & Phase & Modulus & Phase & Modulus & CV & Phase & Phase & Modulus \\
\hline & \multirow[t]{2}{*}{ C } & $\mathrm{Hz}$ & ksi & Degree & ksi & Degree & ksi & Degree & ksi & $\%$ & Deg & Deg & ksi \\
\hline & & 0.1 & 1157.1 & 17.9 & 1045.9 & 17.0 & 1134.2 & 17.1 & \begin{tabular}{|l|}
1112.4 \\
\end{tabular} & 5.3 & 17.3 & 0.5 & 1062.1 \\
\hline & 4 & 1 & 1677.7 & 13.3 & 1483.6 & 12.6 & 1605.0 & 12.6 & 1588.7 & 6.2 & 12.8 & 0.4 & 1555.3 \\
\hline & 4 & 10 & 2238.7 & 9.9 & 1935.2 & 9.5 & 2095.7 & 9.5 & 2089.8 & 7.3 & 9.6 & 0.2 & 2014.8 \\
\hline & 20 & 0.1 & 302.4 & 29.9 & 261.1 & 29.9 & 288.9 & 34.6 & 284.1 & 7.4 & 31.4 & 2.7 & 283.9 \\
\hline & \multirow{2}{*}{\begin{tabular}{|l|}
20 \\
20
\end{tabular}} & 1 & 583.1 & 25.9 & 504.2 & 26.3 & 553.5 & 27.0 & 546.9 & 7.3 & 26.4 & 0.5 & 569.0 \\
\hline & & 10 & 1016.4 & 20.6 & 872.5 & 20.9 & 822.2 & 19.8 & 903.7 & 11.2 & 20.4 & 0.6 & 988.8 \\
\hline & \begin{tabular}{|l|}
20 \\
40
\end{tabular} & 0.01 & 23.9 & 25.0 & 23.0 & 24.5 & 24.5 & 25.1 & 23.8 & 3.1 & 24.9 & 0.4 & 23.4 \\
\hline & $\begin{array}{l}40 \\
40 \\
\end{array}$ & 0.1 & 44.0 & 29.7 & 41.6 & 28.9 & 43.1 & 28.9 & 42.9 & 2.9 & 29.2 & 0.4 & 44.6 \\
\hline & 40 & 1 & 100.1 & 25.9 & 92.1 & 32.7 & 96.0 & 32.6 & 96.1 & 4.2 & 30.4 & 3.9 & 95.4 \\
\hline & 40 & 10 & 234.2 & 34.5 & 213.5 & 34.2 & 225.2 & 34.1 & 224.3 & 4.6 & 34.3 & 0.2 & 211.6 \\
\hline \multirow{5}{*}{ Final Parameters: } & Max & 3148.3 & ksi & Goodne & ess of Fit: & $\mathrm{R}^{2}$ & 0.9974 & & & & & & \\
\hline & Min & 5.3 & ksi & & & Se/Sy & 0.04 & & & & & & \\
\hline & Beta & -1.32988 & & & & & & & & & & & \\
\hline & Gamma & -0.50195 & & & & & & & & & & & \\
\hline & $\mathrm{EA}$ & 209497 & & & & & & & & & & & \\
\hline
\end{tabular}



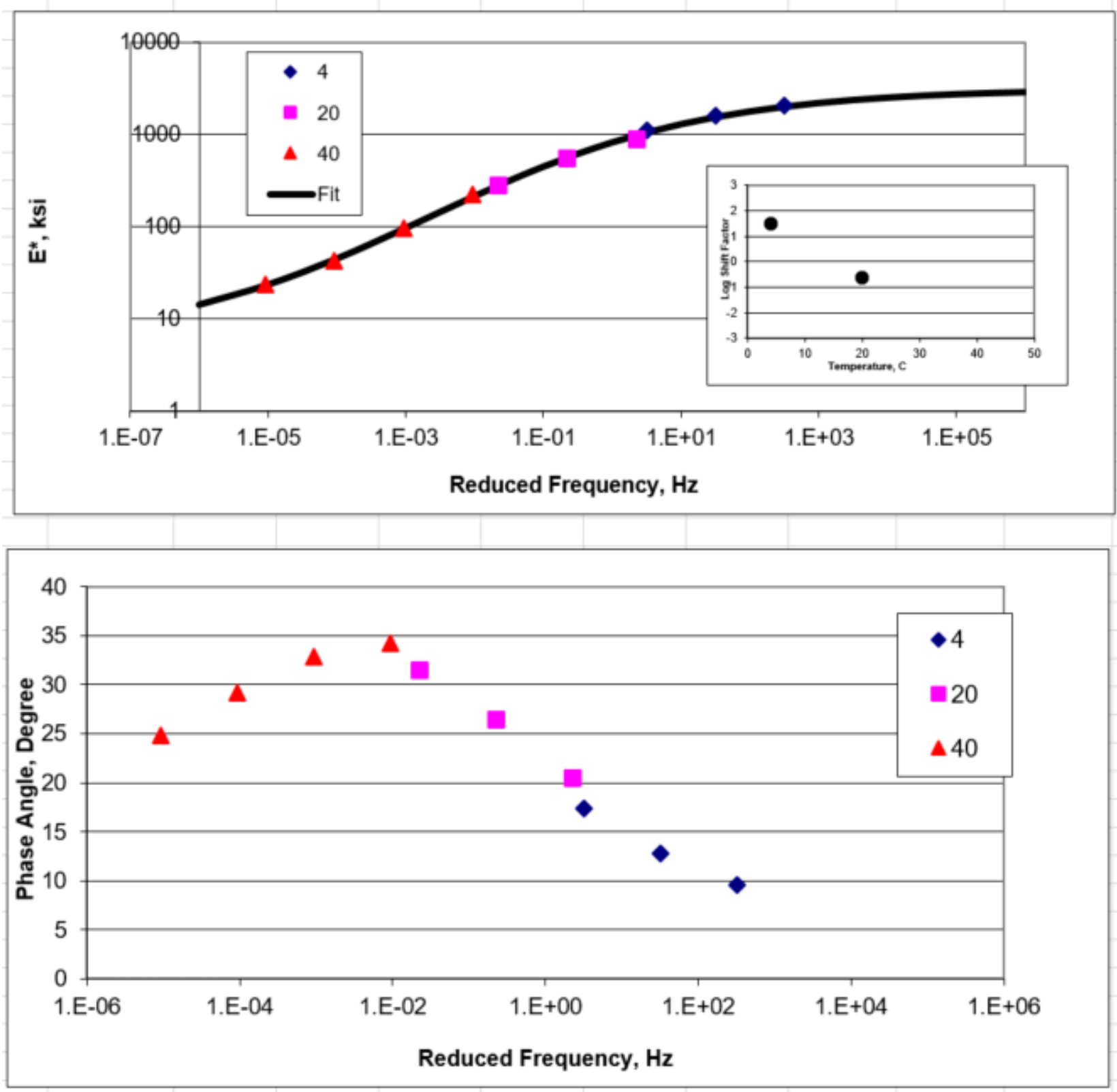


\begin{tabular}{|c|c|}
\hline Project: & Forta \\
\hline Mix Identification: & Fortified Wearing- 1 \\
\hline Date: & 42886 \\
\hline Technician: & Elbert Rohrbough \\
\hline \multirow[t]{2}{*}{ Sample Description: } & \\
\hline & Plant Produced Mix \\
\hline \multirow{2}{*}{ Notes: } & \\
\hline & Forta Project \\
\hline Shift Factors: & Arrhenius $\log 10(\mathrm{a}(\mathrm{T}))=\mathrm{EA} / 19.147143^{*}(1 / \mathrm{T}-1 / \mathrm{Tr})$ \\
\hline Master Curve Model: & $\log \left(\mathrm{E}^{*}\right)=\log$ Min $)+(\log ($ Max $)-\log ($ Min $)) /(1+\mathrm{EXP}($ Beta + Gamma* $\log (w r)))$ \\
\hline Reference Temperature: & \begin{tabular}{|l|l|l|l|l|l|l|}
$15 \quad \mathrm{C}$ & & & & & & \\
\end{tabular} \\
\hline
\end{tabular}

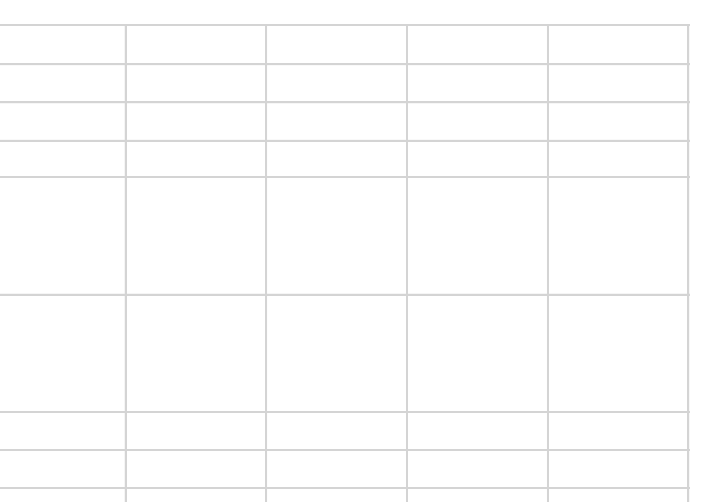

\begin{tabular}{|c|c|c|c|c|c|c|c|c|c|c|c|c|c|}
\hline zererence remperature:[ & & & & & & & & & & & & & \\
\hline & & & & & & & & & & & & & \\
\hline Data: & & & & & & & & & & & & & \\
\hline & VMA: & 18.5 & $\%$ & & & & & & & & & & \\
\hline & VFA: & 60.4 & $\%$ & & & & & & & & & & \\
\hline & Temp & Frequency & Modulus & Phase & Modulus & Phase & Modulus & Phase & Modulus & CV & Phase & Phase & Modulus \\
\hline & C & $\mathrm{Hz}$ & ksi & Degree & ksi & Degree & ksi & Degree & ksi & $\%$ & Deg & Deg & ksi \\
\hline & 4 & 0.1 & 1094.3 & 14.5 & \begin{tabular}{|l|}
1016.7 \\
\end{tabular} & 16.7 & 1104.6 & \begin{tabular}{|r|}
16.3 \\
\end{tabular} & \begin{tabular}{|l|}
1071.9 \\
\end{tabular} & 4.5 & 15.8 & 1.2 & 1010.3 \\
\hline & 4 & 1 & 1475.9 & 11.1 & 1429.8 & 12.5 & 1547.1 & 12.2 & 1484.3 & 4.0 & 11.9 & 0.8 & 1464.2 \\
\hline & 20 & 0.1 & 325.2 & 27.4 & 272.2 & 29.5 & 282.8 & 29.6 & 293.4 & 9.5 & 28.8 & 1.3 & 296.3 \\
\hline & 20 & 1 & 569.9 & 23.1 & 508.8 & 25.5 & 527.8 & 25.6 & 535.5 & 5.8 & 24.7 & 1.4 & 562.9 \\
\hline & 20 & 10 & 917.1 & 18.3 & 868.8 & 20.2 & 902.0 & 20.2 & 895.9 & 2.8 & 19.6 & 1.1 & 946.3 \\
\hline & 40 & 0.01 & 32.9 & 26.0 & 26.3 & 24.6 & 26.8 & 25.3 & 28.6 & 12.9 & 25.3 & 0.7 & 28.5 \\
\hline & 40 & 0.1 & 57.4 & 29.5 & 48.0 & 28.9 & 50.8 & 29.9 & 52.1 & 9.3 & 29.4 & 0.5 & 53.3 \\
\hline & 40 & 1 & 118.0 & 23.1 & 102.8 & 32.7 & 109.6 & 32.8 & 110.1 & 6.9 & 29.5 & 5.5 & 109.0 \\
\hline & 40 & 10 & 247.4 & 31.9 & 226.3 & 33.3 & 240.0 & 33.0 & 237.9 & 4.5 & 32.8 & 0.7 & 227.2 \\
\hline
\end{tabular}

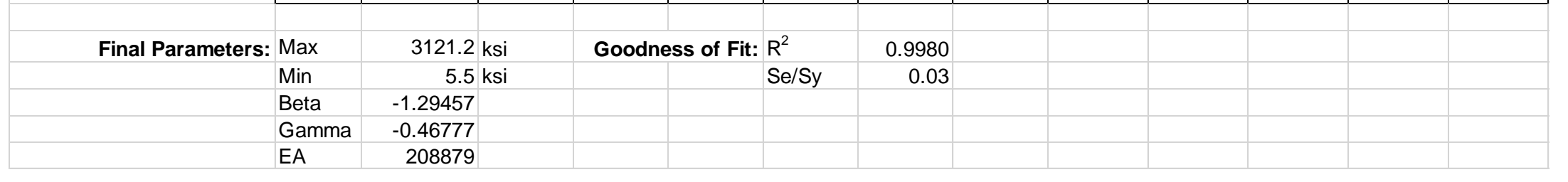



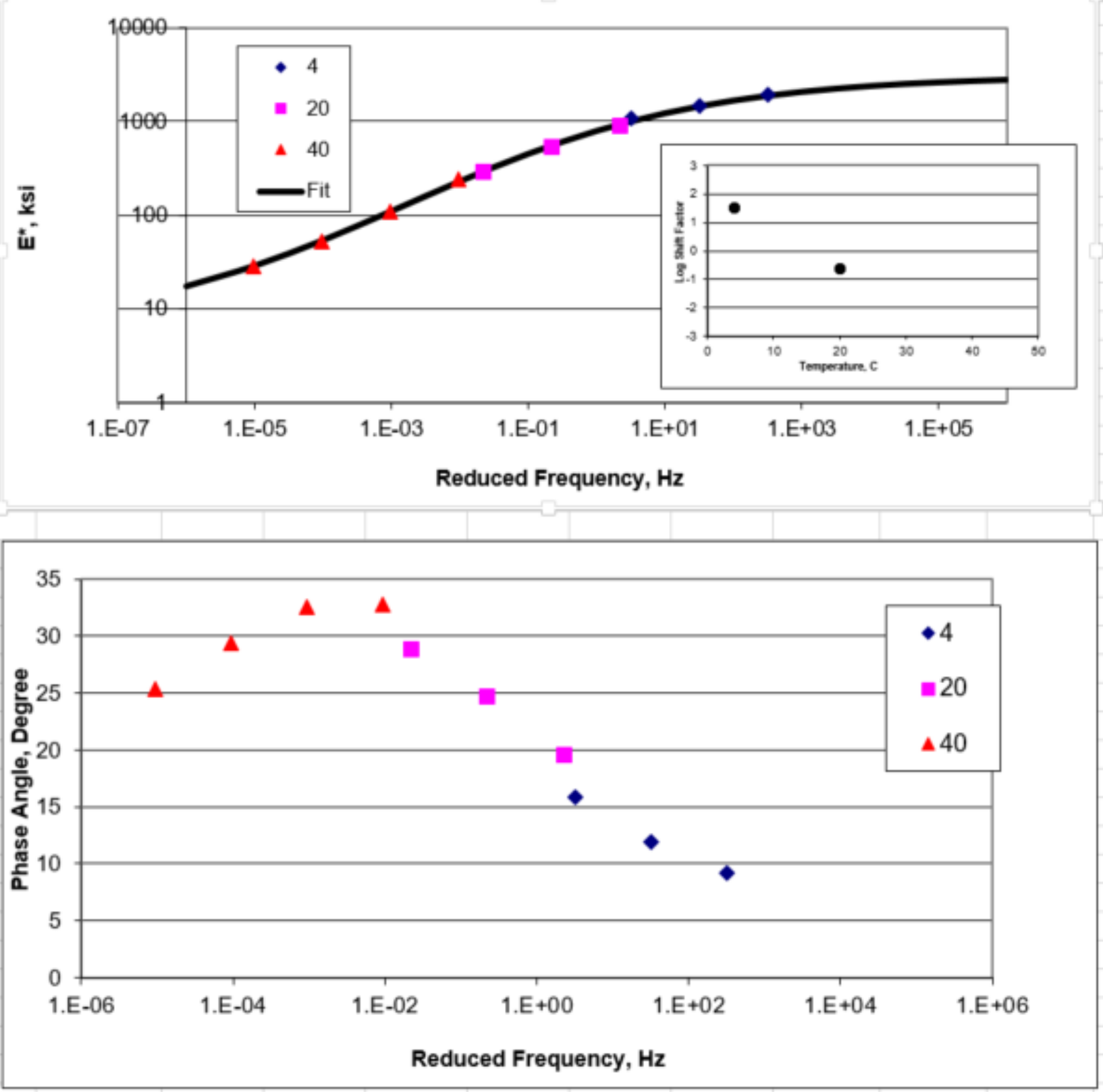


\section{APPENDIX F: Fatigue}

\section{Wearing I Default Analysis}

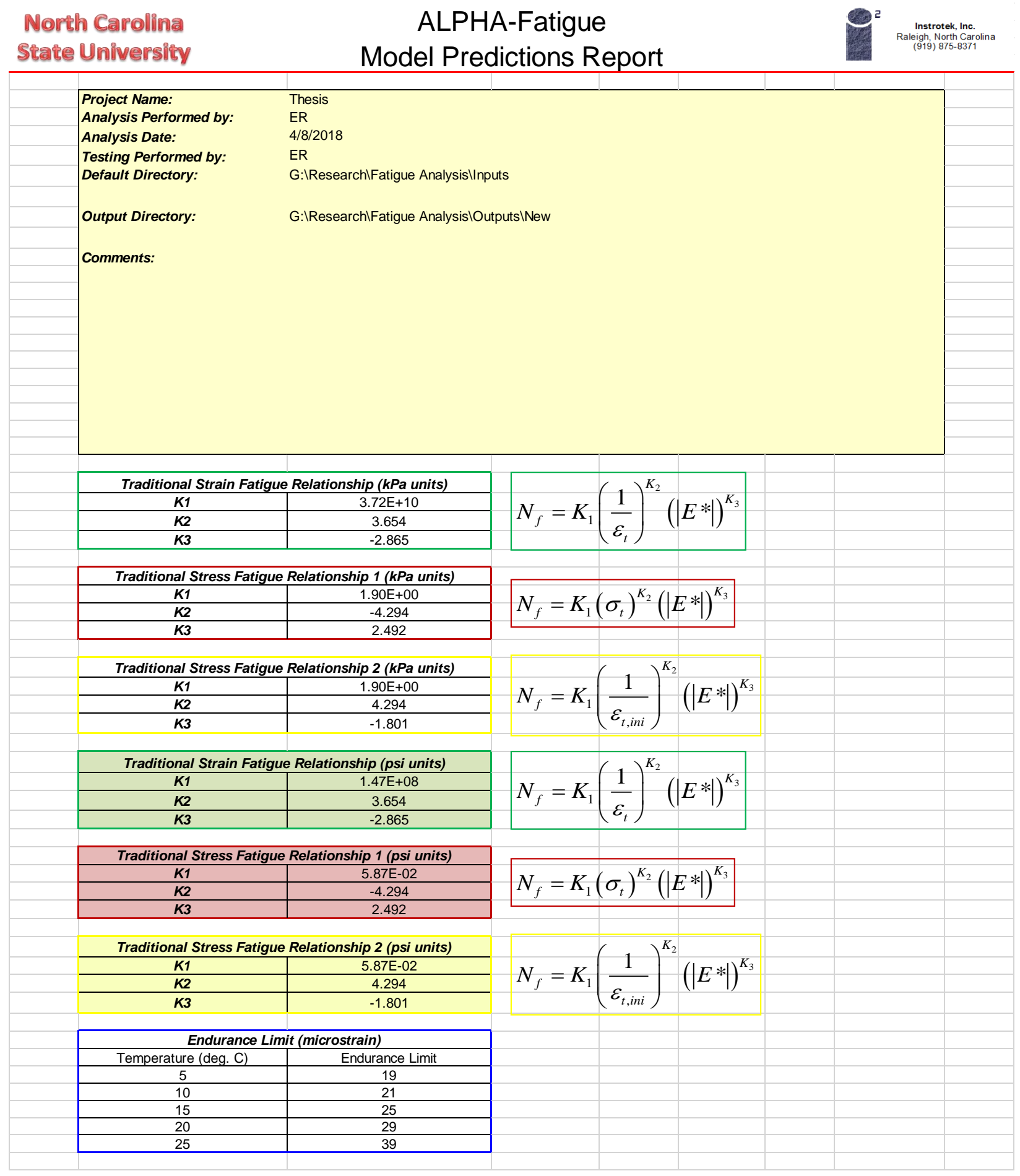




North Carolina
State University $\quad$ ALPHA-Fatigue

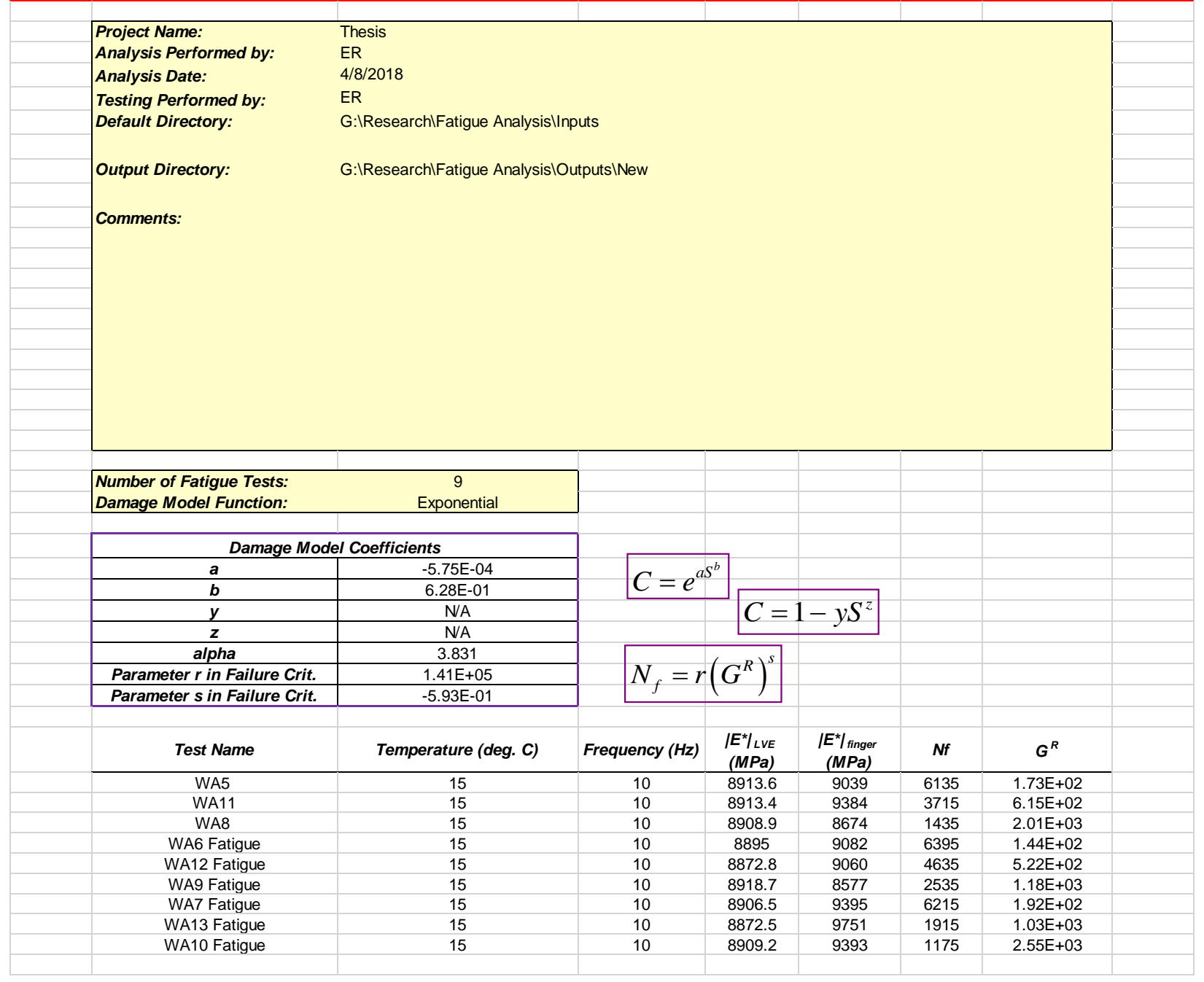




North Carolina
State University $\quad$ ALPHA-Fatigue

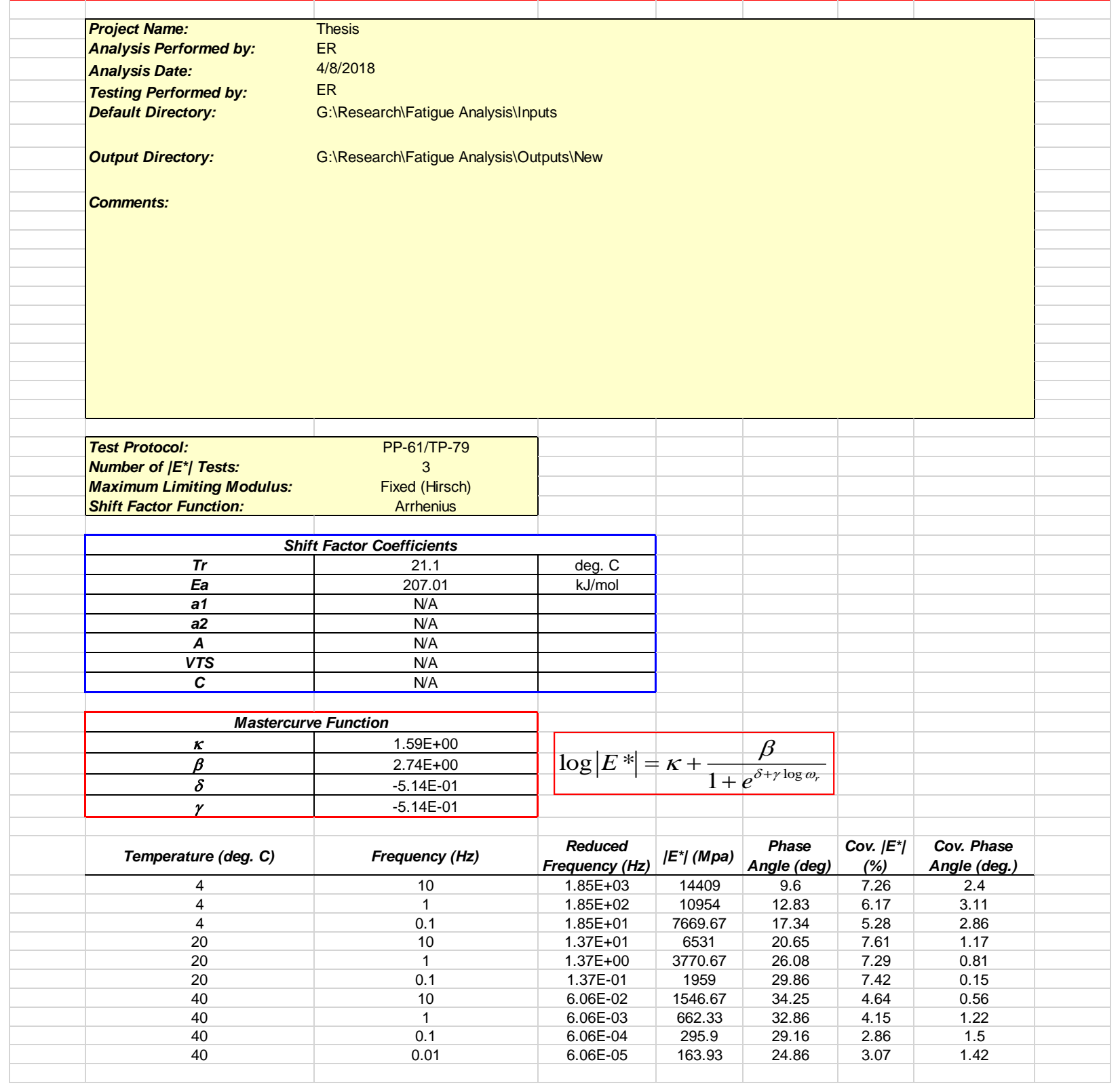




\section{Wearing I Peak Analysis}

$\begin{array}{ccc}\begin{array}{c}\text { North Capolina } \\ \text { State University }\end{array} & \text { ALPHA-Fatigue } \\ \text { Model Predictions Report }\end{array}$

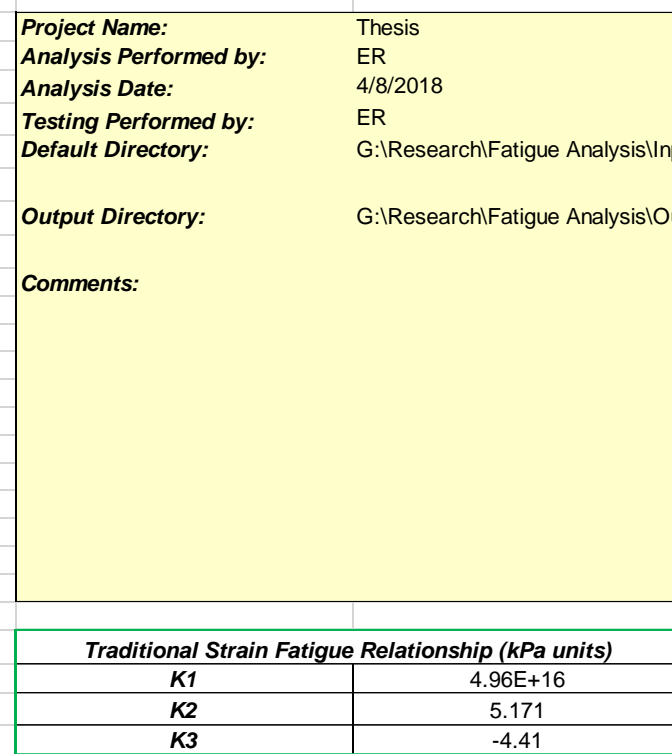

$$
N_{f}=K_{1}\left(\frac{1}{\varepsilon_{t}}\right)^{K_{2}}(\mid E *)^{K_{3}}
$$

\begin{tabular}{|c|c|}
\hline \multicolumn{2}{|c|}{ Traditional Stress Fatigue Relationship 1 (kPa units) } \\
\hline K1 & $2.58 \mathrm{E}-10$ \\
\hline K2 & -5.271 \\
\hline K3 & 4.407 \\
\hline
\end{tabular}

$N_{f}=K_{1}\left(\sigma_{t}\right)^{K_{2}}\left(\left|E^{*}\right|\right)^{K_{3}}$

Traditional Stress Fatigue Relationship 2 ( $\mathrm{kPa}$ units)

\begin{tabular}{|c|c|}
\hline K1 & $2.58 \mathrm{E}-10$ \\
\hline K2 & 5.271 \\
\hline \multicolumn{2}{|c|}{} \\
\hline Traditional Strain Fatigue & -0.864 \\
\hline K1 & $9.96 \mathrm{E}+12$ \\
\hline K2 & 5.171 \\
\hline K3 & -4.41 \\
\hline
\end{tabular}

$$
N_{f}=K_{1}\left(\frac{1}{\varepsilon_{t, i n i}}\right)^{K_{2}}(\mid E *)^{K_{3}}
$$$$
N_{f}=K_{1}\left(\frac{1}{\varepsilon_{t}}\right)^{K_{2}}\left(\left|E^{*}\right|\right)^{K_{3}}
$$

Traditional Stress Fatigue Relationship 1 (psi units)

\begin{tabular}{|c|c|}
\hline \multicolumn{2}{|c|}{ Traditional Stress Fatigue Relationship 1 (psi units) } \\
\hline K1 & $4.87 \mathrm{E}-11$ \\
\hline K2 & -5.271 \\
\hline 3 & 4.407 \\
\hline
\end{tabular}

$N_{f}=K_{1}\left(\sigma_{t}\right)^{K_{2}}\left(\left|E^{*}\right|\right)^{K_{3}}$

Traditional Stress Fatigue Relationship 2 (psi units)

\begin{tabular}{|c|c|}
\hline $\boldsymbol{K} \mathbf{1}$ & $4.87 \mathrm{E}-11$ \\
\hline $\boldsymbol{K} \mathbf{3}$ & 5.271 \\
\hline \multicolumn{2}{|c|}{ Endurance Limit (microstrain) } \\
\hline Temperature (deg. C) & -0.864 \\
\hline 5 & Endurance Limit \\
\hline 10 & 51 \\
\hline 15 & 57 \\
\hline 20 & 67 \\
\hline 25 & 82 \\
\hline
\end{tabular}

$$
N_{f}=K_{1}\left(\frac{1}{\varepsilon_{t, i n i}}\right)^{K_{2}}(\mid E *)^{K_{3}}
$$




North Carolina
State University $\quad$ ALPHA-Fatigue

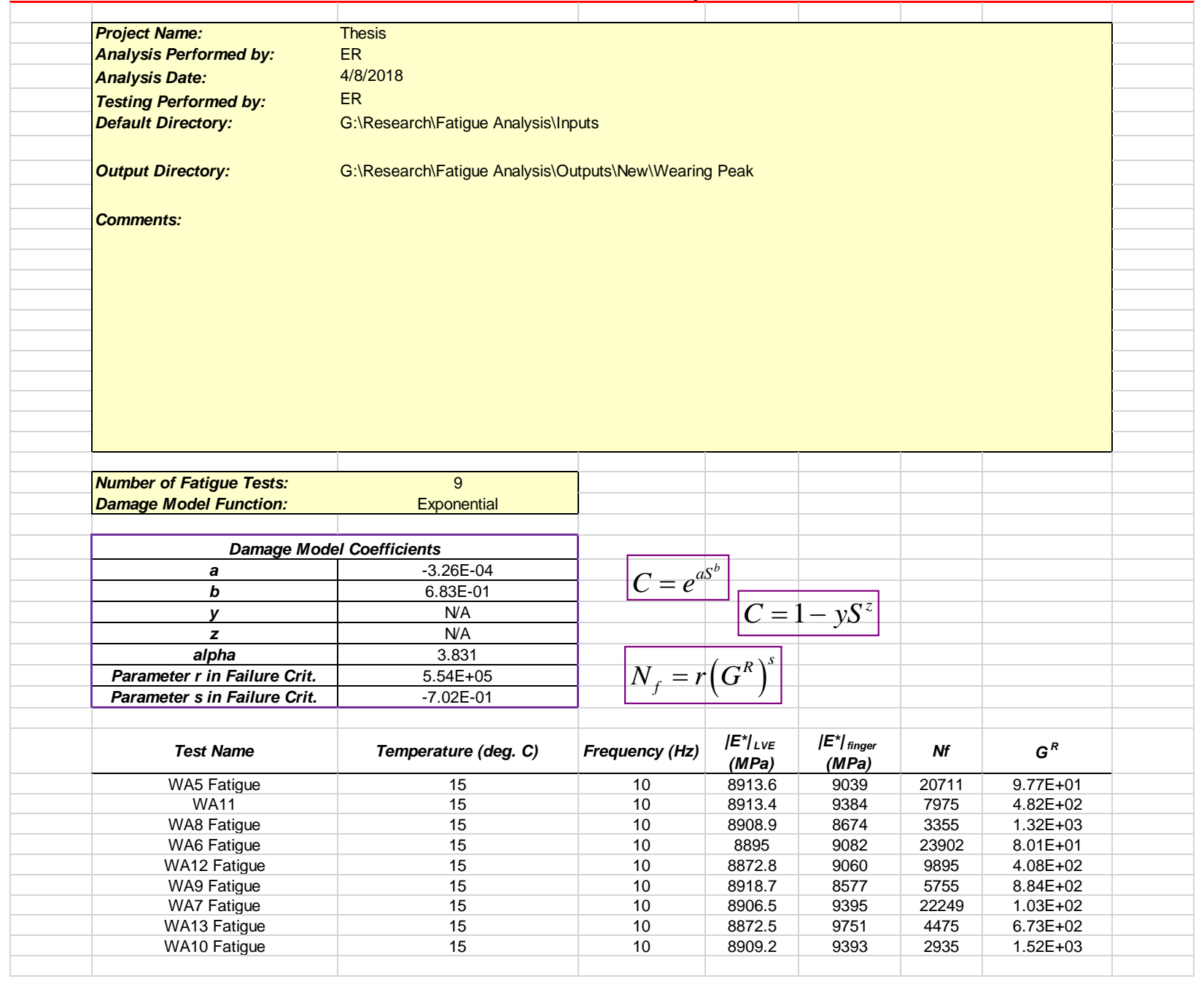




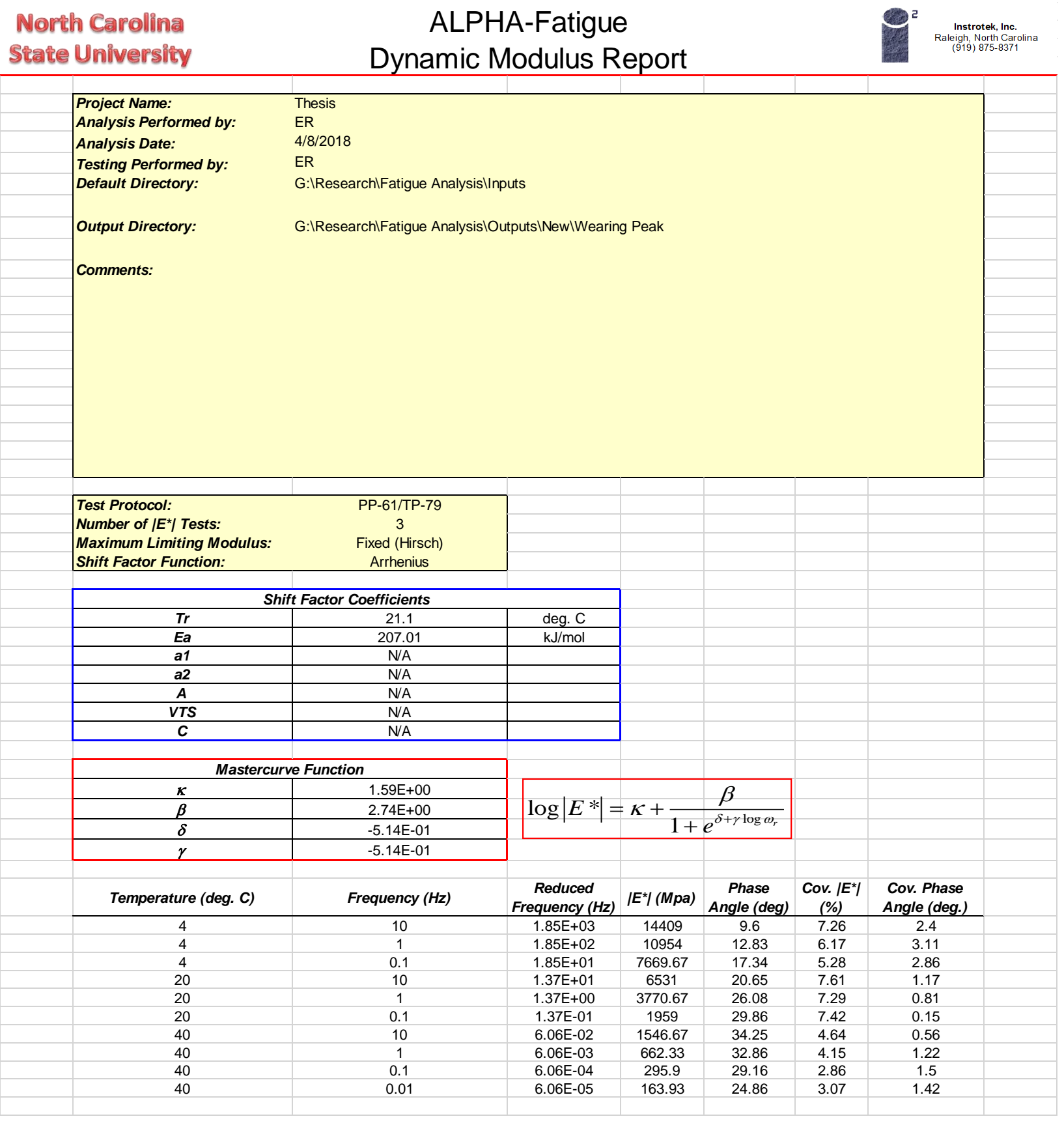




\section{Wearing I with FORTA-FI Default Analysis}

\section{Nopth Carolina State University}

\section{ALPHA-Fatigue Model Predictions Report}

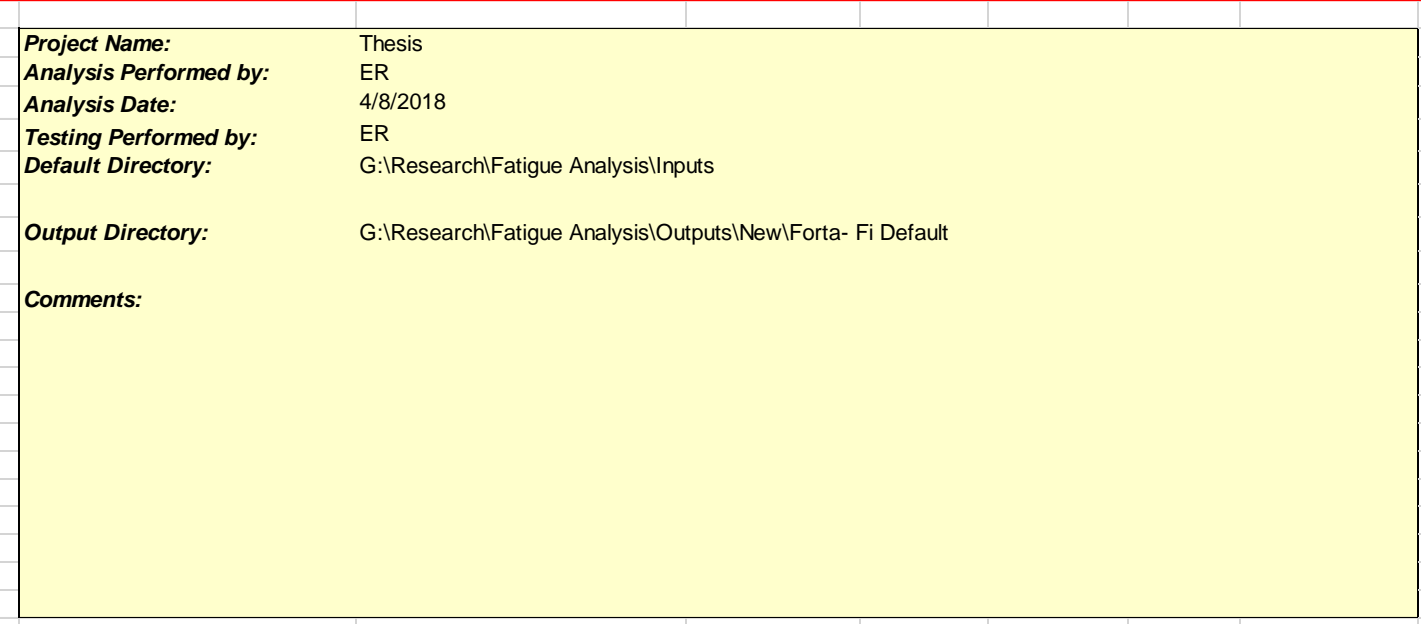

\begin{tabular}{|c|c|}
\hline \multicolumn{2}{|c|}{ Traditional Strain Fatigue Relationship (kPa units) } \\
\hline K1 & $6.50 \mathrm{E}+09$ \\
\hline K2 & 3.684 \\
\hline K3 & -2.78 \\
\hline
\end{tabular}

$N_{f}=K_{1}\left(\frac{1}{\varepsilon_{t}}\right)^{K_{2}}(|E *|)^{K_{3}}$

\begin{tabular}{|c|c|}
\hline \multicolumn{2}{|c|}{ Traditional Stress Fatigue Relationship 1 (kPa units) } \\
\hline K1 & $6.43 \mathrm{E}-01$ \\
\hline K2 & -4.562 \\
\hline K3 & 2.682 \\
\hline
\end{tabular}

$N_{f}=K_{1}\left(\sigma_{t}\right)^{K_{2}}\left(\left|E^{*}\right|\right)^{K_{3}}$

Traditional Stress Fatigue Relationship 2 ( $\mathrm{kPa}$ units)

\begin{tabular}{|c|c|}
\hline $\boldsymbol{K} \mathbf{1}$ & $6.43 \mathrm{E}-01$ \\
\hline $\boldsymbol{K} \mathbf{3}$ & 4.562 \\
\hline \multicolumn{2}{|c|}{-1.88} \\
\hline Traditional Strain Fatigue Relationship (psi units) \\
\hline $\boldsymbol{K} \mathbf{1}$ & $3.03 \mathrm{E}+07$ \\
\hline $\boldsymbol{2} \mathbf{3}$ & 3.684 \\
\hline
\end{tabular}

$N_{f}=K_{1}\left(\frac{1}{\varepsilon_{t, i n i}}\right)^{K_{2}}(|E *|)^{K_{3}}$

Traditional Stress Fatigue Relationship 1 (psi units)

\begin{tabular}{l|c} 
K1 & $1.71 \mathrm{E}-02$ \\
\hline K2 & -4.562 \\
\hline K3 & 2.682
\end{tabular}

Traditional Stress Fatigue Relationship 2 (psi units)

\begin{tabular}{|c|c|}
\hline $\boldsymbol{K} \mathbf{1}$ & $1.71 \mathrm{E}-02$ \\
\hline $\mathbf{2}$ & 4.562 \\
\hline $\boldsymbol{K} \mathbf{3}$ & -1.88 \\
\hline
\end{tabular}

$N_{f}=K_{1}\left(\frac{1}{\varepsilon_{t}}\right)^{K_{2}}(|E *|)^{K_{3}}$

Endurance Limit (microstrain)

\begin{tabular}{|c|c|}
\hline \multicolumn{2}{|c|}{ Endurance Limit (microstrain) } \\
\hline Temperature (deg. C) & Endurance Limit \\
\hline 5 & 21 \\
\hline 10 & 23 \\
\hline 15 & 26 \\
\hline 20 & 31 \\
\hline 25 & 40 \\
\hline
\end{tabular}

$N_{f}=K_{1}\left(\sigma_{t}\right)^{K_{2}}(|E *|)^{K_{3}}$

$N_{f}=K_{1}\left(\frac{1}{\varepsilon_{t, i n i}}\right)^{K_{2}}(|E *|)^{K_{3}}$ 


North Carolina
State University $\quad$ ALPHA-Fatigue

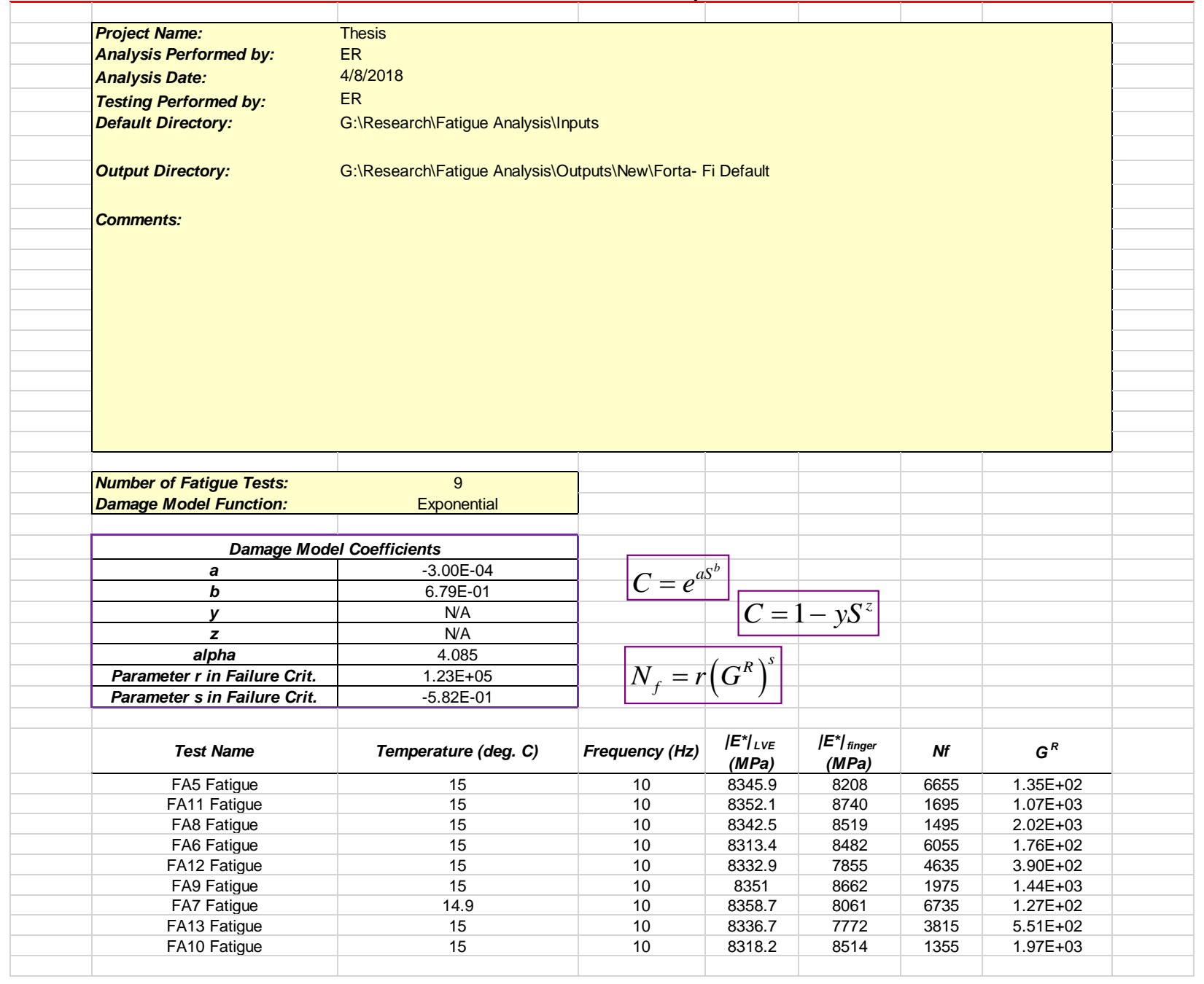




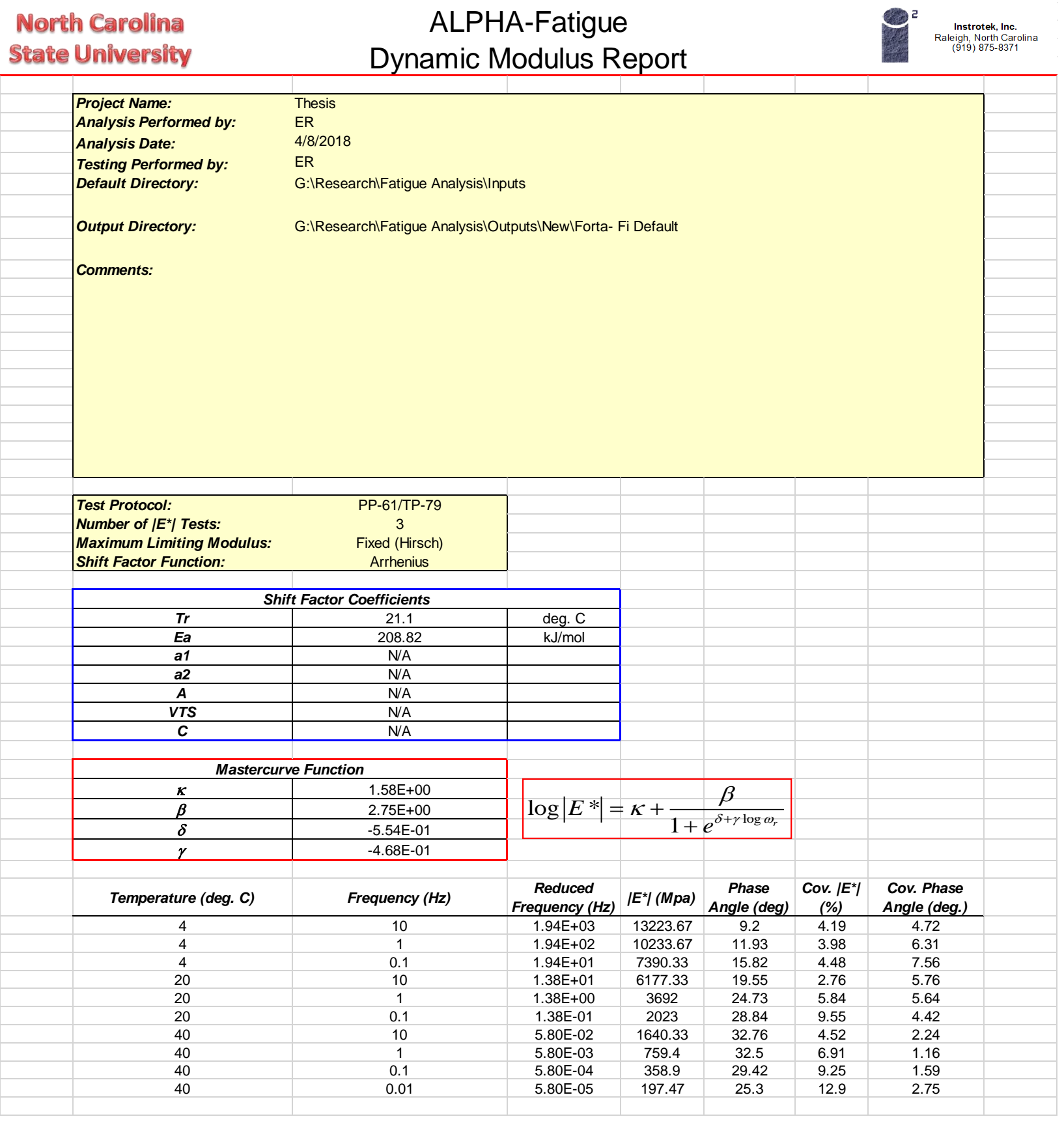




\section{Wearing I with FORTA-FI Peak Analysis}

\section{Nopth Carolina State University}

ALPHA-Fatigue Model Predictions Report

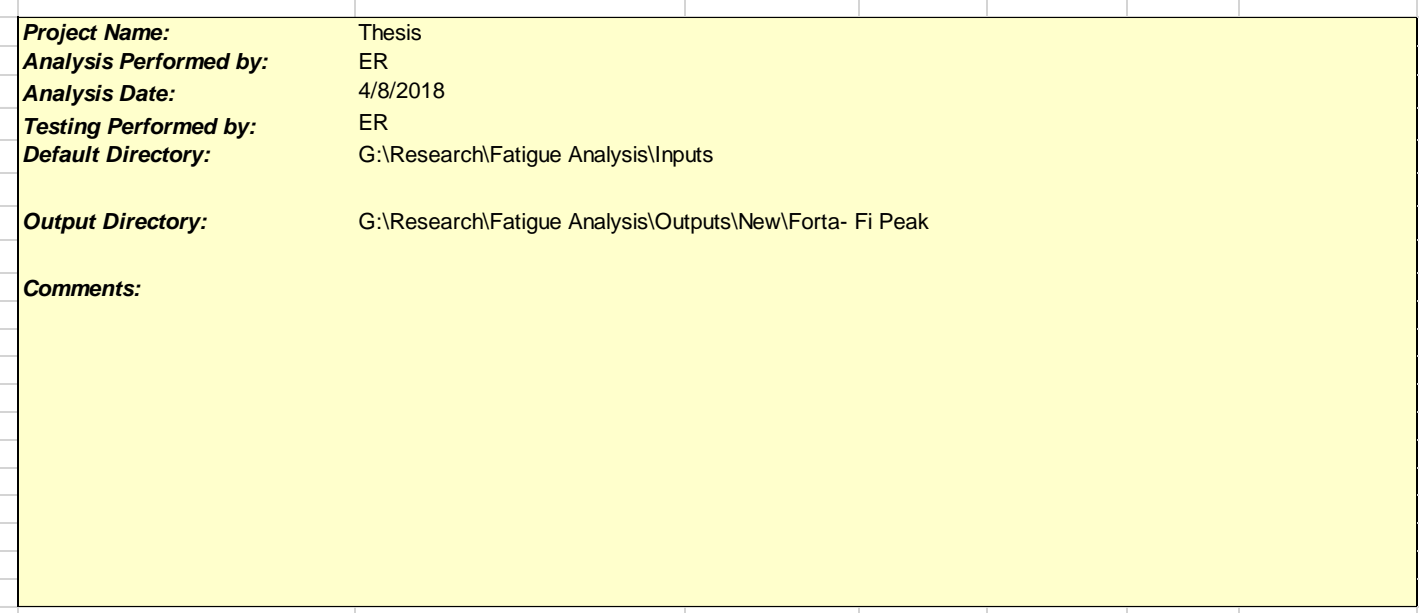

\begin{tabular}{|c|c|}
\hline \multicolumn{2}{|c|}{ Traditional Strain Fatigue Relationship (kPa units) } \\
\hline K1 & $7.84 \mathrm{E}+16$ \\
\hline K2 & 5.486 \\
\hline K3 & -4.611 \\
\hline
\end{tabular}

$$
N_{f}=K_{1}\left(\frac{1}{\varepsilon_{t}}\right)^{K_{2}}(|E *|)^{K_{3}}
$$

\begin{tabular}{|c|c|}
\hline \multicolumn{2}{|c|}{ Traditional Stress Fatigue Relationship 1 (kPa units) } \\
\hline K1 & $3.36 \mathrm{E}-13$ \\
\hline K2 & -5.91 \\
\hline K3 & 5.107 \\
\hline
\end{tabular}

$N_{f}=K_{1}\left(\sigma_{t}\right)^{K_{2}}(\mid E *)^{K_{3}}$

Traditional Stress Fatigue Relationship 2 ( $k P a$ units)

\begin{tabular}{|c|c|}
\hline K1 & $3.36 \mathrm{E}-13$ \\
\hline K3 & 5.91 \\
\hline \multicolumn{2}{|c|}{ Traditional Strain Fatigue Relationship (psi units) } \\
\hline K1 & -0.803 \\
\hline K2 & $1.07 \mathrm{E}+13$ \\
\hline K3 & 5.486 \\
\hline
\end{tabular}

$$
N_{f}=K_{1}\left(\frac{1}{\varepsilon_{t, i n i}}\right)^{K_{2}}(\mid E *)^{K_{3}}
$$$$
N_{f}=K_{1}\left(\frac{1}{\varepsilon_{t}}\right)^{K_{2}}\left(\left|E^{*}\right|\right)^{K_{3}}
$$

Traditional Stress Fatigue Relationship 1 (psi units)

\begin{tabular}{|c|c|}
\hline \multicolumn{2}{|c|}{ Traditional Stress Fatigue Relationship 1 (psi units) } \\
\hline K1 & $7.13 \mathrm{E}-14$ \\
\hline K2 & -5.91 \\
\hline 3 & 5.107 \\
\hline
\end{tabular}

$N_{f}=K_{1}\left(\sigma_{t}\right)^{K_{2}}\left(\left|E^{*}\right|\right)^{K_{3}}$

Traditional Stress Fatigue Relationship 2 (psi units)

\begin{tabular}{|c|c|}
\hline $\mathbf{K 1}$ & $7.13 \mathrm{E}-14$ \\
\hline $\boldsymbol{K} \mathbf{3}$ & 5.91 \\
\hline \multicolumn{2}{|c|}{ Endurance Limit (microstrain) } \\
\hline \multicolumn{2}{|c|}{ Endurance Limit } \\
\hline Temperature (deg. C) & 57 \\
\hline 5 & 64 \\
\hline 10 & 75 \\
\hline 15 & 90 \\
\hline 20 & 121 \\
\hline 25 &
\end{tabular}

$$
N_{f}=K_{1}\left(\frac{1}{\varepsilon_{t, i n i}}\right)^{K_{2}}\left(\left|E^{*}\right|\right)^{K_{3}}
$$




North Carolina
State University $\quad$ ALPHA-Fatigue

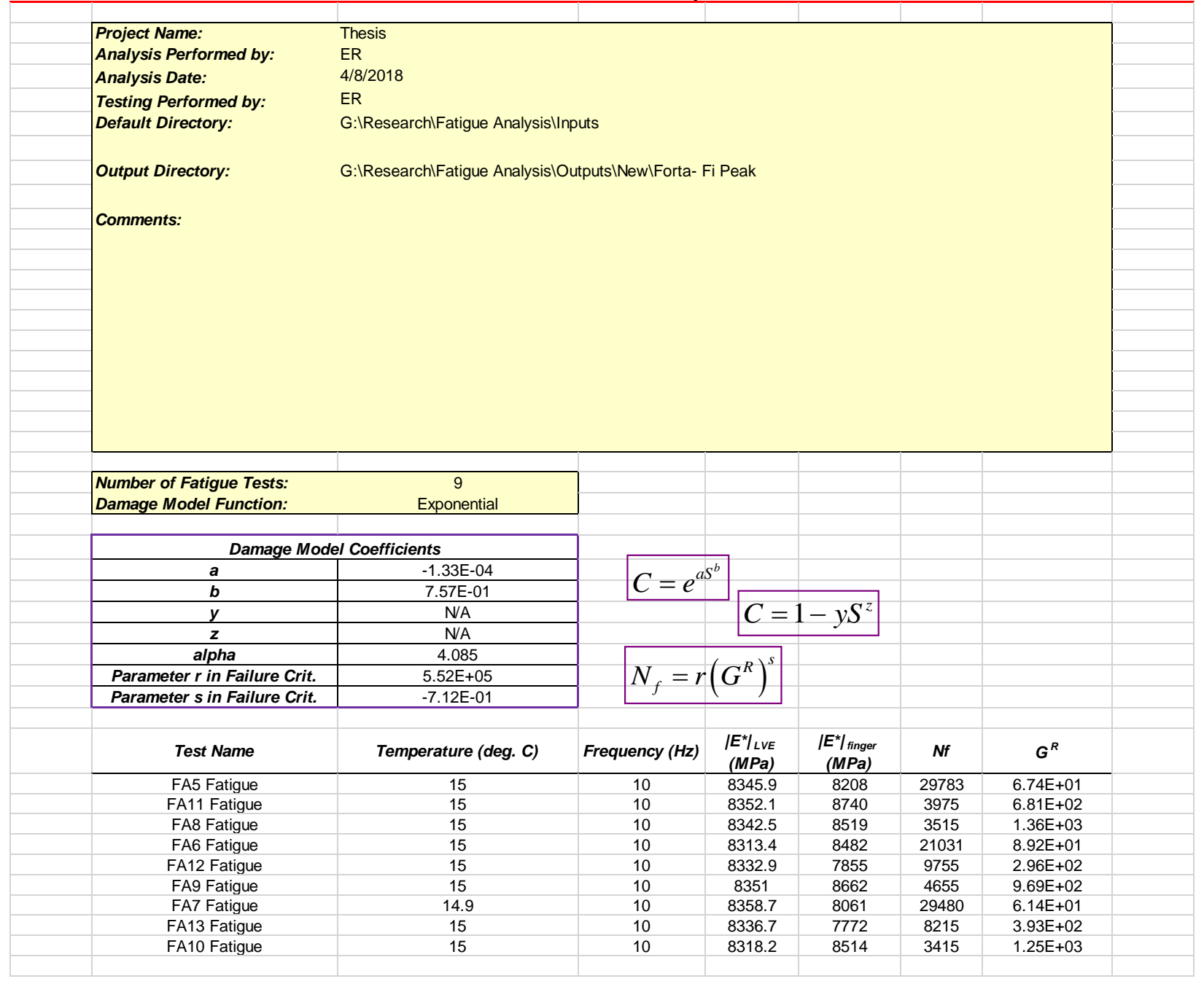




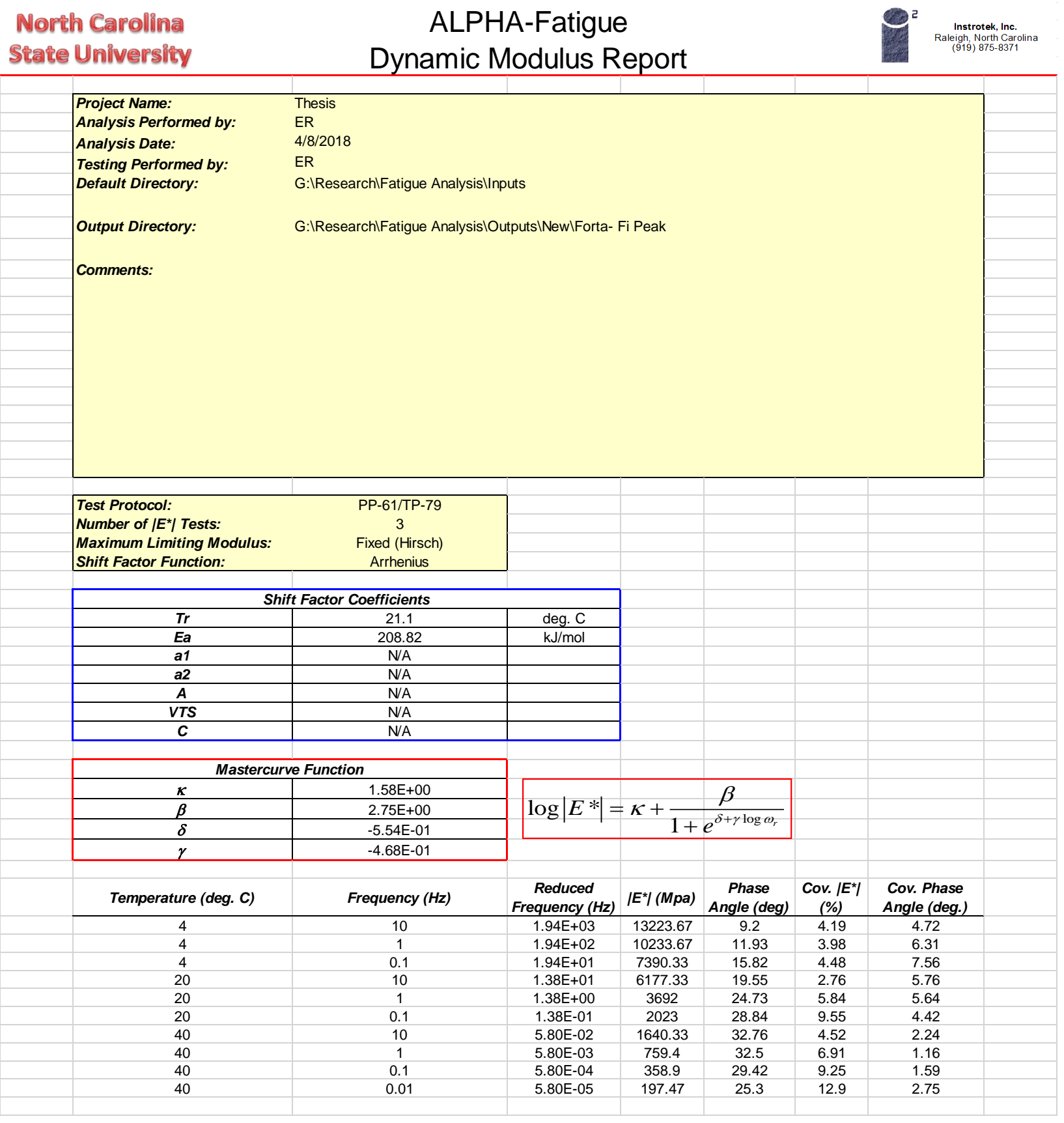




\section{Wearing I Default Fatigue Life Prediction Analysis}

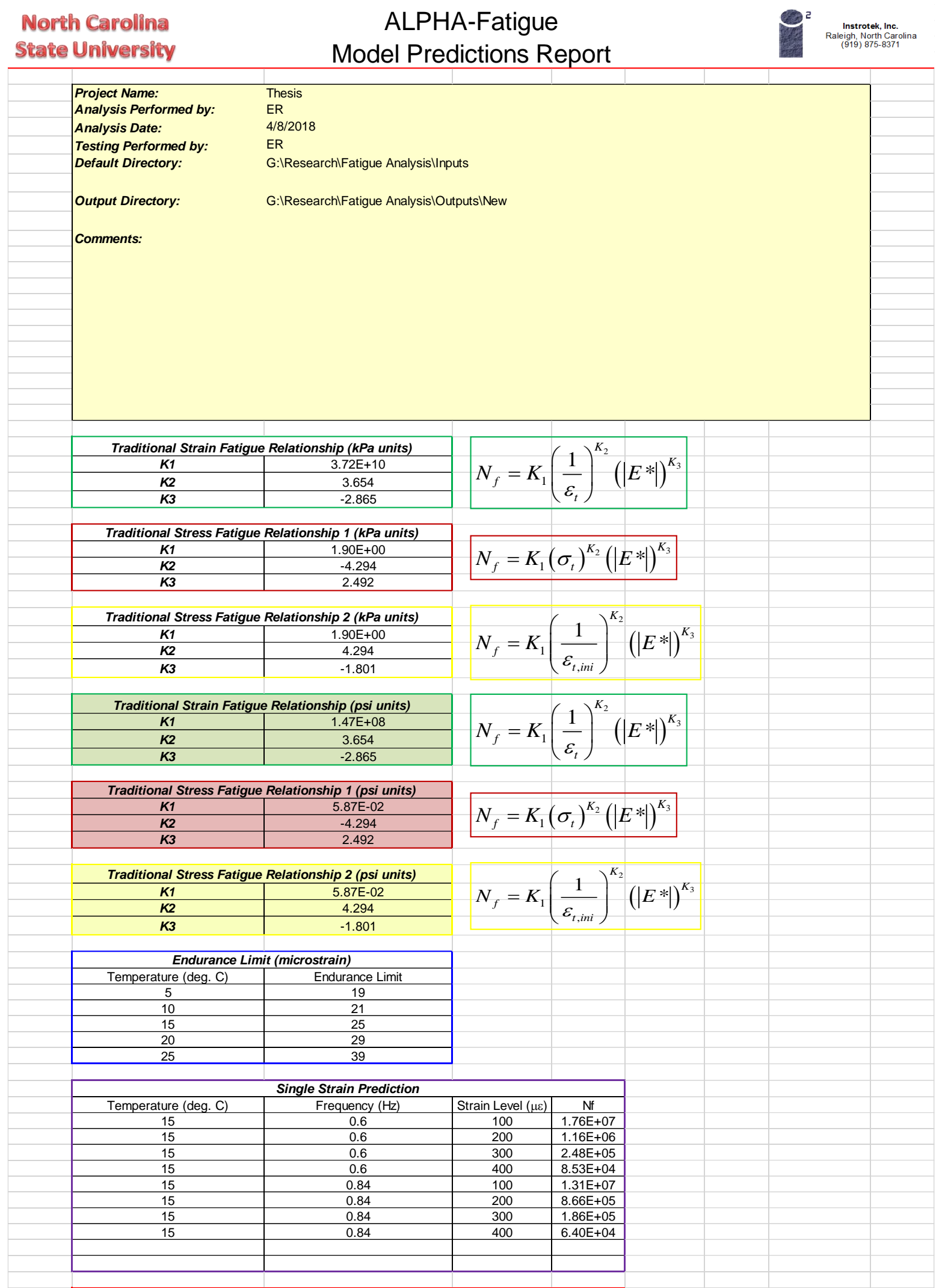




\section{Wearing I Peak Fatigue Life Prediction Analysis}

\section{North Carolina \\ State University}

\section{ALPHA-Fatigue Model Predictions Report}
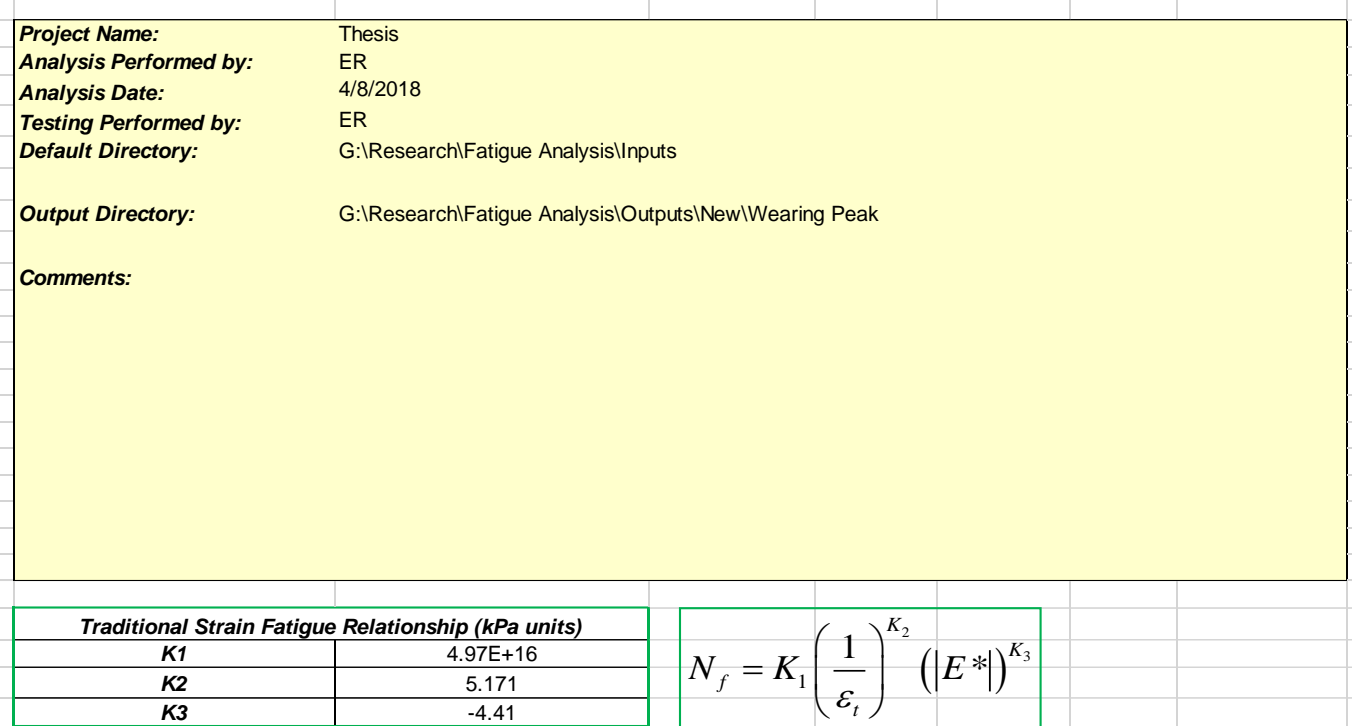

$N_{f}=K_{1}\left(\frac{1}{\varepsilon_{t}}\right)^{K_{2}}(|E *|)^{K_{3}}$

\begin{tabular}{|c|c|}
\hline \multicolumn{2}{|c|}{ Traditional Stress Fatigue Relationship 1(KPa units) } \\
\hline $\mathbf{K 1}$ & $2.59 \mathrm{E}-10$ \\
\hline $\mathbf{2}$ & -5.271 \\
\hline $\mathbf{3}$ & 4.407 \\
\hline
\end{tabular}

$N_{f}=K_{1}\left(\sigma_{t}\right)^{K_{2}}(|E *|)^{K_{3}}$

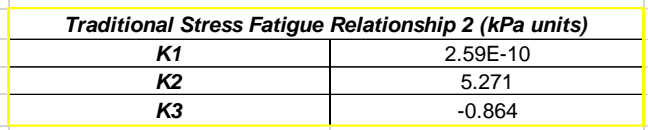

$N_{f}=K_{1}\left(\frac{1}{\varepsilon_{t, i n i}}\right)^{K_{2}}(|E *|)^{K_{3}}$

Traditional Strain Fatigue Relationship (psi units) \begin{tabular}{c|c} 
K1 & $9.97 \mathrm{E}+12$ \\
\hline
\end{tabular}

\begin{tabular}{l|r} 
K2 & 5.171 \\
\hline K3 & -4.41
\end{tabular}

$N_{f}=K_{1}\left(\frac{1}{\varepsilon_{t}}\right)^{K_{2}}(|E *|)^{K_{3}}$

\begin{tabular}{|c|c|}
\hline \multicolumn{2}{|c|}{ Traditional Stress Fatigue Relationship 1 (psi units) } \\
\hline K1 & $4.88 \mathrm{E}-11$ \\
K2 & -5.271 \\
\hline K3 & 4.407 \\
\hline
\end{tabular}

$N_{f}=K_{1}\left(\sigma_{t}\right)^{K_{2}}(|E *|)^{K_{3}}$

Traditional Stress Fatigue Relationship 2 (psi units)

\begin{tabular}{|c|c|}
\hline $\mathbf{K 1}$ & $4.88 \mathrm{E}-11$ \\
\hline $\mathbf{K} \mathbf{3}$ & 5.271 \\
\hline \multicolumn{2}{|c|}{ Endurance Limit (microstrain) } \\
\hline Temperature (deg. C) & -0.864 \\
\hline 5 & Endurance Limit \\
\hline 10 & 51 \\
\hline 15 & 57 \\
\hline 20 & 67 \\
\hline 25 & 82 \\
\hline
\end{tabular}

\begin{tabular}{|c|c|c|c|}
\hline \multicolumn{4}{|c|}{ Single Strain Prediction } \\
\hline Temperature (deg. C) & Frequency $(\mathrm{Hz})$ & Strain Level $(\mu \varepsilon)$ & $\mathrm{Nf}$ \\
\hline 15 & 0.6 & 100 & $3.49 \mathrm{E}+09$ \\
\hline 15 & 0.6 & 200 & $8.43 \mathrm{E}+07$ \\
\hline 15 & 0.6 & 300 & $9.94 \mathrm{E}+06$ \\
\hline 15 & 0.6 & 400 & $2.22 \mathrm{E}+06$ \\
\hline 15 & 0.84 & 100 & $2.28 \mathrm{E}+09$ \\
\hline 15 & 0.84 & 200 & $5.51 \mathrm{E}+07$ \\
\hline 15 & 0.84 & 300 & $6.48 \mathrm{E}+06$ \\
\hline 15 & 0.84 & 400 & $1.45 \mathrm{E}+06$ \\
\hline & & & \\
\hline & & & \\
\hline & & & \\
\hline
\end{tabular}




\section{Wearing I with FORTA-FI Default Fatigue Life Prediction Analysis}

\section{North Capolina \\ State University}

\author{
ALPHA-Fatigue \\ Model Predictions Report
}

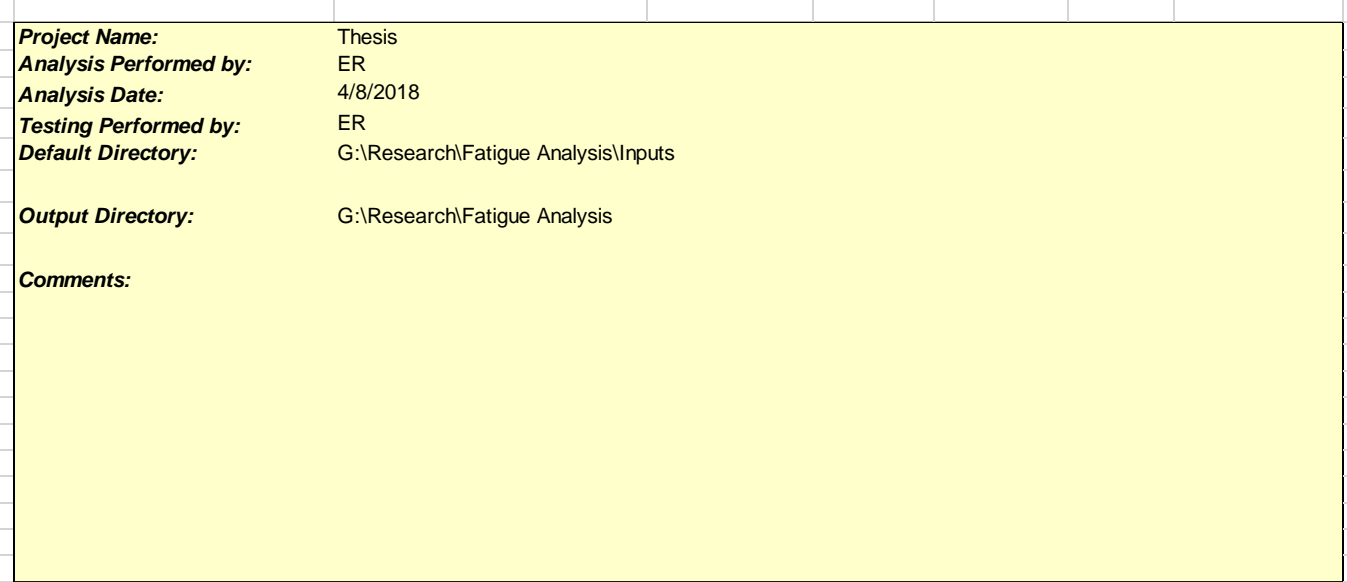

\begin{tabular}{|c|c|}
\hline \multicolumn{2}{|c|}{ Traditional Strain Fatigue Relationship (kPa units) } \\
\hline K1 & $6.49 \mathrm{E}+09$ \\
\hline K2 & 3.684 \\
\hline 3 & -2.78 \\
\hline
\end{tabular}

$N_{f}=K_{1}\left(\frac{1}{\varepsilon_{t}}\right)^{K_{2}}\left(\left|E^{*}\right|\right)^{K_{3}}$

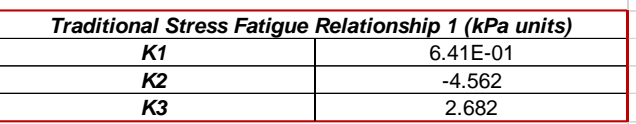

$N_{f}=K_{1}\left(\sigma_{t}\right)^{K_{2}}(|E *|)^{K_{3}}$

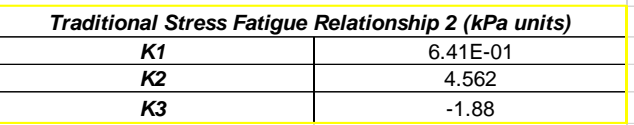

$N_{f}=K_{1}\left(\frac{1}{\varepsilon_{t, i n i}}\right)^{K_{2}}(|E *|)^{K_{3}}$

Traditional Strain Fatigue Relationship (psi units) K1 $3.03 \mathrm{E}+07$

\begin{tabular}{|c|c|}
\hline $\boldsymbol{K} \mathbf{1}$ & $3.03 \mathrm{E}+07$ \\
\hline $\mathbf{2}$ & 3.684 \\
\hline $\mathbf{3}$ & -2.78 \\
\hline
\end{tabular}

$N_{f}=K_{1}\left(\frac{1}{\varepsilon_{t}}\right)^{K_{2}}(|E *|)^{K_{3}}$

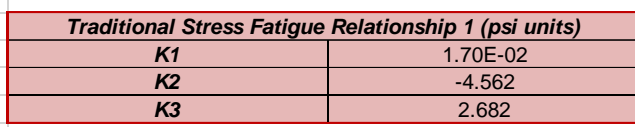

$N_{f}=K_{1}\left(\sigma_{t}\right)^{K_{2}}\left(\left|E^{*}\right|\right)^{K_{3}}$

Traditional Stress Fatigue Relationship 2 (psi units)

\begin{tabular}{|c|c|}
\hline K1 & $1.70 \mathrm{E}-02$ \\
\hline $\mathbf{K} \mathbf{K}$ & 4.562 \\
\hline \multicolumn{2}{|c|}{-1.88} \\
\hline \multicolumn{2}{|c|}{ Endurance Limit (microstrain) } \\
\hline Temperature (deg. C) & Endurance Limit \\
\hline 5 & 21 \\
\hline 10 & 23 \\
\hline 15 & 26 \\
\hline 20 & 31 \\
\hline 25 & 40 \\
\hline
\end{tabular}

$N_{f}=K_{1}\left(\frac{1}{\varepsilon_{t, \text { ini }}}\right)^{K_{2}}(|E *|)^{K_{3}}$

\begin{tabular}{|c|c|c|c|}
\hline \multicolumn{4}{|c|}{ Single Strain Prediction } \\
\hline Temperature (deg. C) & Frequency $(\mathrm{Hz})$ & Strain Level $(\mu \varepsilon)$ & $\mathrm{Nf}$ \\
\hline 15 & 0.6 & 100 & $1.88 \mathrm{E}+07$ \\
\hline 15 & 0.6 & 200 & $1.12 \mathrm{E}+06$ \\
\hline 15 & 0.6 & 300 & $2.31 \mathrm{E}+05$ \\
\hline 15 & 0.6 & 400 & $7.83 \mathrm{E}+04$ \\
\hline 15 & 0.84 & 100 & $1.43 \mathrm{E}+07$ \\
\hline 15 & 0.84 & 200 & $8.58 \mathrm{E}+05$ \\
\hline 15 & 0.84 & 300 & $1.77 \mathrm{E}+05$ \\
\hline 15 & 0.84 & 400 & $6.01 \mathrm{E}+04$ \\
\hline & & & \\
\hline & & & \\
\hline
\end{tabular}




\section{Wearing I with FORTA-FI Peak Fatigue Life Prediction Analysis}

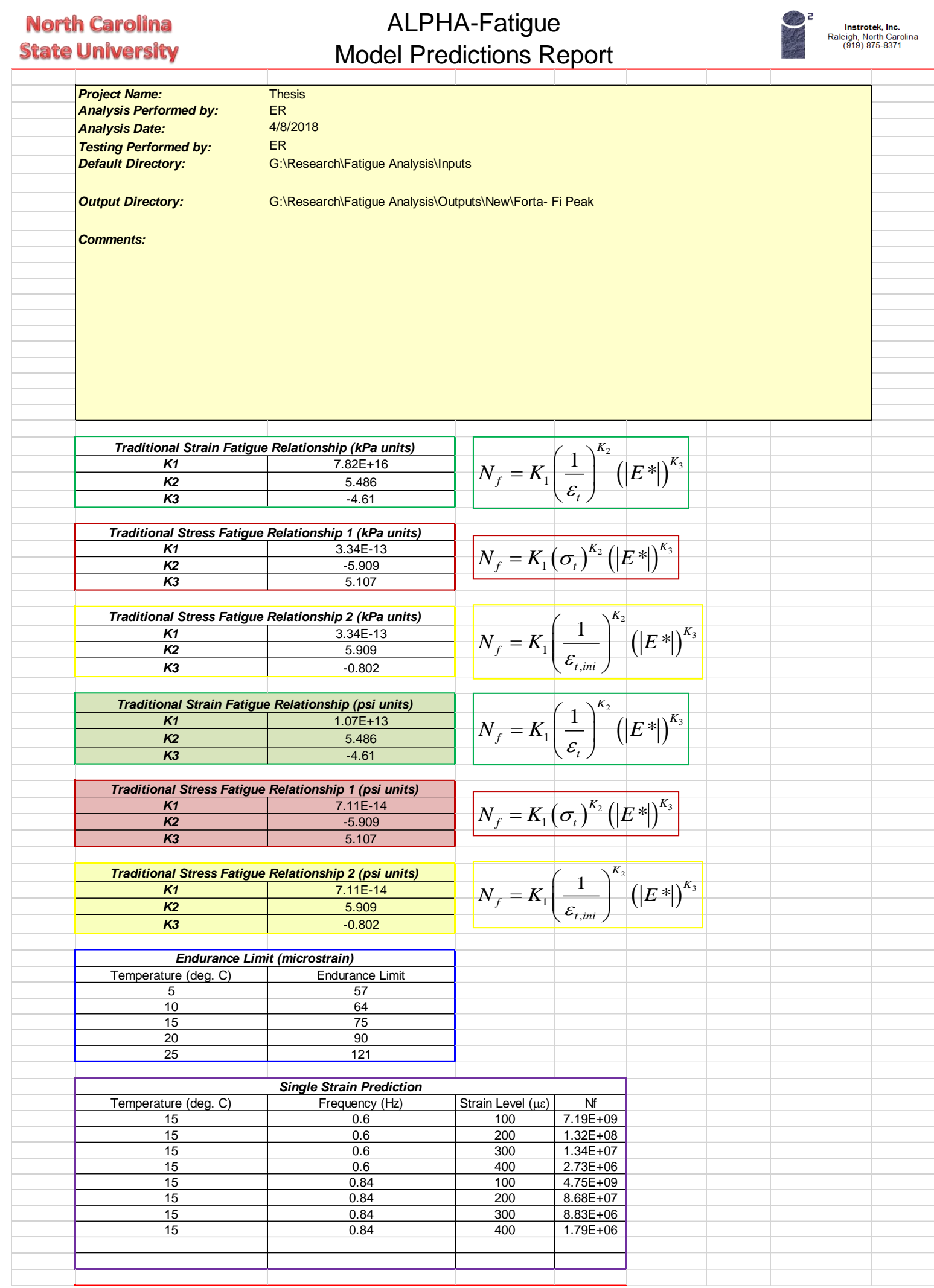

